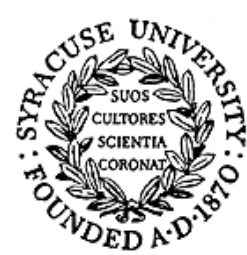

\title{
SYRACUSE UNIVERSITY
}

BUILDING ENERGY AND ENVIRONMENTAL SYSTEMS LABORATORY (BEESL)

263 Link Hall, Syracuse University, Syracuse, NY 13244-1240; http://BEESL.Syr.Edu

\section{SYRACUSE UNIVERSITY TEST REPORT ON UPTAKE FACTOR RESULTING FROM A DROPPED STORAGE CONTAINER}

\author{
FINAL REPORT \\ By \\ Zhi Gao, PhD, Research Associate \\ Jianshun (Jensen) S. Zhang, PhD, Principal Investigator* \\ (*Tel. 315-443-1366; Fax 315-443-9099; Email: jszhang@syr.edu)
}

September 2010

Prepared For

US DOE/B\&W Y-12

Report Number: SU-BEESL/RP-802068-0001 


\section{Disclaimer}

This report was prepared as an account of work sponsored by an agency of the United States Government. Neither the United States Government nor any agency thereof, nor any of their employees, makes any warranty, express or implied, or assumes any legal liability or responsibility for the accuracy, completeness, or usefulness of any information, apparatus, product, or process disclosed, or represents that its use would not infringe privately owned rights. Reference herein to any specific commercial product, process, or service by trade name, trademark, manufacturer, or otherwise, does not necessarily constitute or imply its endorsement, recommendation, or favoring by the United States Government or any agency thereof. The views and opinions of authors expressed herein do not necessarily state or reflect those of the United States Government or any agency thereof. 


\section{EXECUTIVE SUMMARY}

Under certain circumstances, powder from an accidently dropped container can become airborne and inhaled by people nearby such as those who are moving the containers. The inhaled fine particles can deposit on respiratory tracts and lungs, causing asthma, lung cancer, and other acute respiratory illnesses and chronic symptoms. The objective of this study was to develop a standard procedure to measure the airborne concentrations of different size particles within the vicinity of a dropped container where a significant portion of the contained powder is ejected.

Tungsten oxide $\left(\mathrm{WO}_{3}\right)$ was selected in this study to represent relatively heavy powders (7.16 $\mathrm{g} / \mathrm{cm}^{3}$ specific gravity for $\mathrm{WO}_{3}$ ). A typical can with the outer dimensions of 4.25 ” diameter and 4.875" tall was used as the container. The powder was dropped in two different configurations: 1) contained within a can covered by a lid that has a 0.25 ” diameter hole, and 2) contained within a can without a lid. The packing volume of the powder was 51.4 in $^{3}$ $\left(842.7 \mathrm{~cm}^{3}\right)$ and the target mass was $1936 \mathrm{~g}$. The tests were carried out in a full-scale stainless steel environmental chamber with an interior volume of $852 \mathrm{ft}^{3}\left(24.1 \mathrm{~m}^{3}\right)$. The chamber system includes an internal recirculation loop with a rectangular air diffuser and 10 variable frequency drive fans to provide a typical room air recirculation flow pattern. Two air filters were installed in the chamber air supply duct and return duct to achieve the required low background particle concentration. The initial chamber air conditions were set at $70^{\circ} \mathrm{F}\left( \pm 5^{\circ} \mathrm{F}\right)$ and 50\% ( $\pm 10 \%) \mathrm{RH}$. A supporting frame and releasing device were designed and built to trigger consistently the dropping of the can at a height of 8 feet from the bottom of the can to the impacting surface. The particle sampling inlet was placed $5 \mathrm{ft}$ above the floor and 6 inches laterally away from the can's falling path. Concentrations of particles between $0.5 \mu \mathrm{m}$ and 20 $\mu \mathrm{m}$ were recorded in units of mass and number of particles per unit volume. The data acquisition rate was once every 2 seconds during the first 2 hours and every 20 seconds thereafter.

A test procedure was developed and a total of nine drop tests were performed. In most cases (seven tests), the can tipped over after dropping. The can in Test 1 stayed upright. The can in Test 7 showed a special behavior: after the rebound, it turned upside down and stayed upright. Major findings are summarized below:

a The amount of spilled powder varied from $0.12 \mathrm{~g}$ to $252.35 \mathrm{~g}$ and the non-recovered powder varied from $0.11 \mathrm{~g}$ to $1.18 \mathrm{~g}$. The corresponding percentage of the spilled powder ranged from $0.01 \%$ to $13 \%$.

a The peak value of particle number concentration after the dropping of the can occurred at approximately $0.9 \mu \mathrm{m}$ particle size per measured data of individual channels. The peak value of particle mass concentration occurred in the range of 4.3 - $10 \mu \mathrm{m}$ particle size per grouped data calculated from the measured data with the exception of Test 4 where a different batch powder with unexpectedly different bulk density and particle size distribution. 
- After the dropping of the can, the total airborne mass concentrations ranged from 0.03 to $0.35 \mathrm{mg} / \mathrm{m}^{3}$, while the total airborne number concentrations ranged from 2 to 125 $\# / \mathrm{cm}^{3}$ except for Test 4 . The number concentration in Test 4 was 1 or 2 orders of magnitude less than those of other tests because the powder was from a different batch. However, its mass concentration was comparable to that in Test 7 because relatively more big airborne particles were detected in Test 4 . In general, tests with lid (Test 5, 6, 7 and 8) had smaller concentrations than tests without lid (Test $0,1,2$, and 3). The influence of lid was not as prominent as the powder (Test 4). However, this needs more tests for verification.

a The ratio of airborne mass to non-recovered mass ranged from $0.1 \%$ to $2 \%$. This means that it is challenging to use this method to check the mass balance, while the uptake factor and associated inhalation exposure can be readily assessed.

- The calculated cumulative uptake mass within first 10 minutes after the dropping of the can for each test was within the range of $0.002 \mathrm{mg}$ to $0.035 \mathrm{mg}$. Assuming a breathing rate of $1.2 \mathrm{~m}^{3} / \mathrm{h}$, the uptake factor during the first 10 minutes was calculated to be between $10^{-9}$ and $2 \times 10^{-8}$ in reference to the amount loaded; or between $10^{-8}$ and $6 \times 10^{-5}$ in reference to the amount spilled.

The experimental results of this study will be useful for standardizing the test method and provide data for estimating the exposure and associated risk to building occupants in the case of an accidental dropping of heavy powder containers. 


\section{TABLE OF CONTENTS}

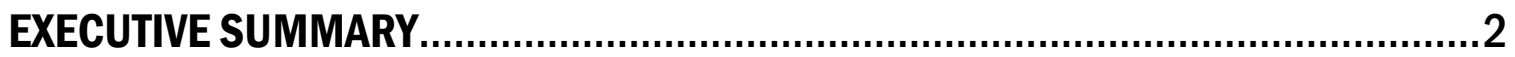

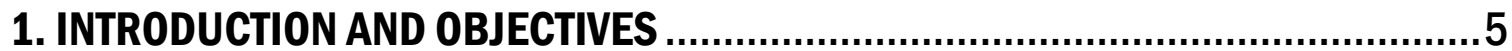

2. TEST FACILITIES

2.1 Full-scale Stainless Steel Environmental Chamber ………..................................... 5

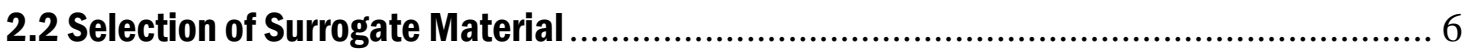

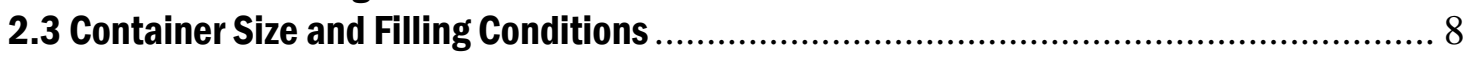

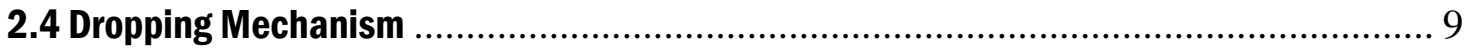

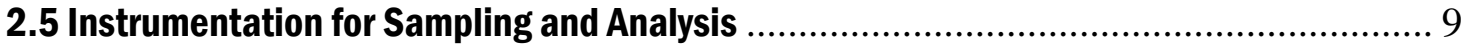

3. EXPERIMENTAL AND DATA ANALYSIS METHODS ....................................10

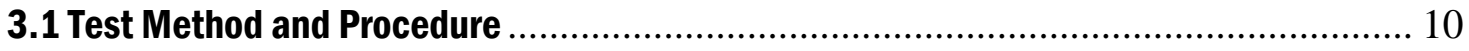

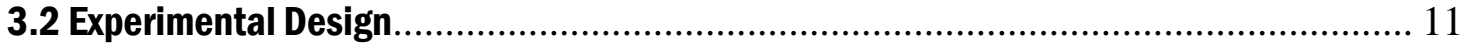

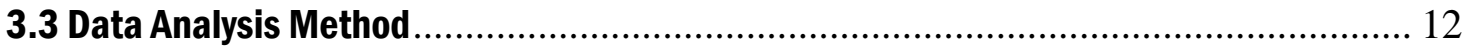

4. EXPERIMENTAL RESULTS AND DISCUSSIONS ........................................13

4.1 Test Conditions ……...................................................................................... 13

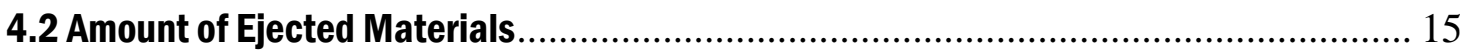

4.3 Airborne Mass and Number Concentrations.............................................................. 16

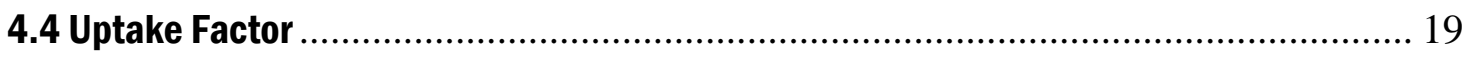

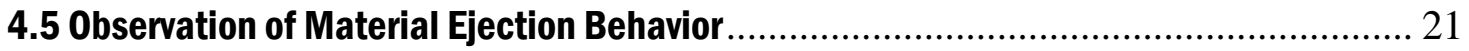

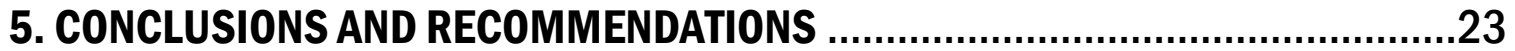

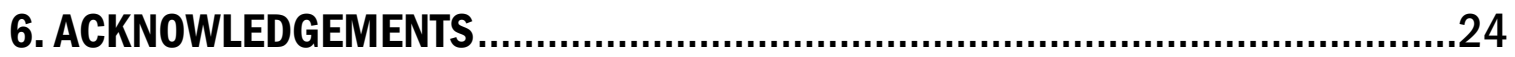

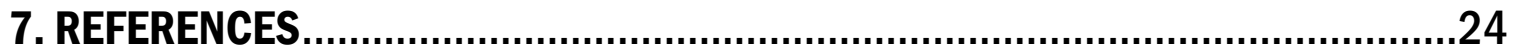

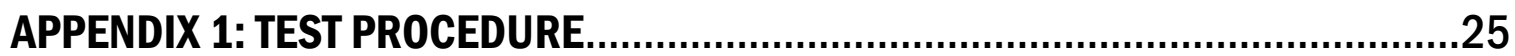

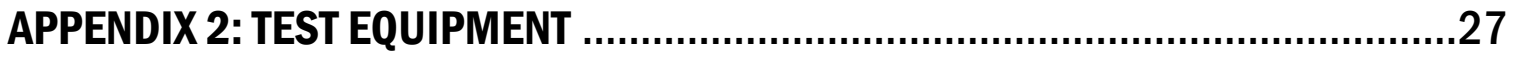

APPENDIX 3: TEST RESULTS

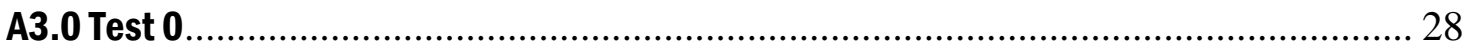

A3.1 Test 1

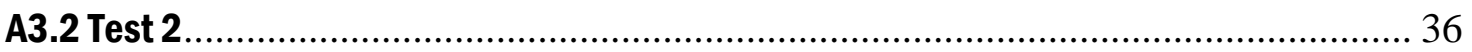

A3.3 Test 3 .

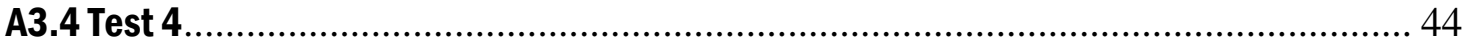

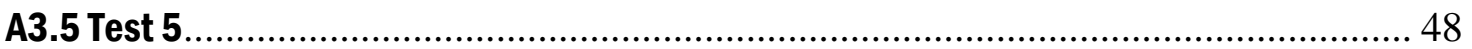

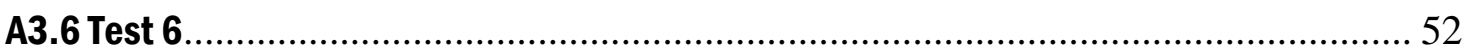

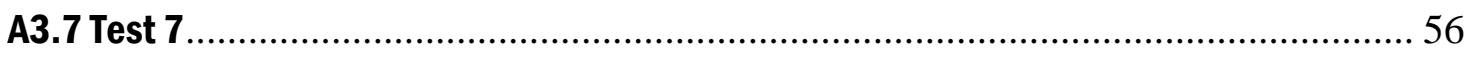

A3.8 Test 8

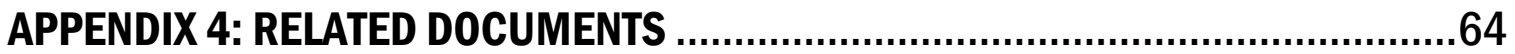

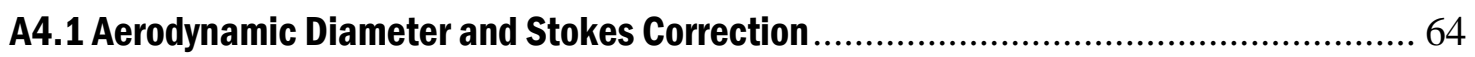

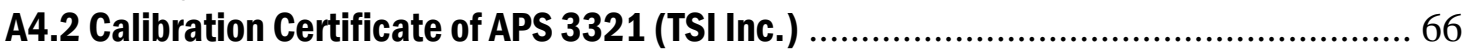

A4.3 Physical Size Distribution Analysis of Tungsten Oxide (LOT \# Q1844) by Powder

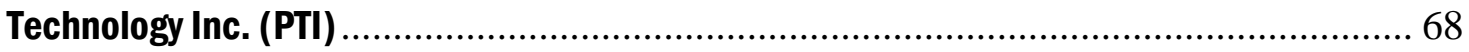

A4.4 In-House Calibration of Veloci-Calc 8347 Air Velocity Meter (TSI Inc.)...................... 69

A4.5 Material Certification of Tungsten Oxide (ESPI Metals) .......................................... 70 


\section{INTRODUCTION AND OBJECTIVES}

Under certain circumstances, powder from an accidently dropped container can become airborne and inhaled by people nearby such as those who are moving the containers. There is a need to develop a standard procedure to measure the airborne concentrations of different size particles within the vicinity of a dropped container where a significant portion of the contained powder is ejected. The ultimate goal of this study is to develop such as a standard, and use it to determine a realistic uptake factor that may replace the $10^{-3}$ estimate published in IAEA Safety Guide TS-G-1.1 and DOE M 441.1-1 for materials in use at the Y-12 National Security Complex. This research project represents the first step in providing measured data and improved understanding of the particle ejection and distribution in support of the standard development and potential replacement of the estimate.

Specific objectives of the present project were to:

1) Measure the actual breathing zone airborne particle concentrations of a surrogate powder resulting from a dropped storage container by using a full-scale environmental chamber under the specified standard test conditions;

2) Experimentally determine the uptake factor;

3) Improve the understanding of the particle ejection behavior by using high speed video imaging technique.

\section{TEST FACILITIES}

\subsection{Full-scale Stainless Steel Environmental Chamber}

A full-scale stainless steel environmental chamber was used in the test. The chamber (Figure 1) has dimensions of $12 \mathrm{ft} \times 7.1 \mathrm{ft} \times 10 \mathrm{ft}$ high $(3.66 \mathrm{~m} \times 2.16 \mathrm{~m} \times 3.05 \mathrm{~m}$ high) and an interior volume of $852 \mathrm{ft}^{3}\left(24.1 \mathrm{~m}^{3}\right)$. Detailed description of this chamber facility and its performance including air-tightness, cleanness, air mixing, environmental control accuracy can be found in Herrmann et al. (2003). For this study, the original chamber system was modified to include an internal recirculation loop with a rectangular air diffuser and 10 variable frequency drive fans to provide a typical room air recirculation flow pattern and the range of air velocity approximately 12 " from the ceiling of the room $(0.25-0.3 \mathrm{~m} / \mathrm{s})$. The slot was adjusted to be 1.5 ” wide and fan frequency was adjusted to be $40 \mathrm{~Hz}$. Two air filters ( 24 " $\times 12$ " $\times 2.75$ ") were installed in the chamber air supply duct and return duct to achieve the required low background particle concentration. The chamber's air-tightness was verified by tracer gas test to be around $0.02 \mathrm{ACH}$. The chamber air conditions were set at $70^{\circ} \mathrm{F}\left( \pm 5^{\circ} \mathrm{F}\right), 50 \%( \pm 10 \%) \mathrm{RH}$. 


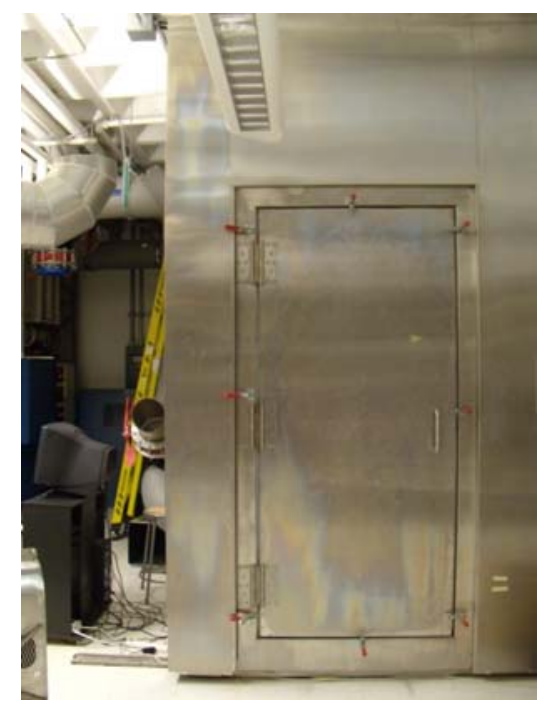

a. Exterior

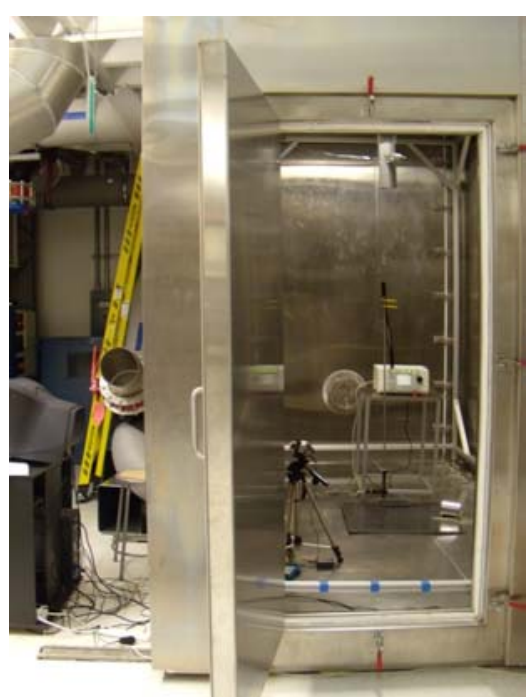

b. Interior

Figure 1. The modified ultra-clean full-scale climate chamber

\subsection{Selection of Surrogate Material}

The most important factor of inhalation hazard is the material's aerodynamic diameter particle size distribution. A typical Y-12 National Security Complex oxide aerodynamic diameter distribution can be found in Hoover et al.'s study (1998). The $\mathrm{U}_{3} \mathrm{O}_{8}$ enriched uranium bulk density of the loose powder measured by Hoover et al. was approximately $2 \mathrm{~g} / \mathrm{cm}^{3}$. Particle density is approximately $8 \mathrm{~g} / \mathrm{cm}^{3}$. Chemical analysis at the Y-12 Plant Laboratory showed that the sample is 0.846 uranium by mass. The total weight of the surrogate material in the can is also important since it affects the impacting energy and hence the ejection of the particles.

In this study, the surrogate was selected from commercially available products. The candidate surrogate materials included titanium oxide, tungsten oxide and Arizona dust (ultrafine, fine, medium and coarse). Tungsten oxide (CAS \#: 1314-35-8) was chosen because it approximately matches the aerodynamic diameter particle size distribution of $\mathrm{U}_{3} \mathrm{O}_{8}$, and has similar particle density. The material properties are shown in Table 1 .

Table 1. Material properties of tungsten oxide

\begin{tabular}{|l|l|l|l|l|l|l|}
\hline Formula & $\begin{array}{l}\text { Specific } \\
\text { gravity }\end{array}$ & $\begin{array}{l}\text { Melting } \\
\text { point }\end{array}$ & $\begin{array}{l}\text { OSHA } \\
\text { /PEL }\end{array}$ & $\begin{array}{l}\text { ACGIH } \\
\text { /TLV }\end{array}$ & $\begin{array}{l}\text { HMIS } \\
\text { ratings }\end{array}$ & Appearance \\
\hline $\mathrm{WO}_{3}$ & $7.16 \mathrm{~g} / \mathrm{cm}^{3}$ & $1473^{\circ} \mathrm{C}$ & $\begin{array}{c}5 \\
\mathrm{mg} / \mathrm{m}^{3}\end{array}$ & $\begin{array}{c}10 \\
\mathrm{mg} / \mathrm{m}^{3}\end{array}$ & $\begin{array}{c}\text { Health: } \\
2\end{array}$ & $\begin{array}{l}\text { Dark green }{ }^{[4]} \text {, heavy } \\
\text { powder, no odor. }\end{array}$ \\
$\begin{array}{l}\text { When heated, it turns } \\
\text { dark orange }\end{array}$
\end{tabular}

Note:

[1] Occupational Safety \& Health Administration / Permissible Exposure Limits. 
[2] American Conference of Governmental Industrial Hygienists / Threshold Limit Value, represented as time-weighted-average (TWA) inhalation exposure for up to 10 hours in a 40 hour working week.

[3] Hazardous Materials Identification System.

[4] Or yellow green from the second batch we purchased. The color can also be yellow or violet blue according to the product's Material Safety Data Sheet.

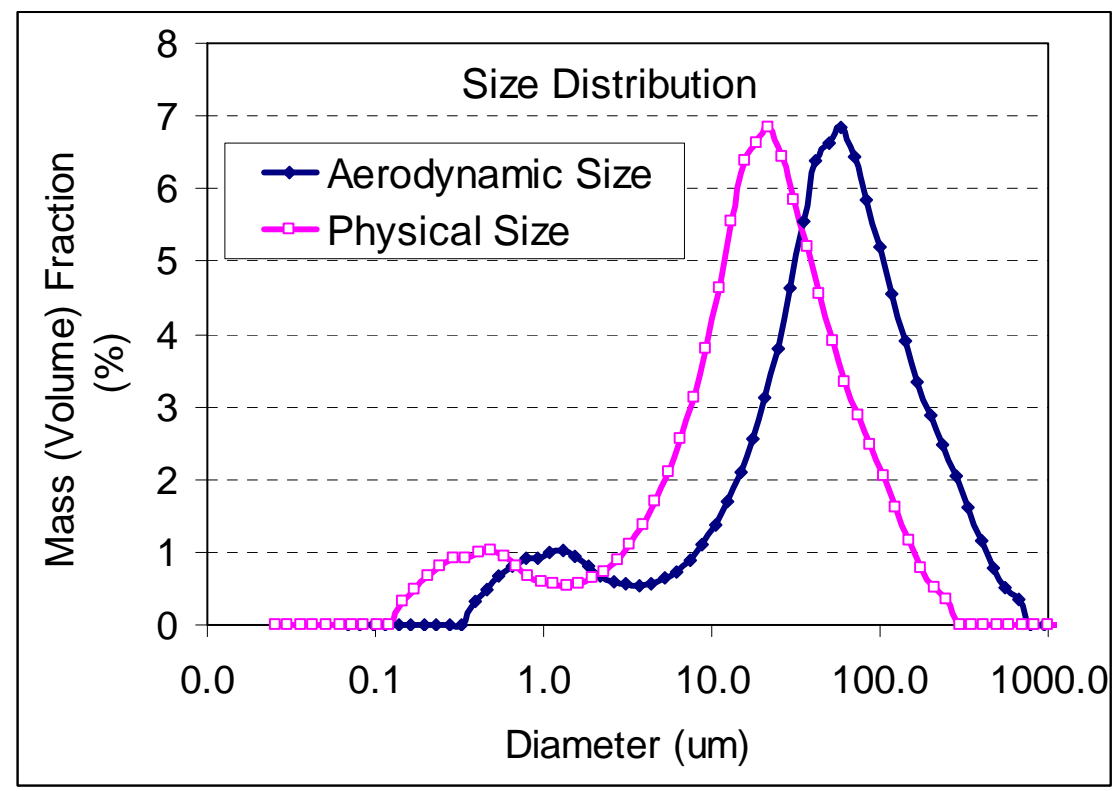

Figure 2. Size distribution of tested tungsten oxide

The physical and aerodynamic size distributions of tested tungsten oxide are shown in Figure 2. The aerodynamic size distributions of uranium oxide and tested tungsten oxide are compared in Table 2.

Table 2. Comparison of aerodynamic size distributions of uranium oxide and tested tungsten oxide

\begin{tabular}{|l|l|l|l|l|l|l|l|l|l|}
\hline \multirow{2}{*}{$\begin{array}{l}\text { Aerodynamic } \\
\text { diameter }(\mu \mathrm{m})\end{array}$} & \multicolumn{2}{|l|}{$\begin{array}{l}\text { Fraction of } \\
\text { the total mass }\end{array}$} & \multicolumn{2}{|l|}{$\begin{array}{l}\text { Fraction of } \\
\text { mass }<50 \mu \mathrm{m}\end{array}$} & \multicolumn{2}{l|}{$\begin{array}{l}\text { Fraction of } \\
\text { mass }<20 \mu \mathrm{m}\end{array}$} & \multicolumn{2}{l}{$\begin{array}{l}\text { Fraction of } \\
\text { mass }<10 \mu \mathrm{m}\end{array}$} \\
\hline & $\mathrm{U}_{3} \mathrm{O}_{8}$ & $\mathrm{WO}_{3}$ & $\mathrm{U}_{3} \mathrm{O}_{8}$ & $\mathrm{WO}_{3}$ & $\mathrm{U}_{3} \mathrm{O}_{8}$ & $\mathrm{WO}_{3}$ & $\mathrm{U}_{3} \mathrm{O}_{8}$ & $\mathrm{WO}_{3}$ \\
\hline $\mathrm{d}>50$ & 0.64 & 0.48 & N.A. & N.A. & N.A. & N.A. & N.A. & N.A. \\
\hline $20<\mathrm{d}<50$ & 0.22 & 0.27 & 0.61 & 0.52 & N.A. & N.A. & N.A. & N.A. \\
\hline $10<\mathrm{d}<20$ & 0.12 & 0.09 & 0.33 & 0.18 & 0.91 & 0.38 & N.A. & N.A. \\
\hline $4.3<\mathrm{d}<10$ & 0.0051 & 0.0476 & 0.014 & 0.091 & 0.039 & 0.19 & 0.44 & 0.30 \\
\hline $2.9<\mathrm{d}<4.3$ & 0.0043 & 0.0112 & 0.012 & 0.021 & 0.033 & 0.045 & 0.37 & 0.07 \\
\hline $2.0<\mathrm{d}<2.9$ & 0.0018 & 0.0116 & 0.005 & 0.022 & 0.014 & 0.046 & 0.16 & 0.07 \\
\hline $1.2<\mathrm{d}<2.0$ & 0.0002 & 0.0243 & 0.0006 & 0.047 & 0.0015 & 0.097 & 0.02 & 0.16 \\
\hline $\mathrm{d}<1.2$ & $<0.0001$ & 0.0616 & 0.0003 & 0.118 & 0.0008 & 0.25 & $<0.01$ & 0.39 \\
\hline
\end{tabular}




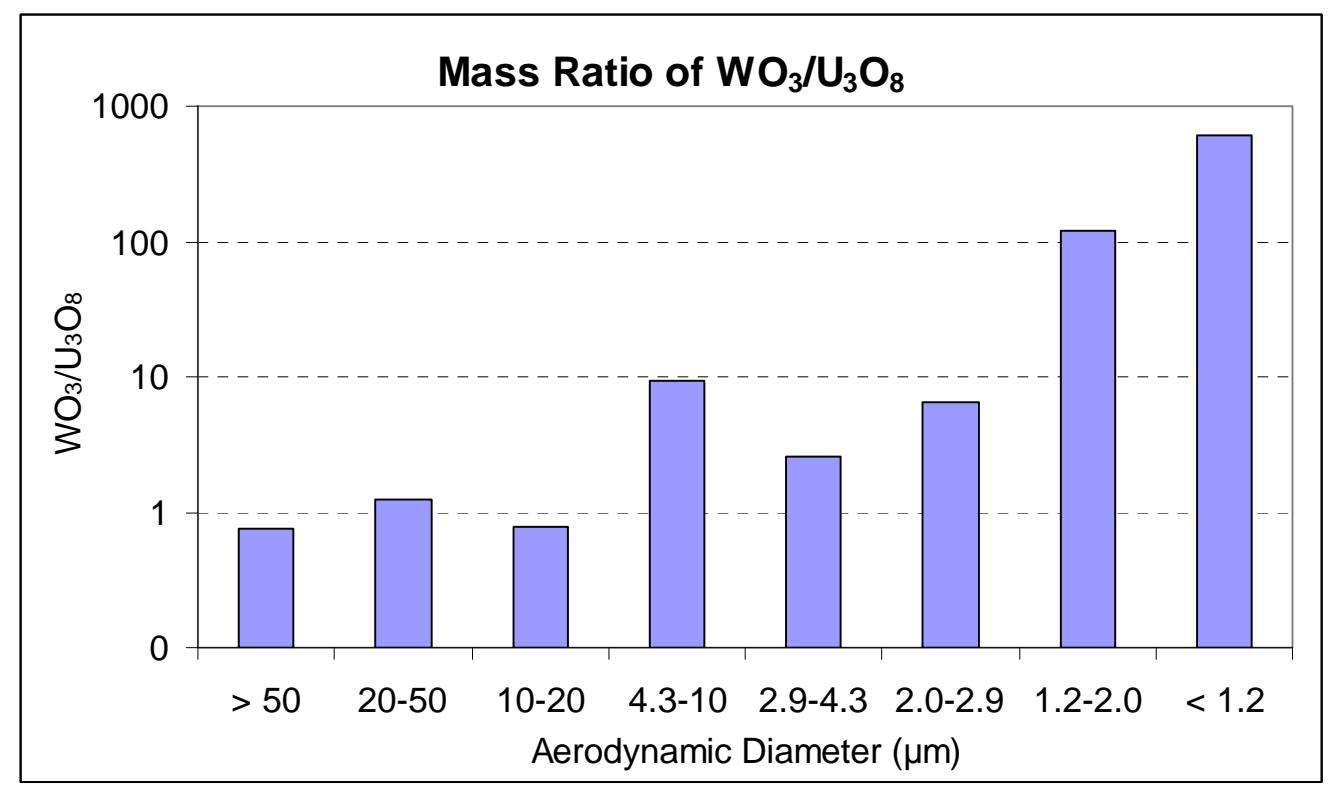

Figure 3. Mass ratio of tungsten oxide to uranium oxide at different aerodynamic sizes

Figure 3 shows the mass ratio of tungsten oxide to uranium oxide at different particle sizes. It can be seen that $\mathrm{WO}_{3}$ and $\mathrm{U}_{3} \mathrm{O}_{8}$ have comparable amounts of large particles (larger than $10 \mu \mathrm{m}$ ). However, this batch of $\mathrm{WO}_{3}$ has more small particles than $\mathrm{U}_{3} \mathrm{O}_{8}$. When particle size is between $1.2 \mu \mathrm{m}$ and $2 \mu \mathrm{m}$, or smaller than $1.2 \mu \mathrm{m}$, the mass ratio of $\mathrm{WO}_{3} / \mathrm{U}_{3} \mathrm{O}_{8}$ is as big as about 120 and 620, respectively. Since particles must be airborne to become an inhalation hazard, using $\mathrm{WO}_{3}$ as the testing material can be seen as the worst case scenario of the real condition of $\mathrm{U}_{3} \mathrm{O}_{8}$, and hence a conservative approach for inhalation exposure control.

\subsection{Container Size and Filling Conditions}

The container (House of Cans 1817) is 4.25” diameter and 4.875” tall from outside. When minus the thickness of top rim ( 0.125 ”) and bottom rim ( 0.125 ”), the can is 4.625 ” tall. The powder was filled to a level 1" below the top rim of the can. So the final packing height was 3.625” and the packing volume was 51.425 in $^{3}\left(842.7 \mathrm{~cm}^{3}\right)$. Loose packing was adopted, and the packing density was determined by averaging the results from three packing density tests (Table 3). The target mass of powder was $1936 \mathrm{~g}$, calculated as the product of the packing volume times the packing density. Figure 4 shows the loose packed powder in the container.

Table 3. Determination of loose pack density

\begin{tabular}{|c|c|c|c|c|}
\hline$\#$ & Loose pack volume $\left(\mathrm{cm}^{3}\right)$ & Mass of powder $(\mathrm{g})$ & Loose pack density $\left(\mathrm{g} / \mathrm{cm}^{3}\right)$ \\
\hline 1 & 33 & 75.55 & 2.289 \\
\hline 2 & 43 & 97.26 & 2.262 & 2.297 \\
\hline 3 & 48 & 112.36 & 2.341 \\
\hline
\end{tabular}




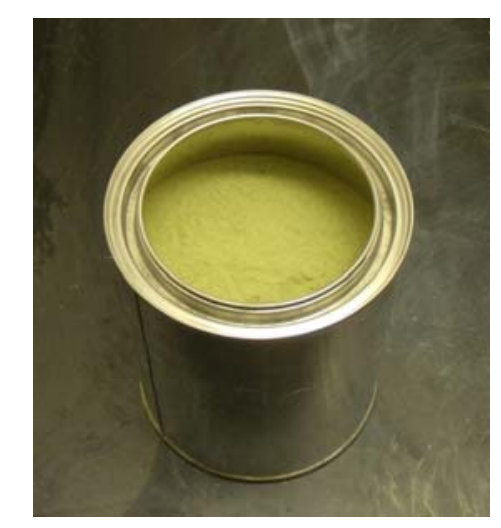

Figure 4. The container with loose packed powder

\subsection{Dropping Mechanism}

A supporting fame and releasing device (Figure 5) were made to trigger the dropping of the can to the impacting surface. The impacting surface was a 0.5 ” thick square steel plate (29”×29”), weighing $54 \mathrm{~kg}(119 \mathrm{lb})$. The releasing device was a solenoid that pulled the rod supporting the bottom of the can in the cylinder.

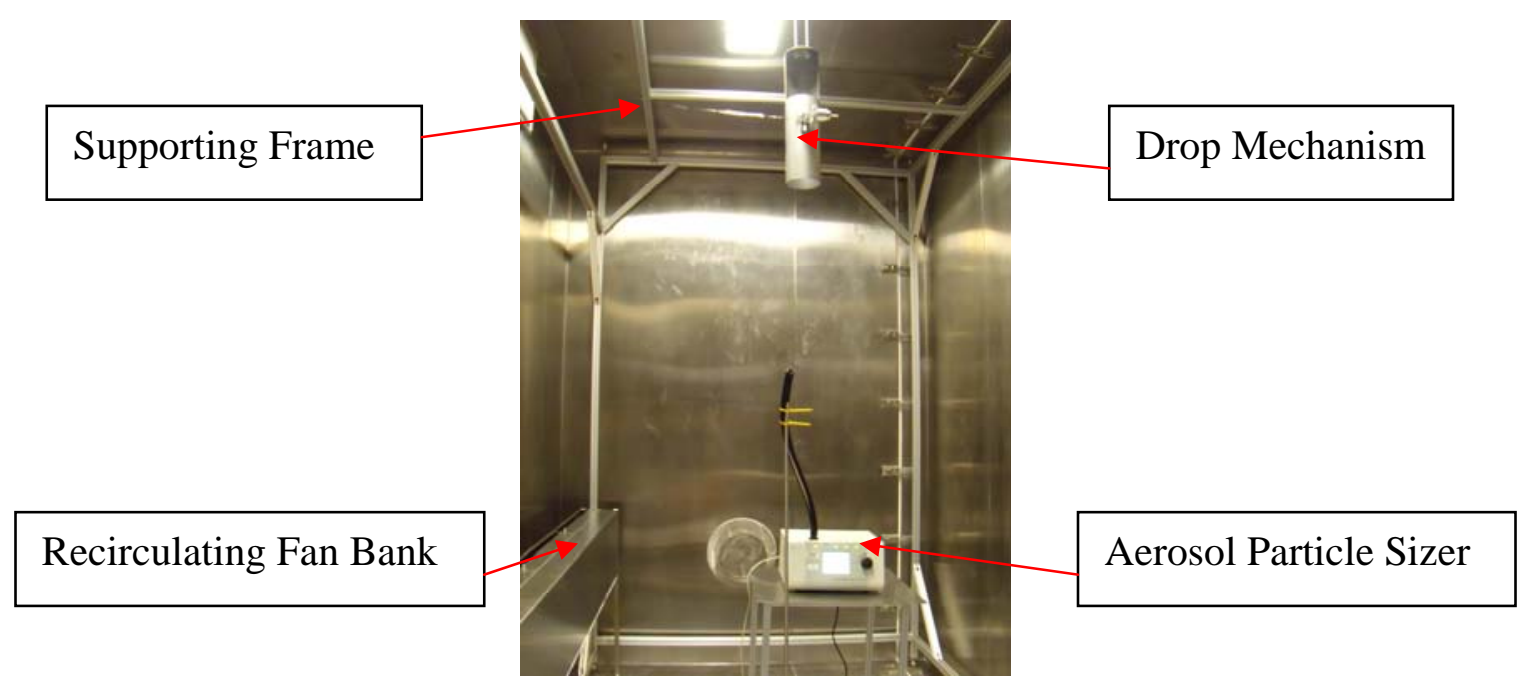

Figure 5. The supporting frame and releasing device

\subsection{Instrumentation for Sampling and Analysis}

APS 3321 (TSI Inc.) aerosol particle sizer was used for measurement of the concentration of particles ranging from 0.5 to $20 \mu \mathrm{m}$ in diameter. Temperature and $\mathrm{RH}$ in the chamber were monitored by IAQ-Calc 8762 (TSI Inc.) meter. A photoacoustic gas monitor (INNOVA 1312) was used for real-time measurement of the concentration of tracer gas $\left(\mathrm{SF}_{6}\right)$ to determine the actual clean air change rate from the decay curve of $\mathrm{SF}_{6}$. The 
detection limit, accuracy and precision of the quantities measured with the sampling and analysis instruments described above are as follows (Table 4):

Table 4. Data quality indicator table

\begin{tabular}{|l|c|c|c|}
\multicolumn{1}{c|}{$\begin{array}{c}\text { Parameter } \\
\text { or } \\
\text { Instrument }\end{array}$} & $\begin{array}{c}\text { Detection Limit } \\
\text { or Range }\end{array}$ & $\begin{array}{c}\text { Accuracy } \\
( \pm \text { STD })\end{array}$ & $\begin{array}{c}\text { Precision } \\
( \pm \text { STD })\end{array}$ \\
\hline APS 3321 & $\begin{array}{c}0.001 \\
\text { particles } / \mathrm{cm}^{3}\end{array}$ & $\begin{array}{c}<5 \% \text { coincidence at } 0.5 \mu \mathrm{m} ; \\
<10 \% \text { coincidence at } 10 \mu \mathrm{m} \\
\left.\text { (at } 1000 \text { particles } / \mathrm{cm}^{3}\right)\end{array}$ & $\begin{array}{c} \pm 10 \% \text { of reading plus } \\
\text { variation from } \\
\text { counting statistics }\end{array}$ \\
\hline Air Change Rate & $/$ & $\pm 5.0 \%$ & $\pm 3.0 \%$ \\
\hline Temperature & $0-60^{\circ} \mathrm{C}$ & $\pm 1.0^{\circ} \mathrm{C}$ & $\pm 0.5^{\circ} \mathrm{C}$ \\
\hline Relative Humidity & $5 \%-95 \%$ & $\pm 5.0 \%$ & $\pm 3.0 \%$ \\
\hline
\end{tabular}

\section{EXPERIMENTAL AND DATA ANALYSIS METHODS}

\subsection{Test Method and Procedure}

Figure 6 shows the conceptual schematic of the test procedure of this project. It consists of four test periods. In the beginning, the chamber is flushed with clean air at 14 air changes per hour (ACH) for more than 10 hours. Three-quarter hour before the dropping of the can, the test performer enters the chamber with proper protective wear, sets up the equipment (light, camera and other equipment) and leaves the chamber. One-quarter hour before the dropping of the can, The HVAC system is shut down and the valves at the supply and return duct are closed. Ten small fans in the diffuser box are turned on and the chamber is operated at full-recirculation mode. At time zero, the solenoid valve of the releasing device is triggered from outside of the chamber to drop the can. Detailed stepby-step procedure is described in Appendix 1.

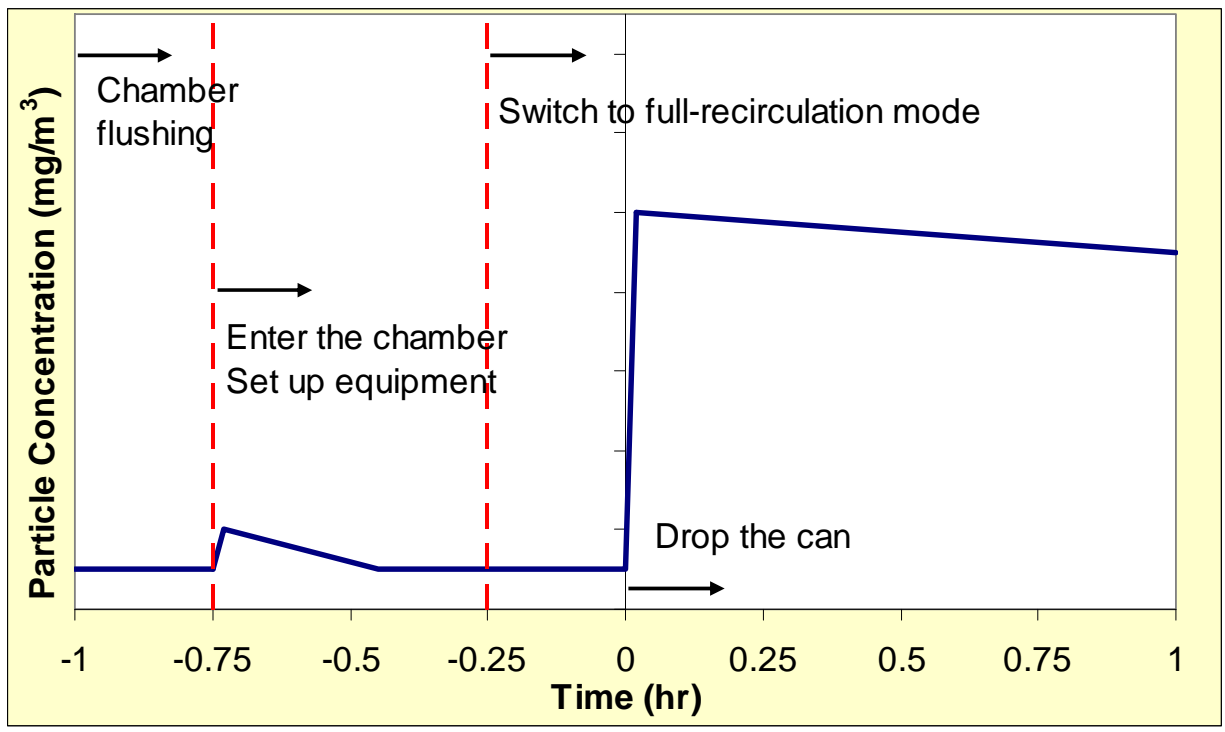

Figure 6. Conceptual schematic of test procedure 
The particle sizer APS 3321 is placed on a stainless steel stand, which is about $3 \mathrm{ft}$ above the floor and in the middle of the chamber. Silicone tubing is used for particle sampling because it reduces the build-up of static charge and minimizes particle loss to the tubing wall. The particle sampling inlet is placed $5 \mathrm{ft}$ above the floor and 6 inches laterally away from the can's falling path. Concentrations of particles between $0.5 \mu \mathrm{m}$ and $20 \mu \mathrm{m}$ were recorded in units of mass and number of particles per unit volume. The data acquisition rate was once every 2 seconds during the first 2 hours and every 20 seconds thereafter.

\subsection{Experimental Design}

The can was dropped in two different configurations: 1) the powder was contained within a can without a lid, and 2) the powder was contained within a can covered by a lid that had a 0.25 ” diameter hole (Figure 7). Nine tests (number in the order of testing) were performed (Table 5).

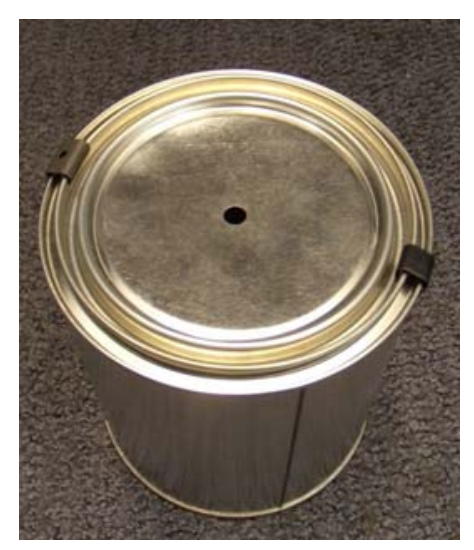

Figure 7. The container covered by a lid with a hole

Table 5. Test cases

\begin{tabular}{|l|c|c|c|c|c|}
\hline Drop Configuration & \multicolumn{5}{|c|}{ Test Number } \\
\hline Without lid & Test $0^{[1]}$ & Test 1 & Test 2 & Test 3 & Test $4^{[2]}$ \\
\hline With lid and a hole & $/$ & Test 5 & Test 6 & Test 7 & Test 8 \\
\hline
\end{tabular}

Notes:

[1] The impacting surface of Test 0 is a 0.25 ” thick round steel plate ( $1 \mathrm{ft}$ diameter) on a 0.5 ” thick square aluminum plate $(2 \mathrm{ft} \times 2 \mathrm{ft})$.

[2] The powder of Test 4 was from the second batch, with the color of yellow green. All other tests were performed with the first batch of powder received, and size distribution measured (Figure 2). 


\subsection{Data Analysis Method}

The uptake factor can be defined as

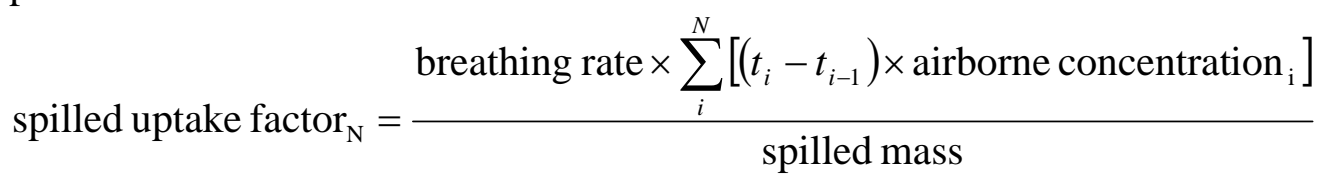

or

$$
\text { loaded uptake } \text { factor }_{\mathrm{N}}=\frac{\text { breathing rate } \times \sum_{i}^{N}\left[\left(t_{i}-t_{i-1}\right) \times \text { airborne concentration }_{\mathrm{i}}\right]}{\text { loaded mass }}
$$

at the Nth data point. The spilled mass is the difference between the initial and final mass of the can. The breathing rate estimate of $1.2 \mathrm{~m}^{3} / \mathrm{h}$ and a 10 -min time interval were used in this study.

Note that Equation (1) defines the uptake factor in reference to the spilled/ejected mass at impacting as in the current standard. Equation (2) defines the uptake factor in reference to the loaded mass - i.e., the initial mass in the can before dropping, which can be controlled precisely, and hence is a more stable reference parameter. Results from both definitions are presented in the following sections. 


\section{EXPERIMENTAL RESULTS AND DISCUSSIONS}

Detailed results for each test are presented in Appendix 3 in the order of time sequence for the tests. In this section, we summarize and discuss the major findings that are of particular interest to the objectives of this study.

\subsection{Test Conditions}

Chamber air temperature and relative humidity during the test are shown in Figure $\mathrm{A}^{*}$-a (“*” denotes test number) in Appendix 3. In general, we can see that when switching from flushing mode to recirculation mode, temperature begins to increase slightly due to heat from the fans and measurement devices, and relative humidity begins to drop slightly due to the increase in temperature. It can be seen that test conditions of Test 8 are significantly different from those of others, in which temperature is about $7^{\circ} \mathrm{F}$ higher due to a problem in the initial temperature control. However, such temperature difference is not expected to significantly change the particle ejection, distribution in the room and the intake factor in the present study. The ranges of test conditions of all eight tests except Test 8 (10-min duration after the dropping of the can) are: 1 ) temperature: $68.0 \sim 73.4^{\circ} \mathrm{F}$; and 2) RH: $44.3 \sim 58.7 \%$. The test conditions after the dropping of the can are summarized in Table 6.

Table 6. Summary of test conditions after the dropping of the can

\begin{tabular}{|c|c|c|c|c|}
\hline \multirow{2}{*}{ Test No. } & \multicolumn{2}{|c|}{ 10-min duration after can dropping } & \multicolumn{2}{|c|}{1 - hr duration after can dropping } \\
\hline & Temperature $\left({ }^{\circ} \mathrm{F}\right)$ & $\mathrm{RH}(\%)$ & Temperature $\left({ }^{\circ} \mathrm{F}\right)$ & $\mathrm{RH}(\%)$ \\
\hline $0^{[1]}$ & $70.2 \pm 0.0$ & $48.3 \pm 0.9$ & $70.8 \pm 0.7$ & $51.8 \pm 4.3$ \\
\hline 1 & $68.0 \pm 0.5$ & $55.6 \pm 0.8$ & $69.8 \pm 1.7$ & $51.8 \pm 2.5$ \\
\hline 2 & $73.8 \pm 0.3$ & $47.1 \pm 0.3$ & $75.4 \pm 1.1$ & $44.7 \pm 1.6$ \\
\hline 3 & $68.1 \pm 0.2$ & $58.7 \pm 0.3$ & $71.3 \pm 2.3$ & $53.6 \pm 3.7$ \\
\hline 4 & $73.3 \pm 0.2$ & $50.4 \pm 0.4$ & $75.0 \pm 1.1$ & $47.8 \pm 1.7$ \\
\hline 5 & $73.2 \pm 0.3$ & $49.6 \pm 0.4$ & $74.8 \pm 1.1$ & $47.1 \pm 1.6$ \\
\hline 6 & $73.1 \pm 0.2$ & $44.3 \pm 0.4$ & $74.7 \pm 1.1$ & $42.0 \pm 1.5$ \\
\hline 7 & $73.2 \pm 0.2$ & $47.8 \pm 0.4$ & $74.9 \pm 1.1$ & $45.4 \pm 1.6$ \\
\hline 8 & $81.5 \pm 0.3$ & $47.2 \pm 0.3$ & $82.8 \pm 0.9$ & $45.4 \pm 1.2$ \\
\hline
\end{tabular}

Note:

[1] The readings of Test 0 are from the control system (Andover system) and may not exactly represent the real conditions inside the chamber. 


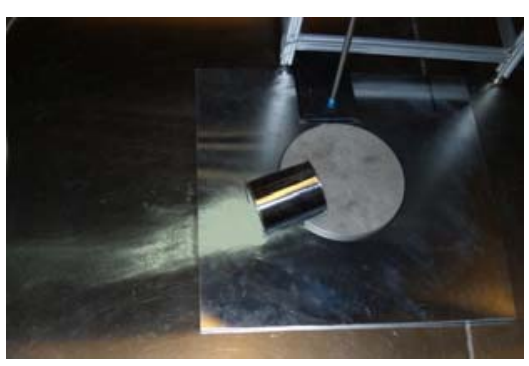

Test 0

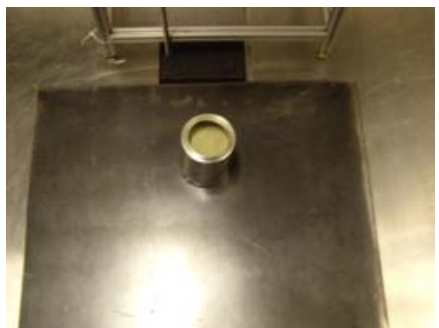

Test 1

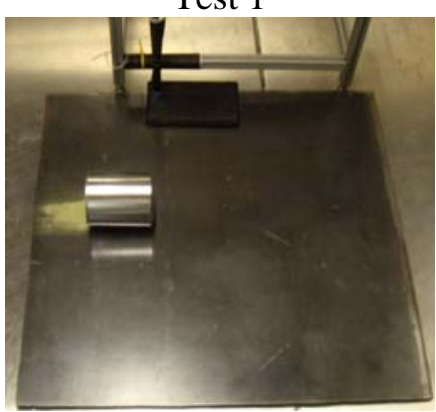

Test 3

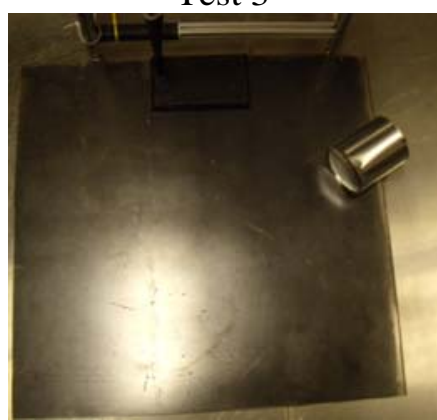

Test 5

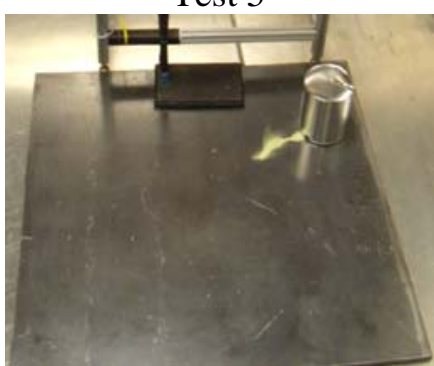

Test 7

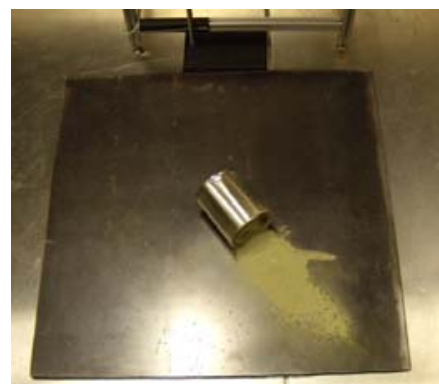

Test 2

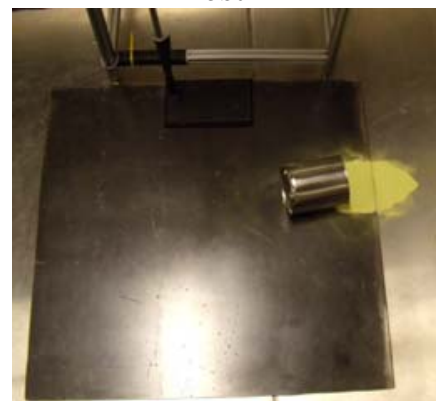

Test 4

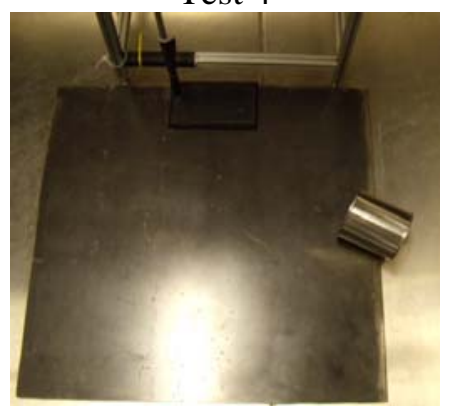

Test 6

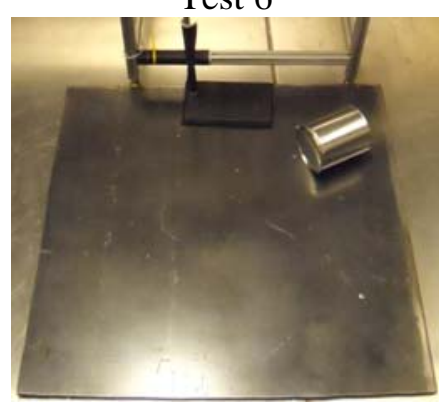

Test 8

Figure 8. The position of the container after dropping (Note that the position of the impacting surface was slightly adjusted about 2" toward the sampling stand after Test 1 and Test 2) 


\subsection{Amount of Ejected Materials}

Of the nine drop tests conducted, most of the cans (seven) tipped over after dropping. The can in Test 1 stayed upright. The can in Test 7 showed a special behavior: after the rebound, it turned upside down and stayed upright. Lots of powder spilled out in Test 0,2 and 4 . Figure 8 shows the position of the container after dropping for each test.

Table 7a . Mass measurement before the dropping of the can

\begin{tabular}{l|l|l|l|l|l|l|}
\multirow{2}{*}{$\begin{array}{l}\text { Test } \\
\#\end{array}$} & \multicolumn{7}{|c|}{ Before can dropping (g) } \\
\cline { 2 - 8 } & Can Body & Can Lid & Clips & Can & Powder & Total Weight \\
\hline 0 & 100.89 & $/$ & $/$ & 100.89 & 1937.76 & 2038.65 \\
\hline 1 & 100.83 & $/$ & $/$ & 100.83 & 1936.00 & 2036.83 \\
\hline 2 & 100.13 & $/$ & $/$ & 100.13 & 1936.00 & 2036.13 \\
\hline 3 & 100.07 & $/$ & $/$ & 100.07 & 1936.00 & 2036.07 \\
\hline 4 & 100.61 & $/$ & $/$ & 100.61 & 1936.00 & 2036.61 \\
\hline 5 & 101.00 & 23.22 & 1.90 & 126.12 & 1936.00 & 2062.12 \\
\hline 6 & 100.19 & 23.33 & 1.90 & 125.42 & 1936.00 & 2061.42 \\
\hline 7 & 100.52 & 23.10 & 1.90 & 125.52 & 1936.00 & 2061.52 \\
\hline 8 & 100.76 & 23.47 & 1.90 & 126.13 & 1936.00 & 2062.13 \\
\hline
\end{tabular}

Table 7b . Mass measurement after the dropping of the can

\begin{tabular}{|c|c|c|c|c|c|}
\hline \multirow{3}{*}{$\begin{array}{l}\text { Test } \\
\#\end{array}$} & \multicolumn{5}{|c|}{ After can dropping (g) } \\
\hline & 7 & $8(=7-4)$ & $9(=6-7$ or $=5-8)$ & 10 & $11(=9-10)$ \\
\hline & $\begin{array}{l}\text { Can }+ \\
\text { Powder Inside }\end{array}$ & $\begin{array}{l}\text { Powder } \\
\text { Inside }\end{array}$ & $\begin{array}{l}\text { Spilled } \\
\text { Powder }\end{array}$ & $\begin{array}{l}\text { Powder on } \\
\text { Floor }\end{array}$ & $\begin{array}{l}\text { Non-recovered } \\
\text { Powder }{ }^{[1]}\end{array}$ \\
\hline 0 & 1907.09 & 1806.20 & 131.56 & 130.88 & 0.68 \\
\hline 1 & 2036.40 & 1935.57 & 0.43 & 0.07 & 0.36 \\
\hline 2 & 1918.13 & 1818.00 & 118.00 & 116.82 & 1.18 \\
\hline 3 & 2010.09 & 1910.02 & 25.98 & 25.79 & 0.19 \\
\hline 4 & 1784.26 & 1683.65 & 252.35 & 251.43 & 0.92 \\
\hline 5 & 2061.89 & 1935.77 & 0.23 & 0.02 & 0.21 \\
\hline 6 & 2060.93 & 1935.51 & 0.49 & 0.28 & 0.21 \\
\hline 7 & 2057.10 & 1931.58 & 4.42 & 4.29 & 0.13 \\
\hline 8 & 2062.01 & 1935.88 & 0.12 & 0.01 & 0.11 \\
\hline
\end{tabular}

Note:

[1] The calculation of the non-recovered mass is based on the mass of spilled powder and the recovered mass of powder visibly on the floor. 
Table 7a and Table 7b show the mass measurement before and after the dropping of the can. The spilled powder varies from $0.12 \mathrm{~g}$ to $252.35 \mathrm{~g}$ and the non-recovered powder varies from $0.11 \mathrm{~g}$ to $1.18 \mathrm{~g}$. Figure 9 shows the corresponding percentage of powder spilled, ranging from $0.01 \%$ to $13 \%$.

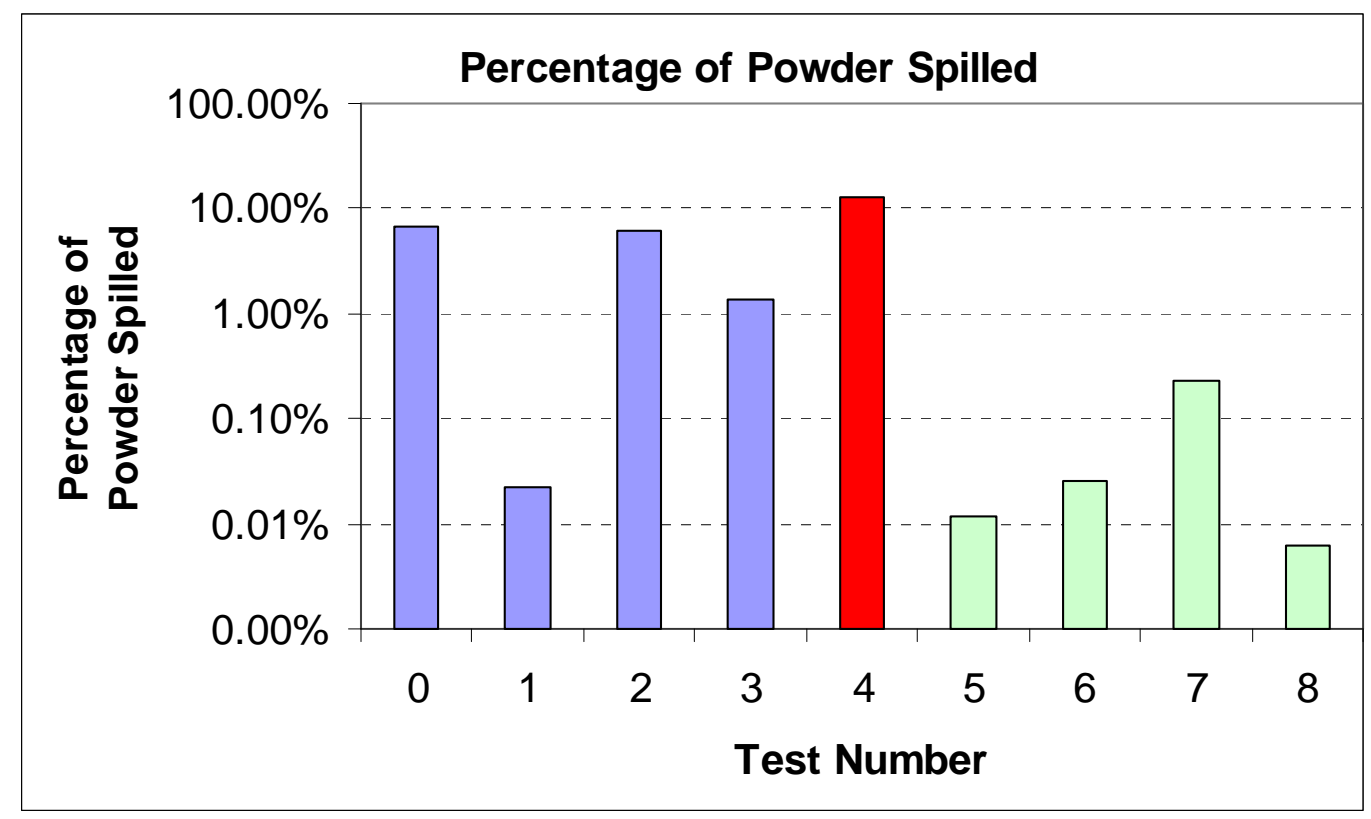

Figure 9. Percentage of powder spilled for each test

\subsection{Airborne Mass and Number Concentrations}

Particle mass and number concentrations before and after the dropping of the can for each test are shown in Figure A*-b and Figure A*-c in Appendix 3 (“*” denotes test number). The size distributions (mass and number) for channel data are also shown in Figure $A^{*}$-d and Figure $A^{*}$-f. The size distributions (mass and number) for grouped data $(<1.2 \mu \mathrm{m}$, $1.2-2 \mu \mathrm{m}, 2-2.9 \mu \mathrm{m}, 2.9-4.3 \mu \mathrm{m}, 4.3-10 \mu \mathrm{m}$ and $10-20 \mu \mathrm{m}$ ) are shown in Figure $A^{*}$-e and Figure $A^{*}$-g. We can see that for channel data, the peak value of number concentration after the dropping of the can appears at approximately $0.9 \mu \mathrm{m}$. Smaller particles always have bigger number concentrations than large particles despite their significantly smaller mass fraction. For grouped data, the group of $4.3-10 \mu \mathrm{m}$ usually has the maximum mass concentration value after the dropping of the can except for Test 4 cause of the different powder used.

Figure 10a and Figure 10b show the total airborne mass and number concentration versus time for each test. We can see that after the dropping of the can, it takes less than 1 or 2 minutes for the system to get a stable particle concentration reading in the dynamic process. Then the particle concentration begins to drop due to natural deposition. 


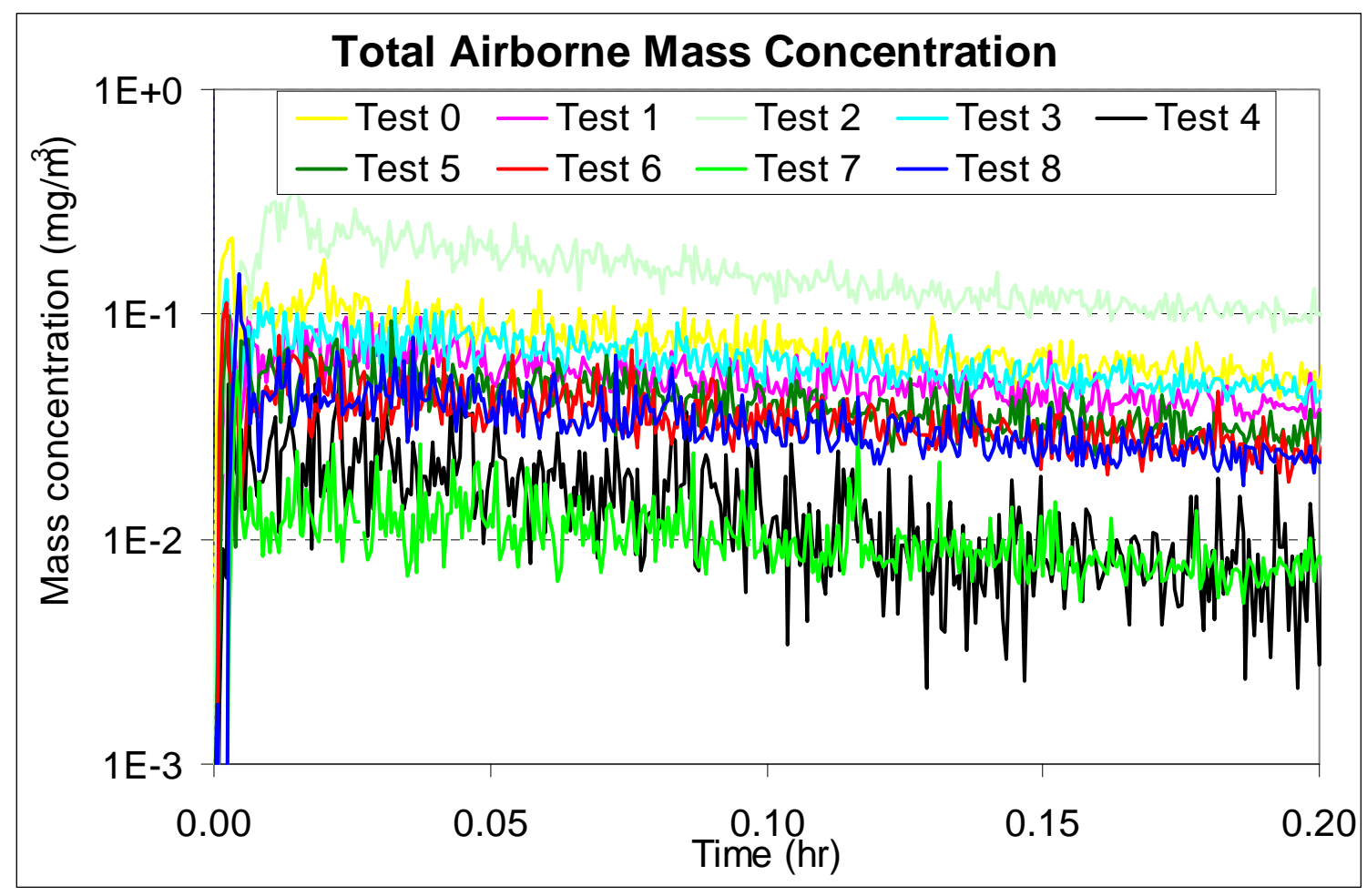

Figure 10a. Total airborne mass concentration versus time for each test

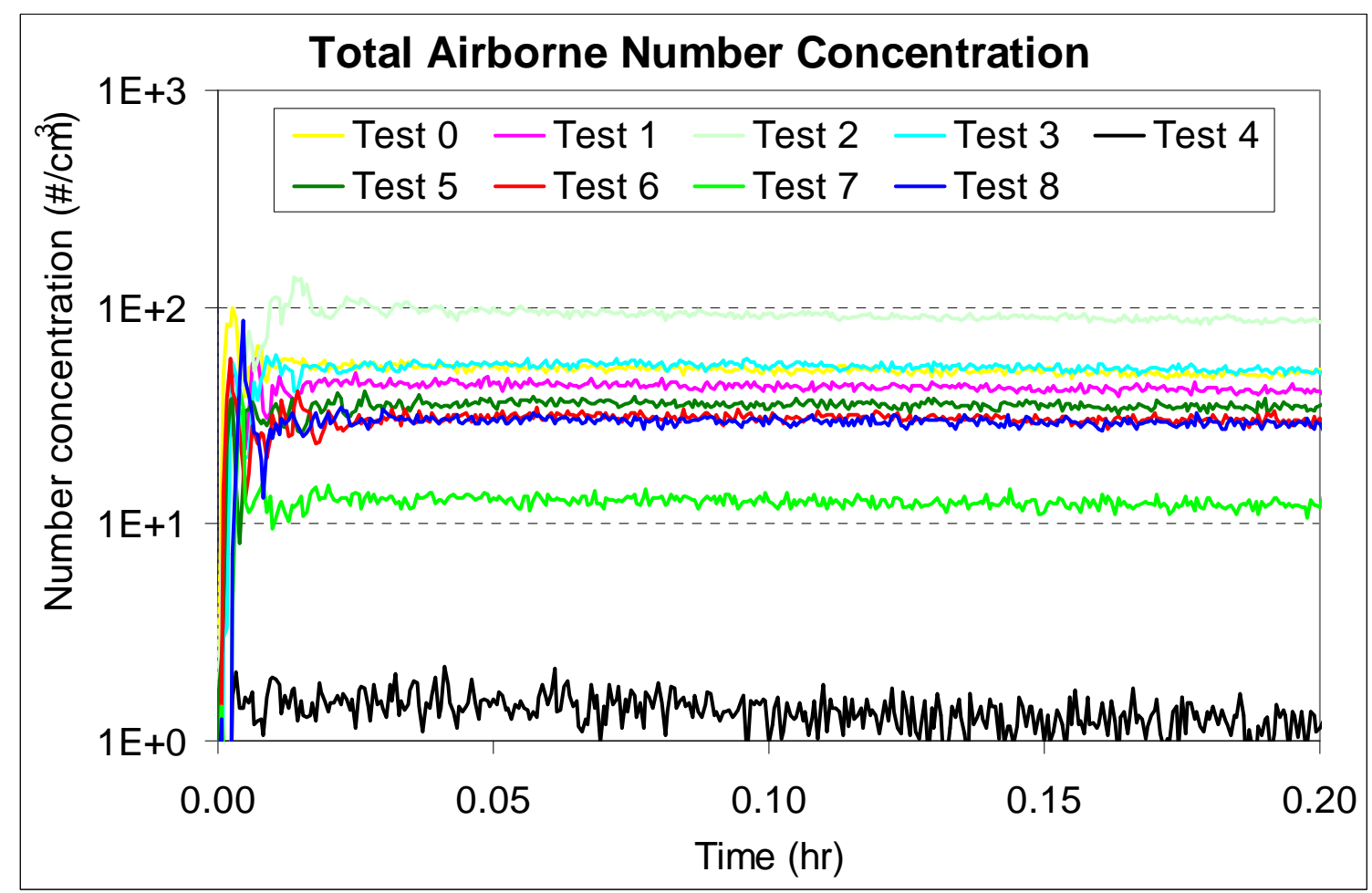

Figure 10b. Total airborne number concentration versus time for each test 


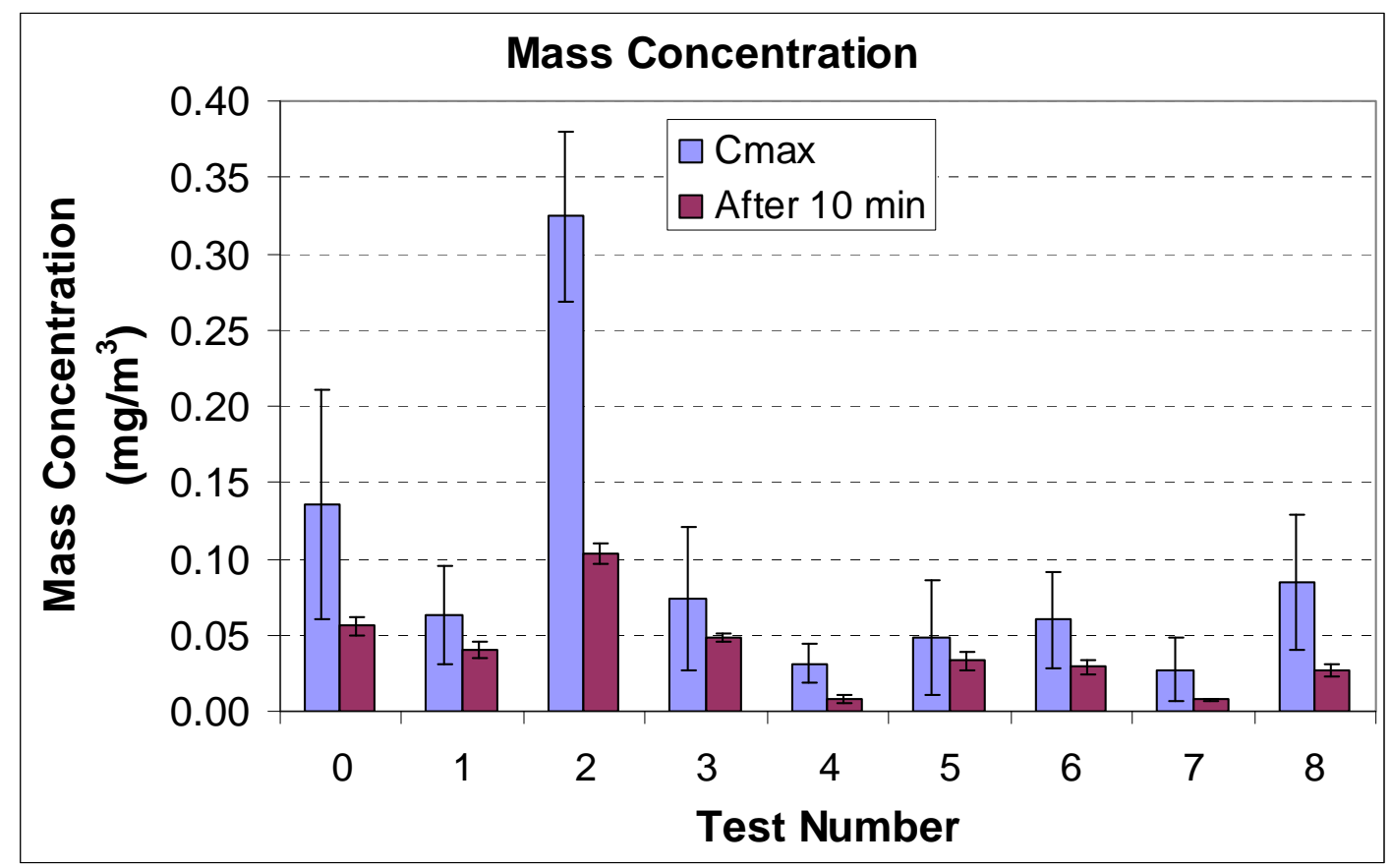

Figure 11a. Total airborne mass concentration

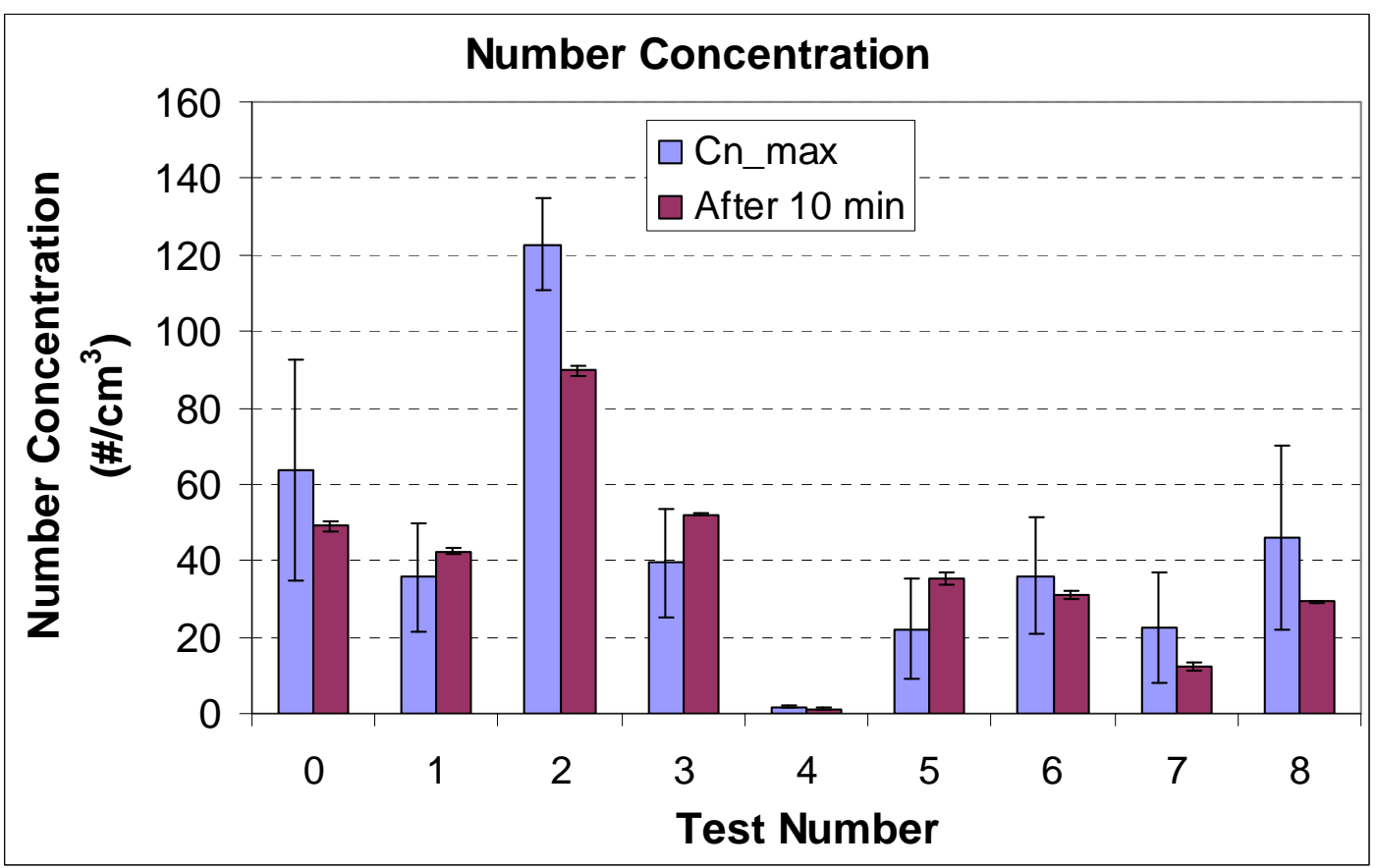

Figure 11b. Total airborne number concentration

Notes:

[1] " $\mathrm{C}_{\max }$ " is the first peak value per mass concentration with a 10 seconds averaged value. " $\mathrm{C}_{\mathrm{n} \_\max }$ " is the number concentration at the time mass concentration " $\mathrm{C}_{\max }$ " occurred.

[2] "After 10 min" denotes the 10 seconds averaged value centered at 10 minutes after " $\mathrm{C}_{\max }$ ". 
Figure 11a and Figure 11b show the comparison of airborne total mass and number concentration. It should be noted that because the definition of " $\mathrm{C}_{\max }$ " is based on mass concentration, the number concentration of " $\mathrm{C}_{\mathrm{n} \_\max }$ " may not necessarily be the maximum value. We can also notice that " $\mathrm{C}_{\max }$ " has relatively big variance due to the unsteadiness of the system.

From Figure 11a and Figure 11b we can also find that after the dropping of the can, the total airborne mass concentrations are within the range of 0.03 and $0.35 \mathrm{mg} / \mathrm{m}^{3}$, while the total airborne number concentrations are within the range of 2 and $125 \# / \mathrm{cm}^{3}$. Test 2 has the maximum values for both mass and number concentrations. The number concentration in Test 4 is 1 or 2 orders of magnitude less than those of other tests because the powder is from a different batch. However, its mass concentration is comparable to that in Test 7 because relatively more airborne big particles are detected in Test 4 . In general, tests with lid (Test 5, 6, 7 and 8) have smaller concentrations compared with tests without lid (Test $0,1,2$, and 3 ) as expected. The influence of lid is not as prominent as that of the powder (Test 4). However, it needs more tests for verification.

re

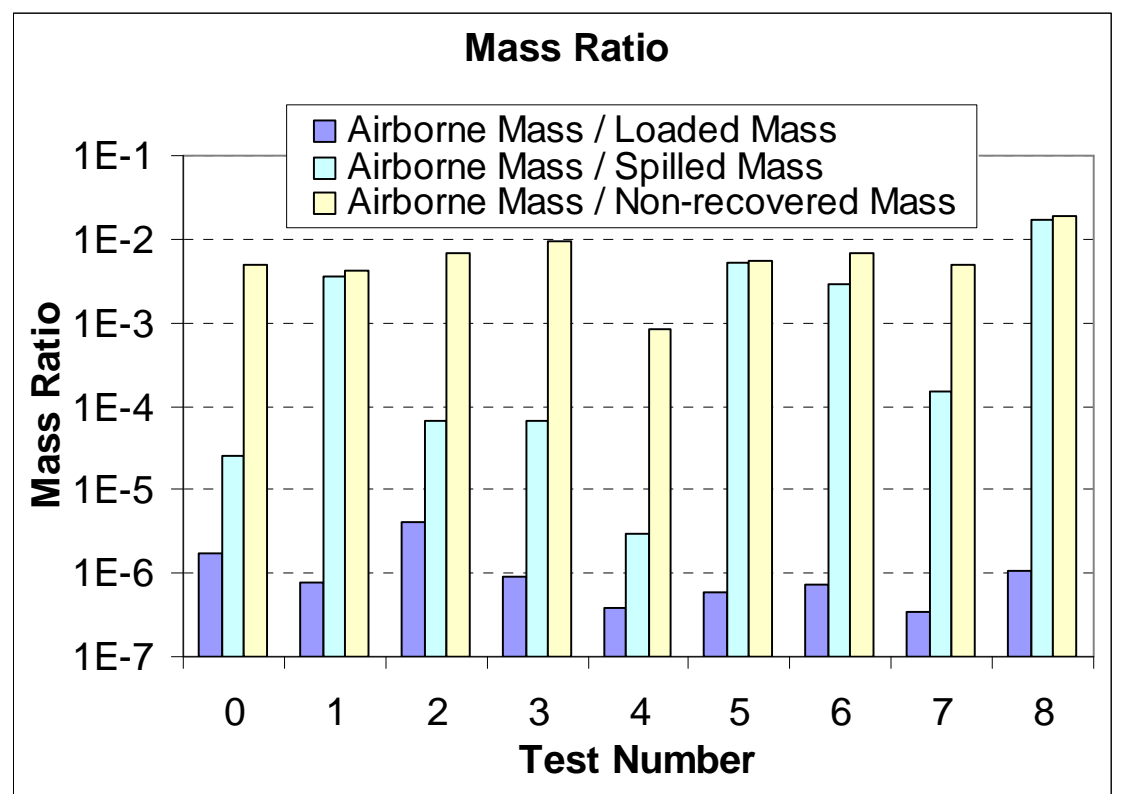

Figure 12. Ratio of airborne mass to loaded mass, spilled mass and non-recovered mass

From the total airborne mass concentration, we can calculate the airborne particle mass. Figure 12 shows the ratio of airborne mass to loaded mass, spilled mass and nonrecovered mass. The ratio of airborne mass to non-recovered mass ranges from $0.1 \%$ to $2 \%$. This means that it is challenging to use this method to check the mass balance.

\subsection{Uptake Factor}

Figure 13 shows the calculated cumulative uptake mass within first 10 minutes after the dropping of the can for each test. The range is within $0.002 \mathrm{mg}$ to $0.035 \mathrm{mg}$. 


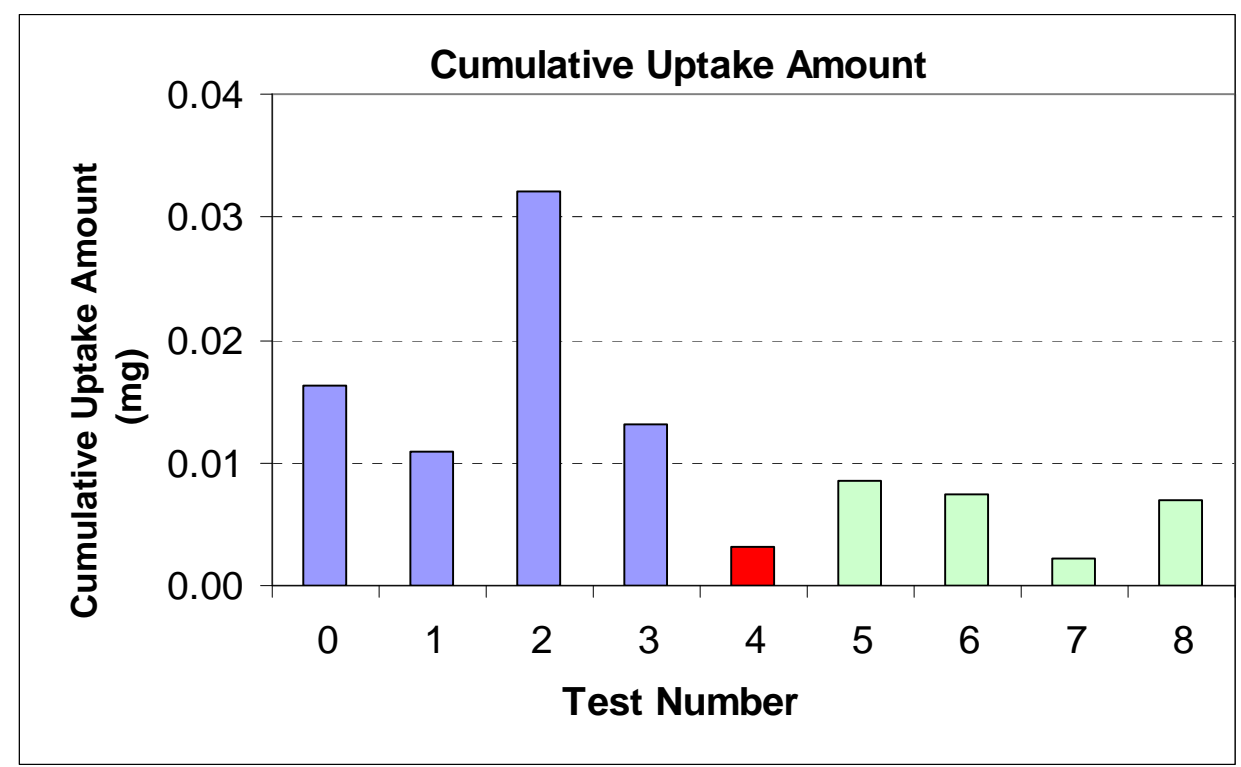

Figure 13. Cumulative uptake mass

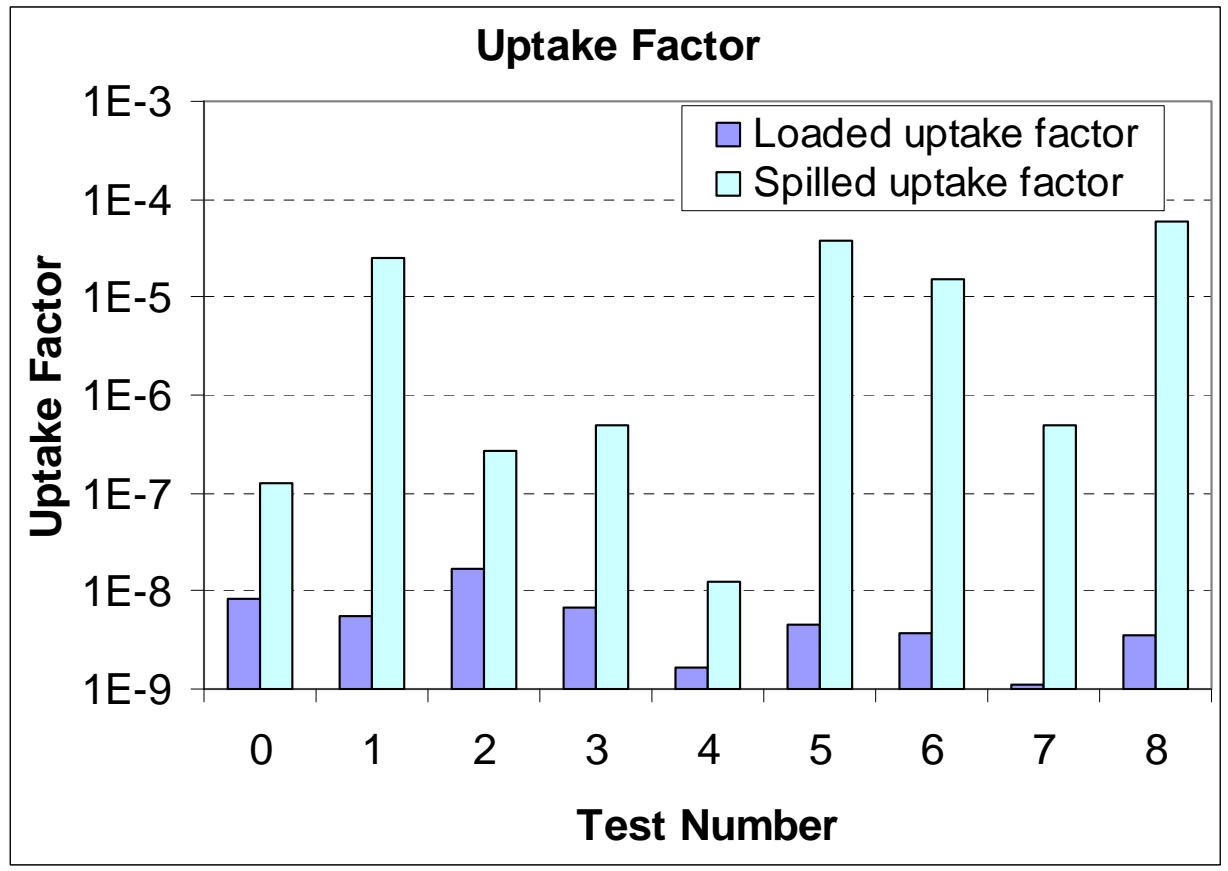

Figure 14. Uptake factor

By using Equations (1) and (2), we can calculate the particle uptake factor. The results are shown in Figure 14. The loaded uptake factor is within the range of $10^{-9}$ to $2 \times 10^{-8}$, while the spilled uptake factor is within the range of $10^{-8}$ to $6 \times 10^{-5}$. The tabulated data on cumulative uptake mass and uptake factor for each test are shown in Table 8. 
Table 8. Tabulated data on cumulative uptake mass and uptake factor for each test

\begin{tabular}{|l|c|c|c|}
\hline Test \# & Cumulative uptake amount (mg) & Loaded uptake factor & Spilled uptake factor \\
\hline 0 & $1.62 \times 10^{-2}$ & $8.38 \times 10^{-9}$ & $1.23 \times 10^{-7}$ \\
\hline 1 & $1.09 \times 10^{-2}$ & $5.62 \times 10^{-9}$ & $2.53 \times 10^{-5}$ \\
\hline 2 & $3.20 \times 10^{-2}$ & $1.65 \times 10^{-8}$ & $2.74 \times 10^{-7}$ \\
\hline 3 & $1.31 \times 10^{-2}$ & $6.76 \times 10^{-9}$ & $5.04 \times 10^{-7}$ \\
\hline 4 & $3.18 \times 10^{-3}$ & $1.64 \times 10^{-9}$ & $1.26 \times 10^{-8}$ \\
\hline 5 & $8.59 \times 10^{-3}$ & $4.44 \times 10^{-9}$ & $3.74 \times 10^{-5}$ \\
\hline 6 & $7.36 \times 10^{-3}$ & $3.80 \times 10^{-9}$ & $1.50 \times 10^{-5}$ \\
\hline 7 & $2.19 \times 10^{-3}$ & $1.13 \times 10^{-9}$ & $4.96 \times 10^{-7}$ \\
\hline 8 & $6.99 \times 10^{-3}$ & $3.61 \times 10^{-9}$ & $5.82 \times 10^{-5}$ \\
\hline
\end{tabular}

\subsection{Observation of Material Ejection Behavior}

In order to improve the understanding of the phenomenon of particle ejection from the can due to impacting on the surface, a video camera was used for this application. The particle cloud was illuminated by a light-sheet generated by an incandescent flight sheet (part of a bubble flow visualization system, without generating bubbles in this application). Under almost all circumstances, the can would deviate from the light sheet and could not be illuminated well entirely after impacting. Test 1 was an exception, of which the whole ejection processes was recorded (shown in Figure 15a). It took approximately 8 seconds for the particle cloud to visibly disappear. Figure 16a shows the impacting process in Test 4. It should be noted that in Test 4, the powder from the second batch was used. It took approximately 3 seconds for the particle cloud to visibly disappear in Test 4. For all other tests, the duration of the visibly particle cloud was within this range (3 seconds to 8 seconds).

The qualitative and quantitative analyses of the material ejection process need further investigation.

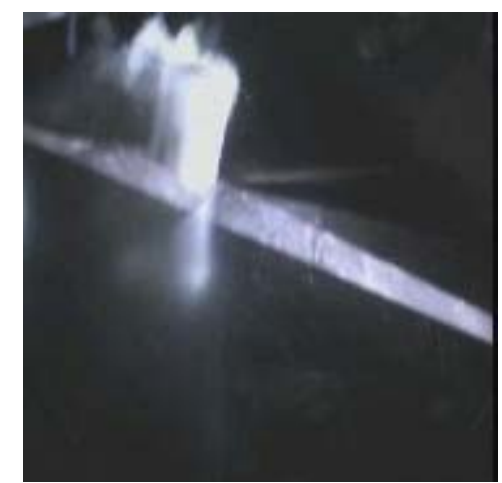

$\mathrm{T}=0 \mathrm{~s}$

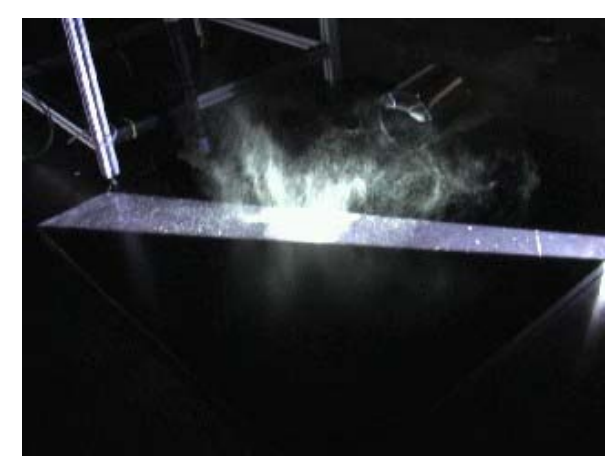

$\mathrm{T}=0 \mathrm{~s}$ 


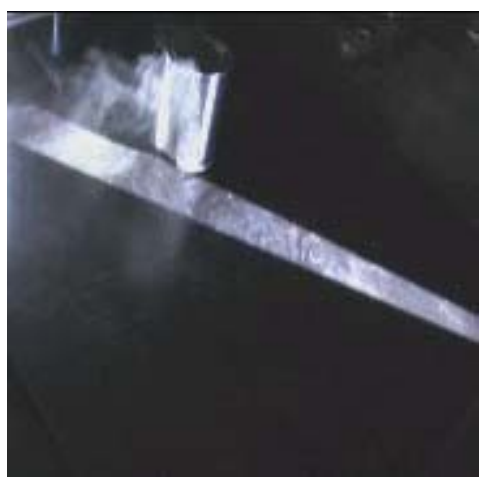

Test $=1 \mathrm{~s}$

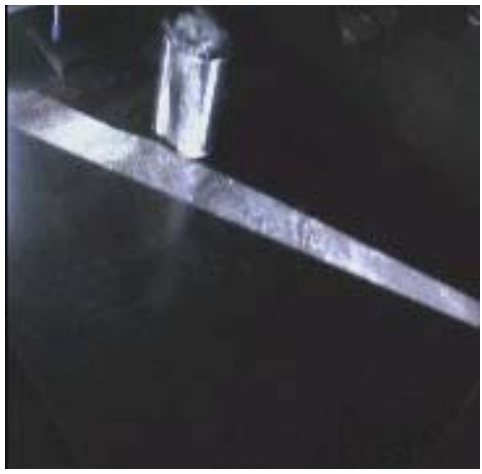

Test $=2 \mathrm{~s}$

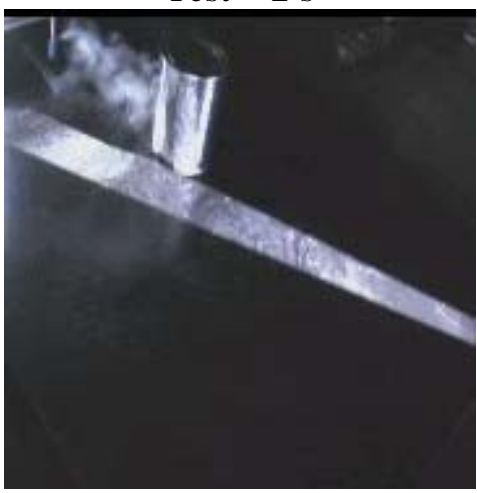

$\mathrm{T}=3 \mathrm{~s}$

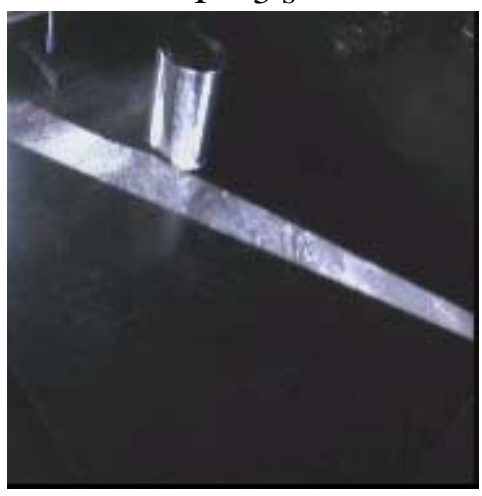

$\mathrm{T}=6 \mathrm{~s}$

Figure 15a Test 1

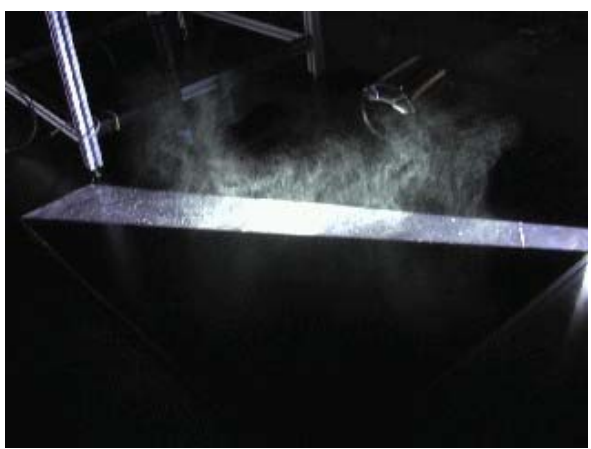

Test $=0.5 \mathrm{~s}$

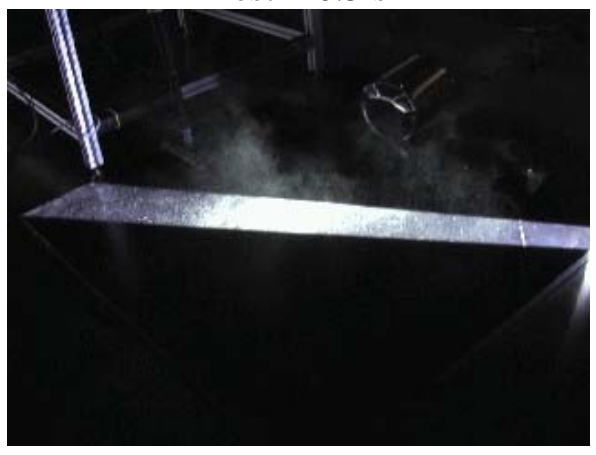

$\mathrm{T}=1 \mathrm{~s}$

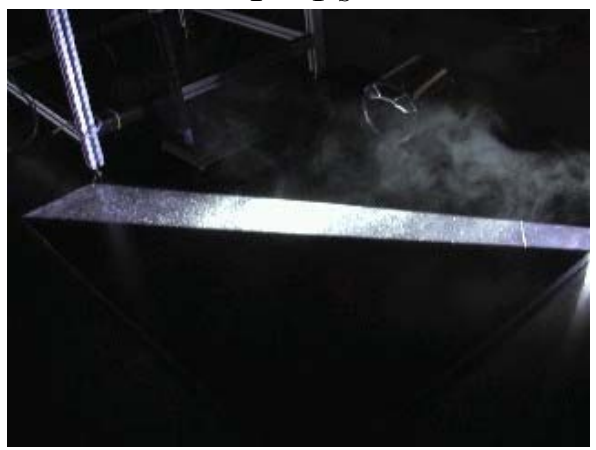

$\mathrm{T}=2 \mathrm{~s}$

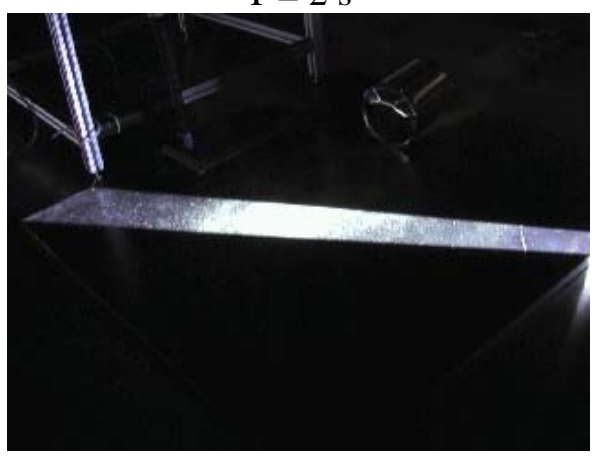

$$
\mathrm{T}=3 \mathrm{~s}
$$

Figure 15b Test 4

Figure 15. The observation of material ejection behavior 


\section{CONCLUSIONS AND RECOMMENDATIONS}

A test procedure has been developed and used to measure the airborne concentrations of different size particles within the vicinity of a dropped container where a significant portion of the contained powder is ejected. The following conclusions may be drawn:

- A total of nine drop tests were performed. In most cases (seven tests), the can tipped over after dropping. The can in Test 1 stayed upright. The can in Test 7 showed a special behavior: after the rebound, it turned upside down and stayed upright.

a The amount of spilled powder varied from $0.12 \mathrm{~g}$ to $252.35 \mathrm{~g}$ and the nonrecovered powder varied from $0.11 \mathrm{~g}$ to $1.18 \mathrm{~g}$. The corresponding percentage of the spilled powder ranged from $0.01 \%$ to $13 \%$.

- The peak value of particle number concentration after the dropping of the can occurred at approximately $0.9 \mu \mathrm{m}$ particle size per measured data of individual channels. The peak value of particle mass concentration occurred in the range of 4.3 - $10 \mu \mathrm{m}$ particle size per grouped data calculated from the measured data with the exception of Test 4 where a different batch powder with unexpectedly different bulk density and particle size distribution.

- After the dropping of the can, the total airborne mass concentrations ranged from 0.03 to $0.35 \mathrm{mg} / \mathrm{m}^{3}$, while the total airborne number concentrations ranged from 2 to $125 \# / \mathrm{cm}^{3}$ except for Test 4 . The number concentration in Test 4 was 1 or 2 orders of magnitude less than those of other tests because the powder was from a different batch. However, its mass concentration was comparable to that in Test 7 because relatively more big airborne particles were detected in Test 4 . In general, tests with lid (Test 5, 6, 7 and 8) had smaller concentrations than tests without lid (Test $0,1,2$, and 3). The influence of lid was not as prominent as the powder (Test 4). However, this needs more tests for verification.

- The ratio of airborne mass to non-recovered mass ranged from $0.1 \%$ to $2 \%$. This means that it is challenging to use this method to check the mass balance, while the uptake factor and associated inhalation exposure can be readily assessed.

- The calculated cumulative uptake mass within first 10 minutes after the dropping of the can for each test was within the range of $0.002 \mathrm{mg}$ to $0.035 \mathrm{mg}$. The uptake factor was between $10^{-9}$ and $2 \times 10^{-8}$ in reference to the amount loaded; or between $10^{-8}$ and $6 \times 10^{-5}$ in reference to the amount spilled.

Further investigation on this study may include: 
- Test the influence of additional parameters, such as the mass in the can, height of the drop, size of the lid hole, room air flow condition and other materials with different size distribution.

- Procure and set up better resolution video camera and lighting system for flow and particle visualization of the impacting process.

․ Study the feasibility of numerical simulation on the dropping process of the can.

\section{ACKNOWLEDGEMENTS}

The authors appreciate the fruitful discussions with and insightful advises from Y-12 researchers including Mohamed Alsharif, Jerry Byington, Sanford Bloom, Douglas Clark, Walter Irwin North, and Donna Bennett. They would also like to thank Mr. Jim Smith, Ms. Robbin Mocarski, Shewangizaw Semahegn and Denis Pradhan of BEESL for their help in setting up the test facility and purchasing the test materials. The use of NYSTAR Funded Research Facility and Instruments for conducting experiments in this study is also gratefully acknowledged.

\section{REFERENCES}

1. Hoover M.D., Newton G.J., Guilmette R.A., Howard R.J., Ortiz R.N., Thomas J.M., Trotter S.M. and Ansoborlo E. Characterization of Enriched Uranium Dioxide Particles from a Uranium Handling Facility. Radiation Protection Dosimetry,1998. 79 (1-4), pp57-62.

2. International Atomic Energy Agency (IAEA). Advisory Material for the IAEA Regulations for the Safe Transport of Radioactive Material, IAEA Safety Standards Series No. TS-G-1.1 (Rev. 1), IAEA, Vienna (2008). International Atomic Energy Agency (IAEA)

3. US Department of Energy (DOE). Office of Nuclear Safety and Environment. Nuclear Material Packaging Manual. DOE M441.1-1. 2008.

4. US Department of Transportation (DOT). Pipeline and Hazardous Materials Safety Administration. Shippers--General Requirements for Shipments and Packagings. 49 CFR 173.435. 2008.

5. Herrmann TJ, Zhang JS, Zhang Z, Smith J, Gao X, Li H, Chen W, Wang S. Performance Test Results for an Innovative Large Coupled Indoor/Outdoor Environmental Simulator (C-I/O-ES). ASHRAE Transaction, 2003. 109 (2), pp503516. 


\section{APPENDIX 1: TEST PROCEDURE}

\section{Container Preparation}

$>$ Prepare 4 can lids with a 0.25 " diameter hole in the center.

$>$ Check the weight of each empty can and lid by balance.

$>$ Pack 8 cans with tungsten oxide. The powder should be loosely filled to a level approximately 1 " below the top rim of the can.

$>$ Check the weight of each full can by balance. The weight differences of all 8 cans should be within $1 \%$ and recorded to $0.01 \mathrm{~g}$.

$>$ Label each can with a unique test name.

\section{Chamber Preparation}

$>$ Close the valves at the air supply duct and return duct.

$>$ Turn on 10 small fans in the chamber.

$>$ Use velocity meter to check the air velocity near the top of the room (6 12" from the ceiling) to be 0.25 to $0.3 \mathrm{~m} / \mathrm{s}$. Adjust the fan speed as needed by using the variable frequency drive (VFD).

$>$ Inject tracer gas into the chamber from the sampling port and monitor its concentration by gas monitor. Calculate the air-tightness. The value should be below $0.02 \mathrm{ACH}$.

\section{Chamber Cleaning}

Use vacuum cleaner to clean floor surfaces.

$>$ Use paper towel or clean cloth (with isopropyl alcohol 70\% solution and distilled water) to clean all surfaces, including fan blades and interior surfaces of the diffuser box.

\section{Equipment Setup and Background Sampling}

$>$ Keep the valves at the air supply duct and return duct open.

$>$ Use Andover system to pre-condition the chamber at $70^{\circ} \mathrm{F} \pm 5^{\circ} \mathrm{F}$ in temperature and $50 \% \pm 10 \% \mathrm{RH}$ in relative humidity.

$>$ Enter the chamber with shoe covers and mask. Put the can into the chamber and hold it with the magnetic device at $8 \mathrm{ft}$ above the impacting surface.

$>$ Set up particle sizer APS 3321 with $2 \mathrm{~s}$ as the sampling time.

$>$ Set up IAQ-Calc 8762 meter for measurements of temperature and relative humidity with $20 \mathrm{~s}$ as the sampling time.

$>$ Set up the video camera and lighting system. Close the chamber.

$>$ Run the system to achieve the required low background particle concentration (clean room class 3.5).

\section{Recirculation Mode}


$>$ Shut down Andover system.

$>$ Close the valves at the air supply duct and return duct.

$>$ Turn on 10 small fans in the chamber from outside. Record the time.

$>$ Let the system run 15 minutes.

6. Can Dropping

$>$ Trigger the dropping of the can by using the magnetic solenoid valve from outside of the chamber. Record the time.

$>$ Monitor particle concentrations at least 30 minutes or wait the concentrations to go back to the background.

7. Test Wrap-up

$>$ Take pictures of the system, especially the can and the powder.

$>$ Check the weight of the can.

$>$ Download the data of particle sizer APS 3321. Turn off particle sizer.

$>$ Download the data of temperature and RH from Andover system and IAQ-Calc 8762.

$>$ Download the video file.

$>$ Analyze the data.

8. Repeat the Test

$>$ Repeat the procedure 3-7 for 4 tests without a lid.

$>$ Repeat the procedure 3-7 for 4 tests with a tight lid with a 0.25 ” diameter hole in the center. 


\section{APPENDIX 2: TEST EQUIPMENT}

(1) Aerodynamic Particle Sizer Spectrometer - Model 3321 (TSI Inc.)

$>$ Particle size range: 0.5 to $20 \mu \mathrm{m}$ aerodynamic sizing, 0.37 to $20 \mu \mathrm{m}$ optical detection (PSL equivalent)

$>$ Aerodynamic size resolution: $0.02 \mu \mathrm{m}$ at $1.0 \mu \mathrm{m} ; 0.03 \mu \mathrm{m}$ at $10 \mu \mathrm{m}$

$>$ Display resolution: 32 channels per decade of particle size (logarithmic), 52 channels total; 1,024 bins of raw time-of-flight data (4 nsec per bin) in uncorrelated mode

$>$ Particle type: airborne solids and nonvolatile liquids

> Maximum recommended particle concentration: 1000 particles $/ \mathrm{cm}^{3}$ at $0.5 \mu \mathrm{m}$ with $<5 \%$ coincidence; 1000 particles $/ \mathrm{cm}^{3}$ at $10 \mu \mathrm{m}$ with $<10 \%$ coincidence; usable data up to 10,000 particles $/ \mathrm{cm}^{3}$

$>$ Minimum particle concentration: 0.001 particles $/ \mathrm{cm}^{3}$

$>$ Concentration range : $\pm 10 \%$ of reading plus variation from counting statistics

$>$ Maximum processing rate for aerodynamic sizing: $>200,000$ particles/sec

$>$ Sampling time: programmable and repeatable from 1 sec to $18 \mathrm{hr}$ per sample; sampling schedules selected by user

$>$ Flow rates: aerosol sample: $1.0 \pm 0.1 \mathrm{lpm}$; sheath air: $4.0 \pm 0.1 \mathrm{lpm}$; total flow rate: $5.0 \pm 0.2 \mathrm{lpm}$

(2) Weighing balance GF-2000 (A\&D Company, Limited). Max: 2100 g, Min: 0.5 g, e = 0.1 $\mathrm{g}, \mathrm{d}=0.01 \mathrm{~g}$

(3) IAQ-Calc 8762 Meter (TSI Inc.) for measurement of temperature and RH

(4) Veloci-Calc 8347 air velocity meter (TSI Inc.)

(5) 1312 Photoacoustic Multi-gas Monitor (INNOVA Air Tech Instruments) for continuously monitoring tracer gas concentration

(6) SAI (Sage Action Inc.) Arc Lamp Optical Shroud OS 300-3 and Perkinelmer Arc Lamp Power Supply PS 300-13

(7) GE 7 day indoor plug-in digital heavy duty timer with 2 grounded outlets - Model 15079

(8) DC 500 heavy duty 2 gallon cordless/corded wet/dry vacuum (DeWALT)

(9) Tracer gas cylinder 


\section{APPENDIX 3: TEST RESULTS}

\section{A3.0 Test 0}

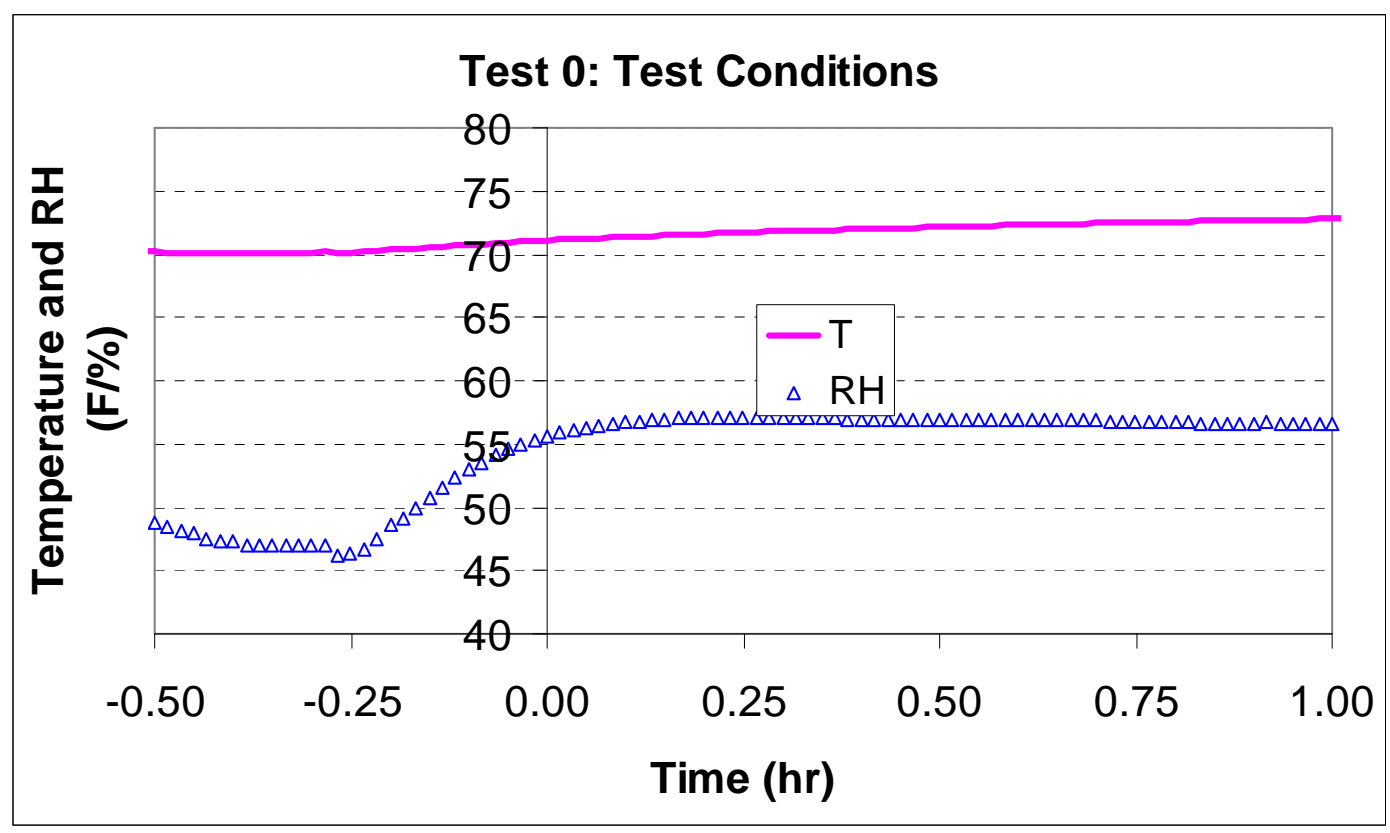

Figure A0-a. Chamber conditions during Test 0

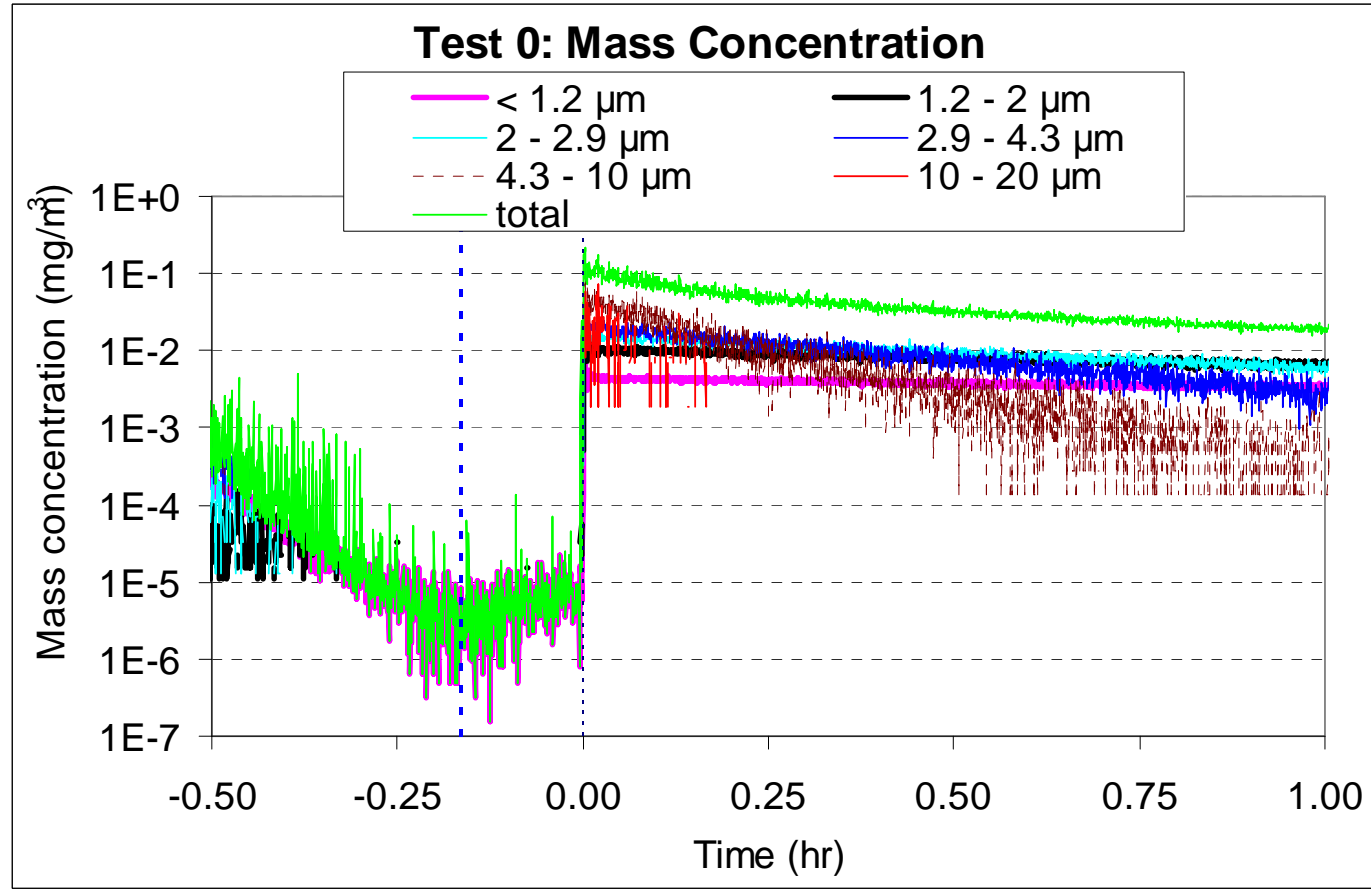

Figure A0-b. Particle mass concentration before and after the dropping of Test 0 


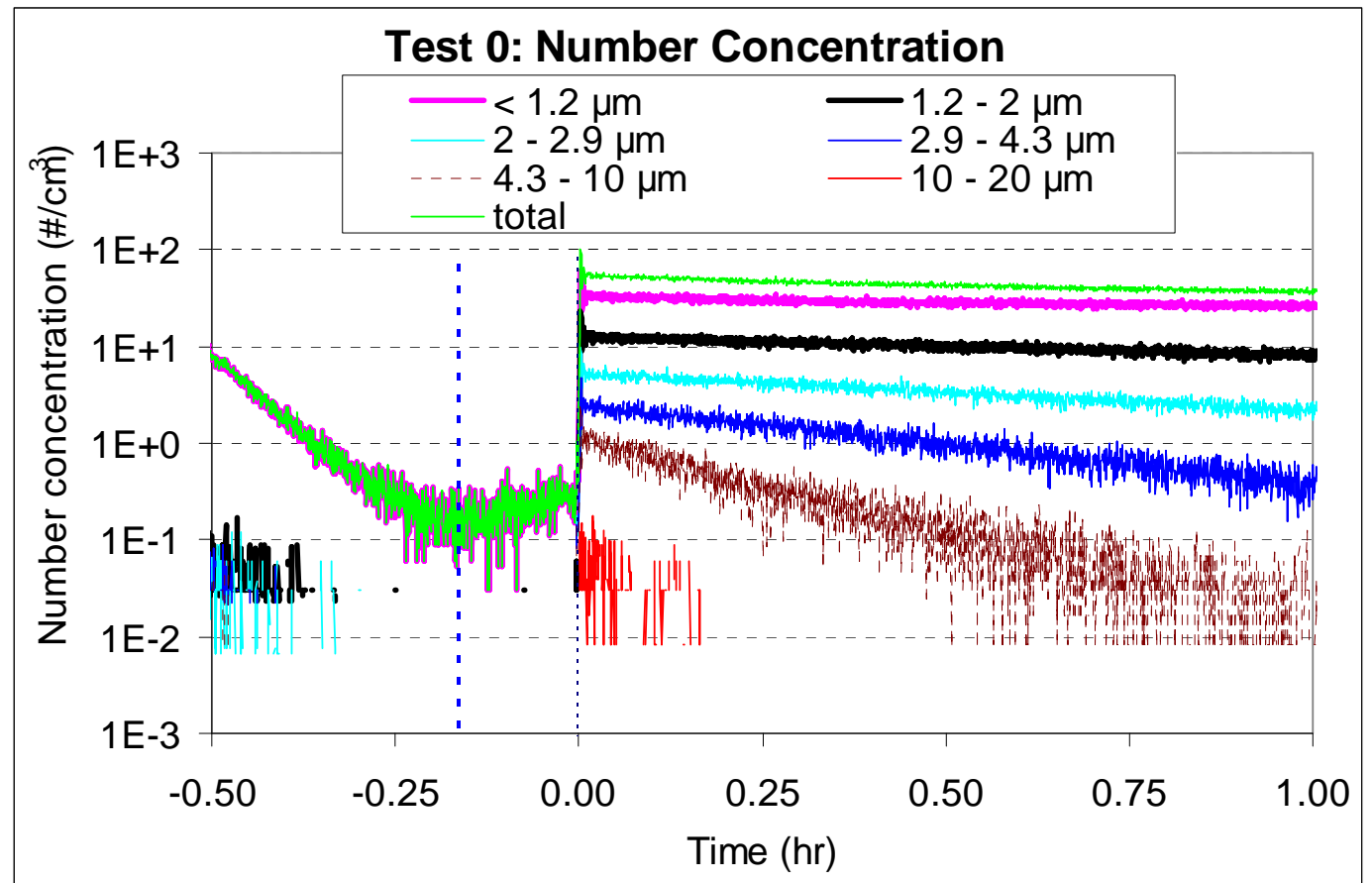

Figure A0-c. Particle number concentration before and after the dropping of Test 0

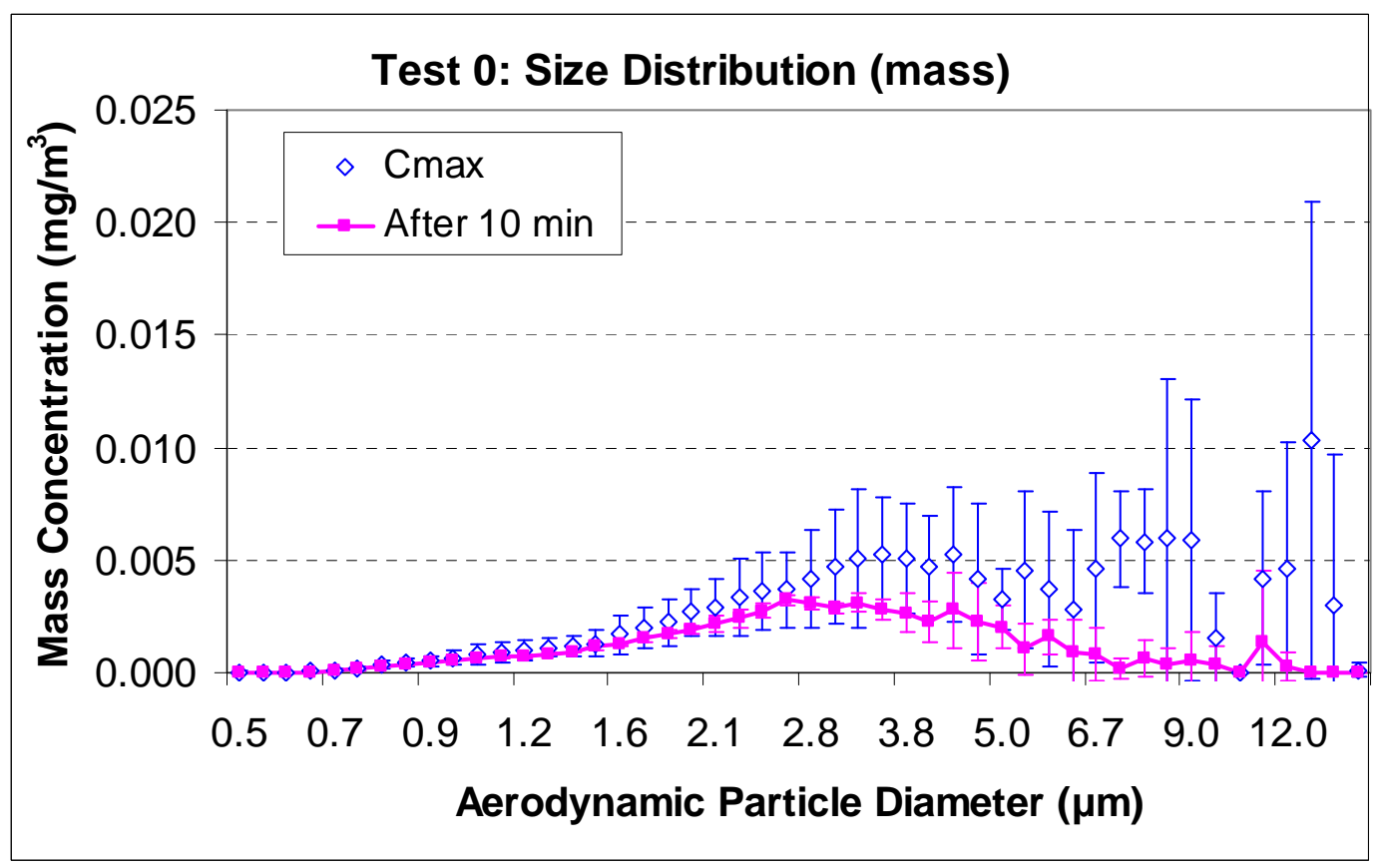

Figure A0-d. Particle mass concentration versus particle size (channel data) of Test 0 


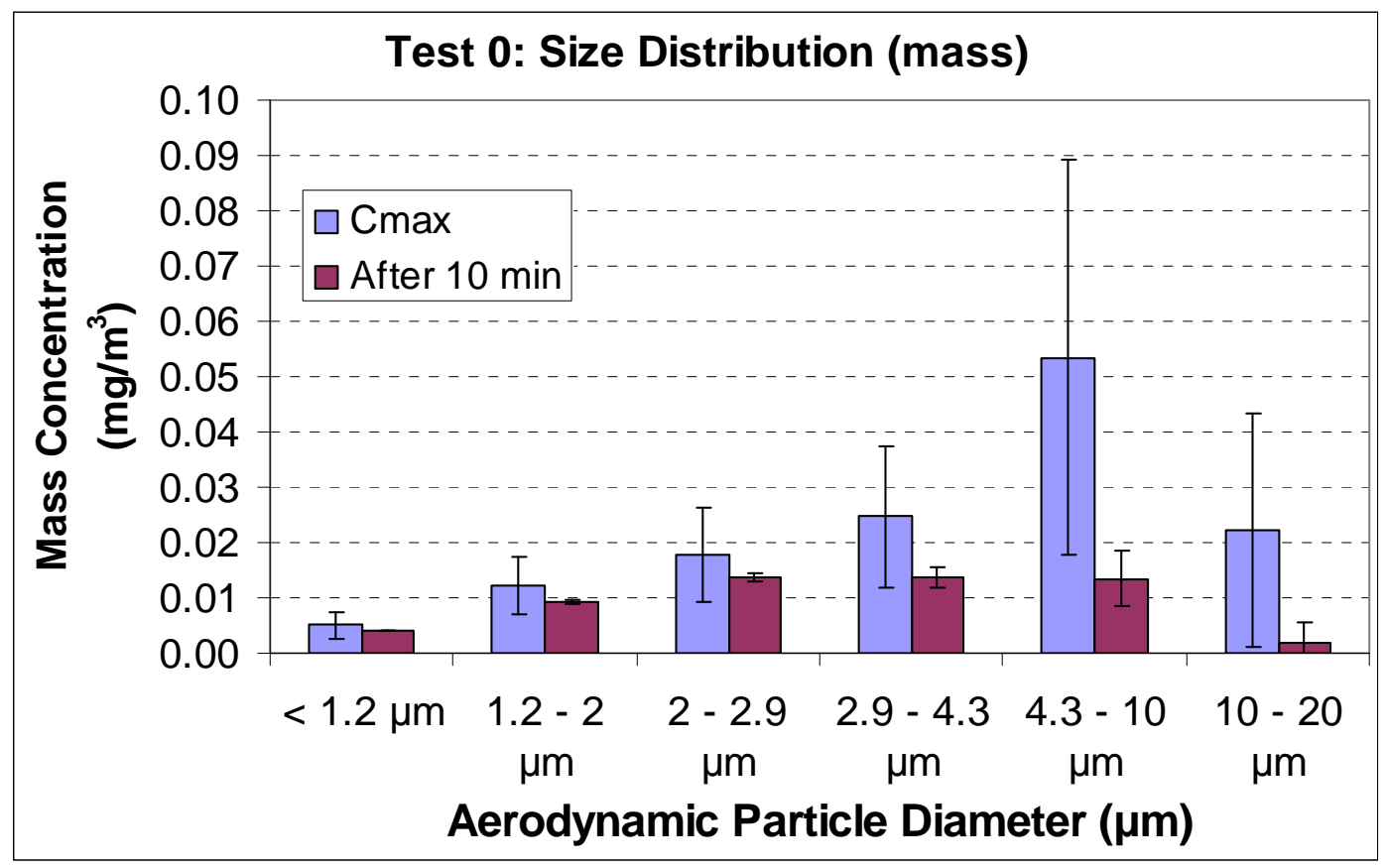

Figure A0-e. Particle mass concentration versus particle size of Test 0

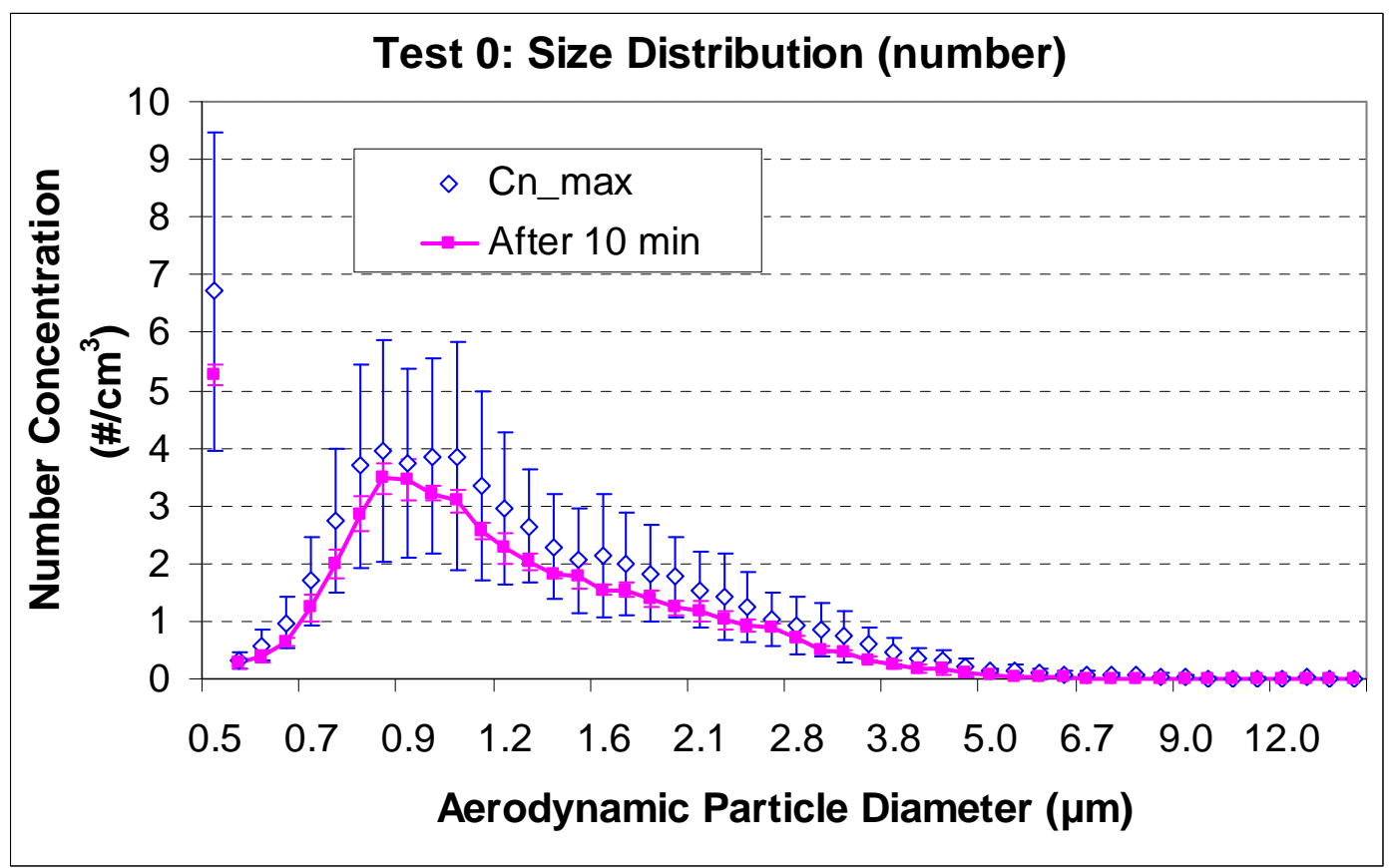

Figure A0-f. Particle number concentration versus particle size (channel data) of Test 0 


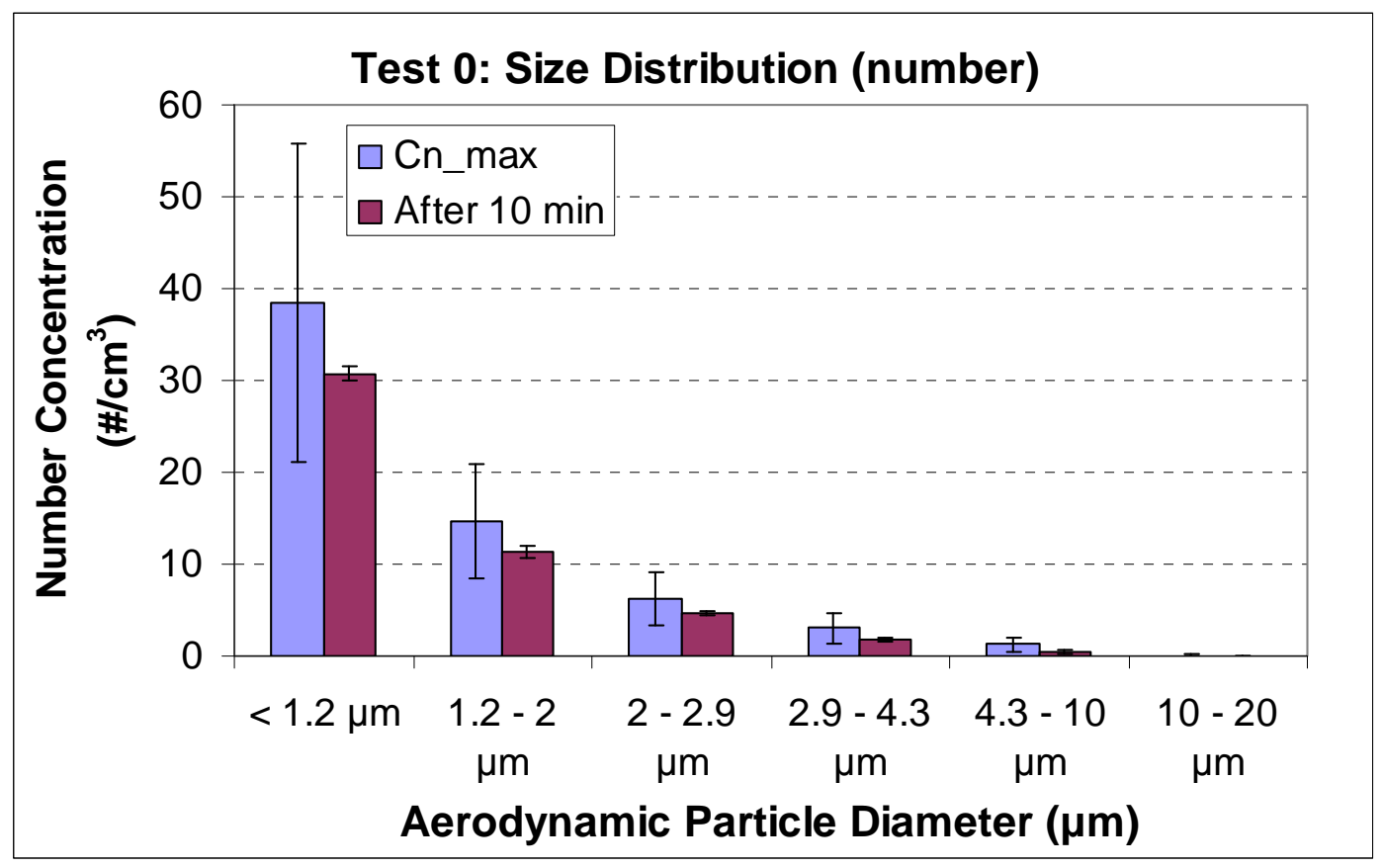

Figure A0-g. Particle number concentration versus particle size of Test 0

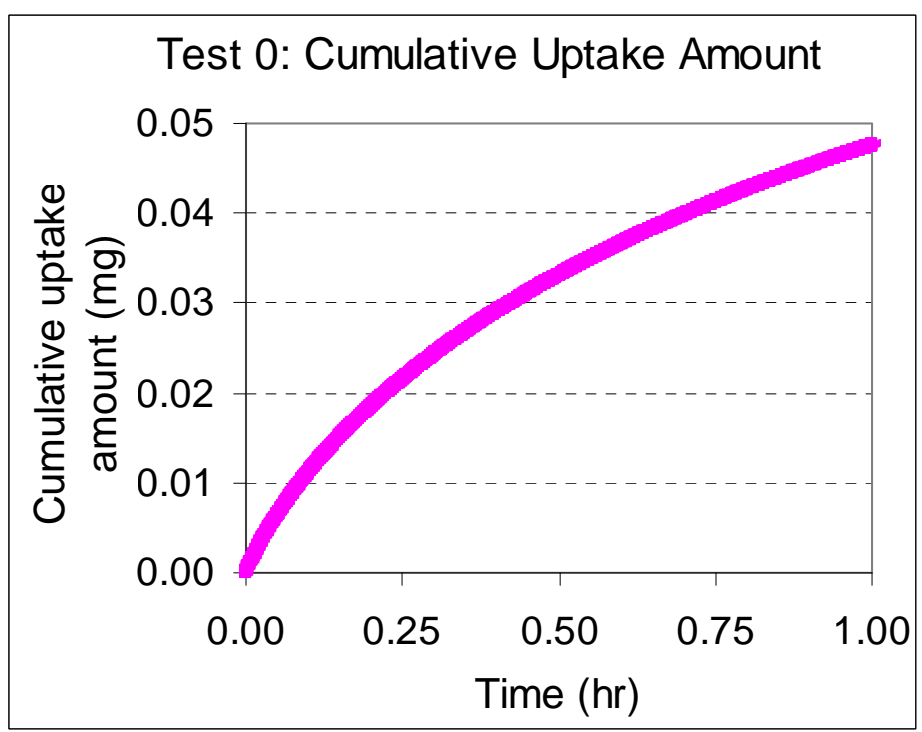

Figure A0-h. Cumulative uptake amount of particle mass of Test 0 
A3.1 Test 1

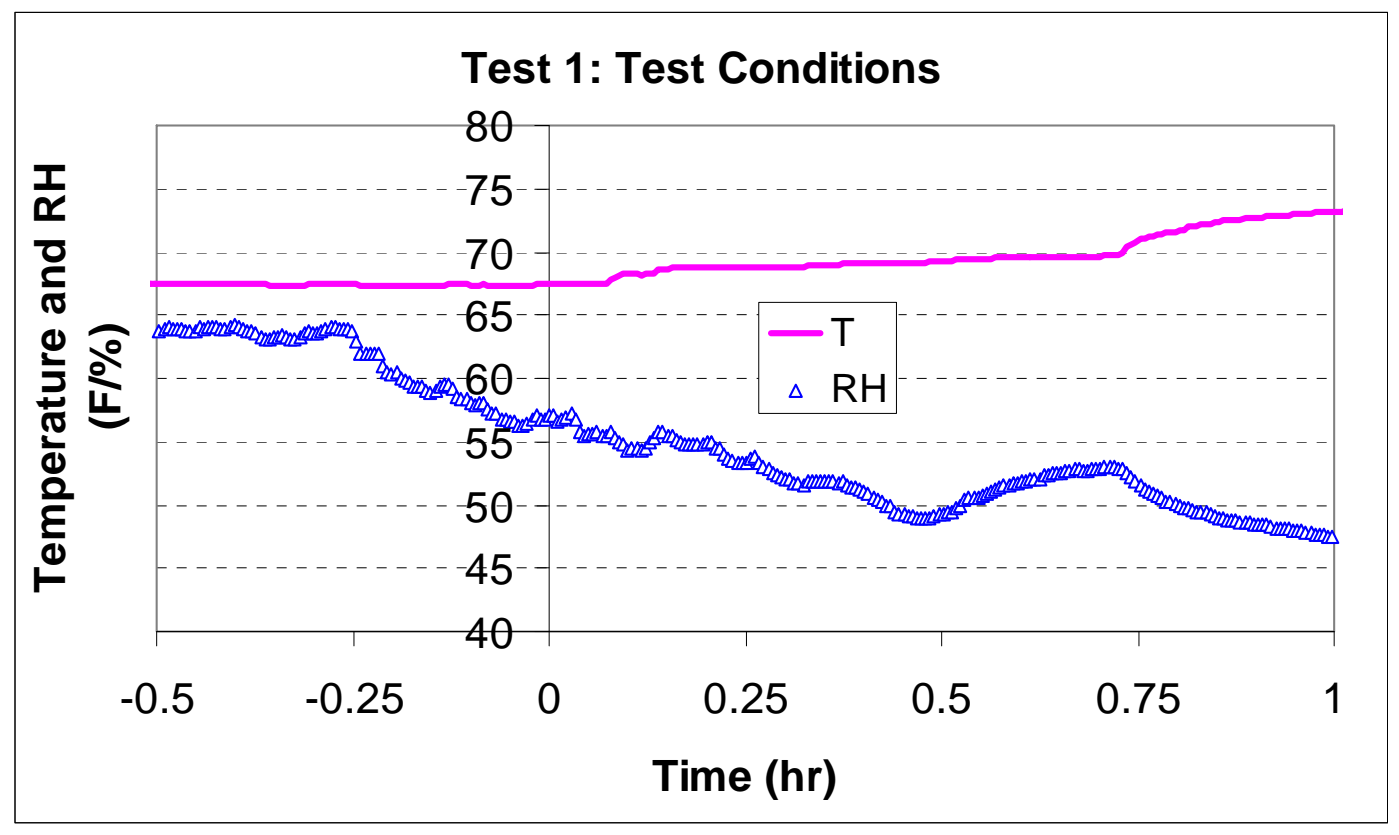

Figure A1-a. Chamber conditions during Test 1

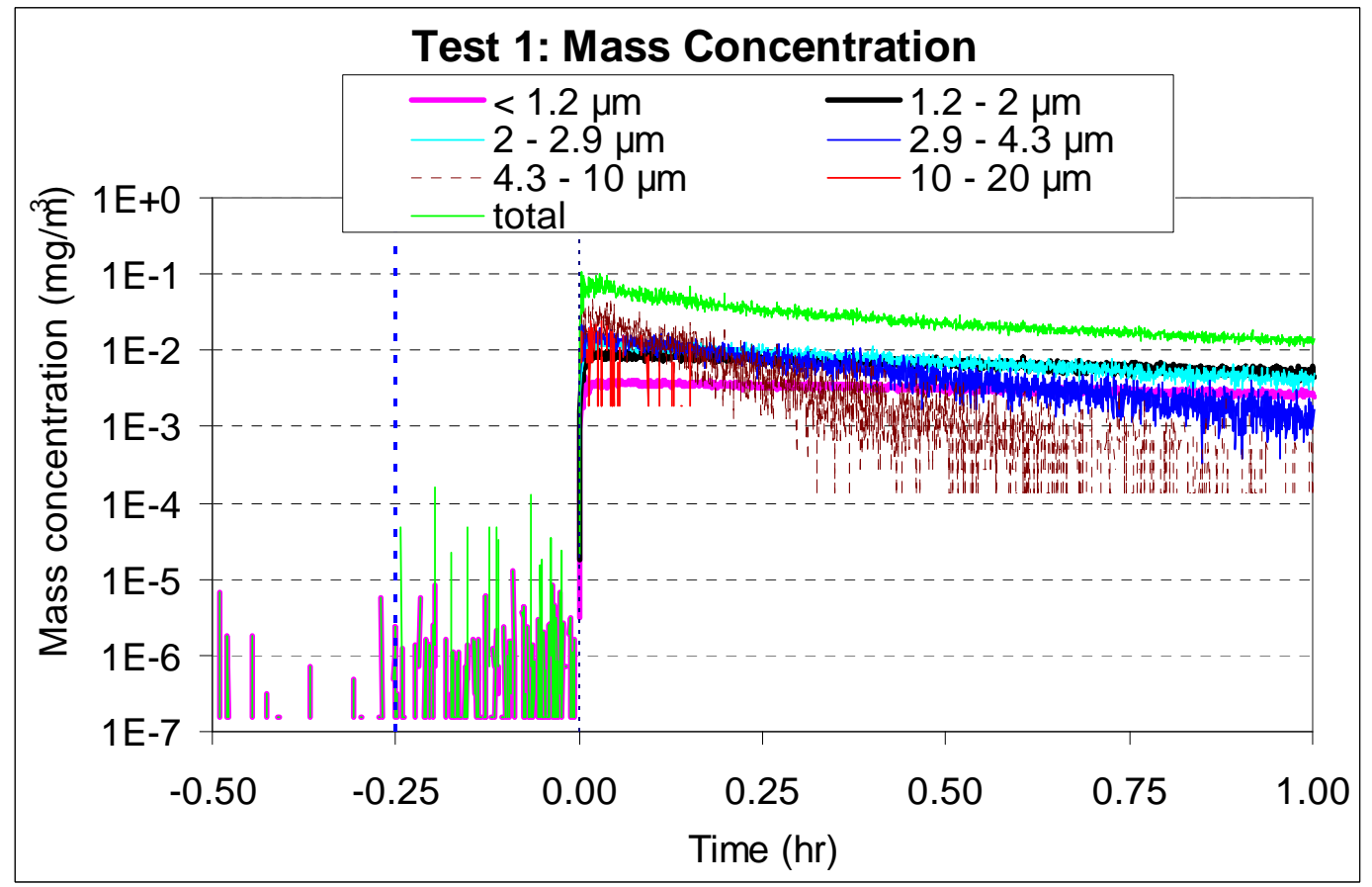

Figure A1-b. Particle mass concentration before and after the dropping of Test 1 


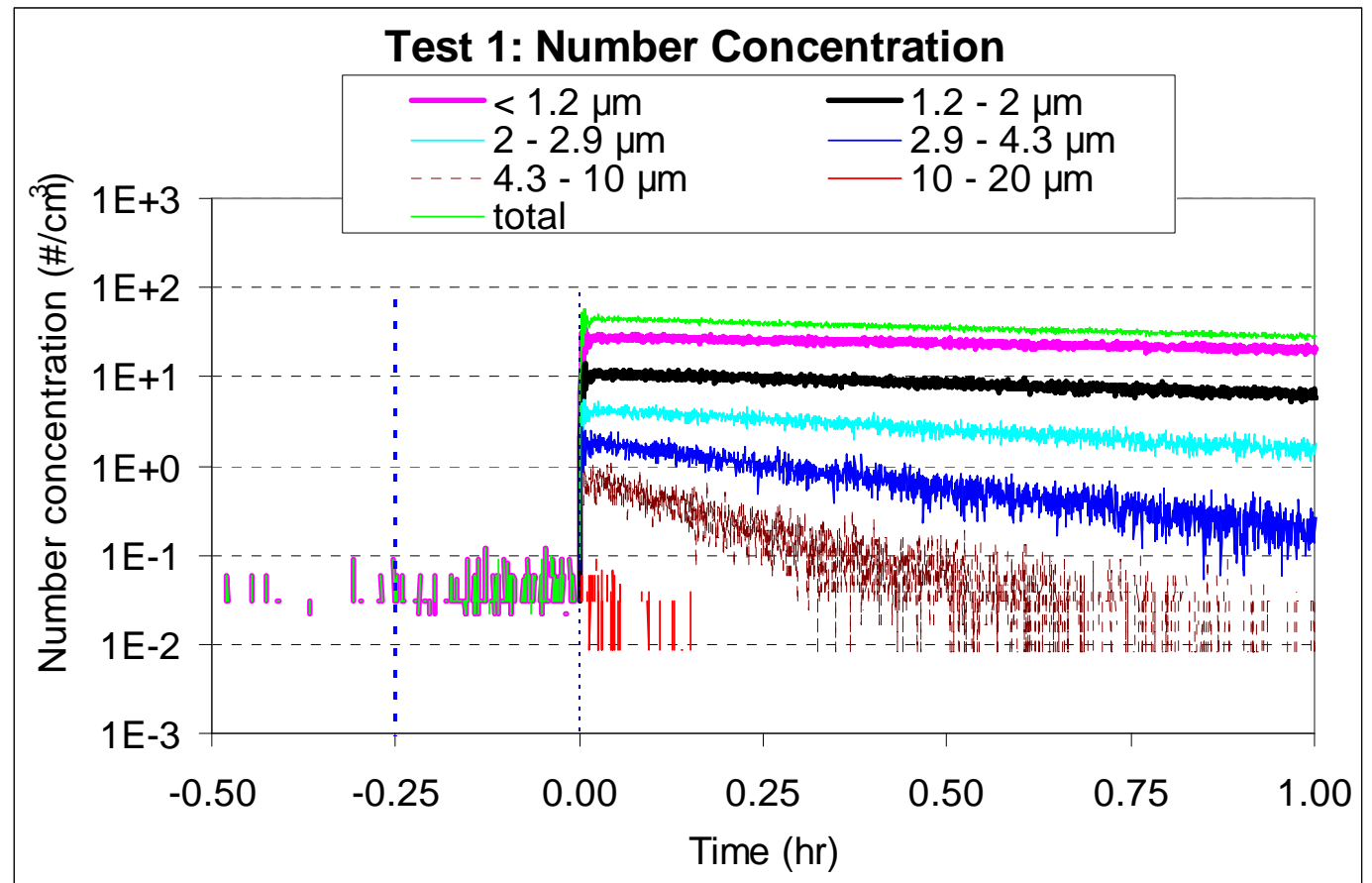

Figure A1-c. Particle number concentration before and after the dropping of Test 1

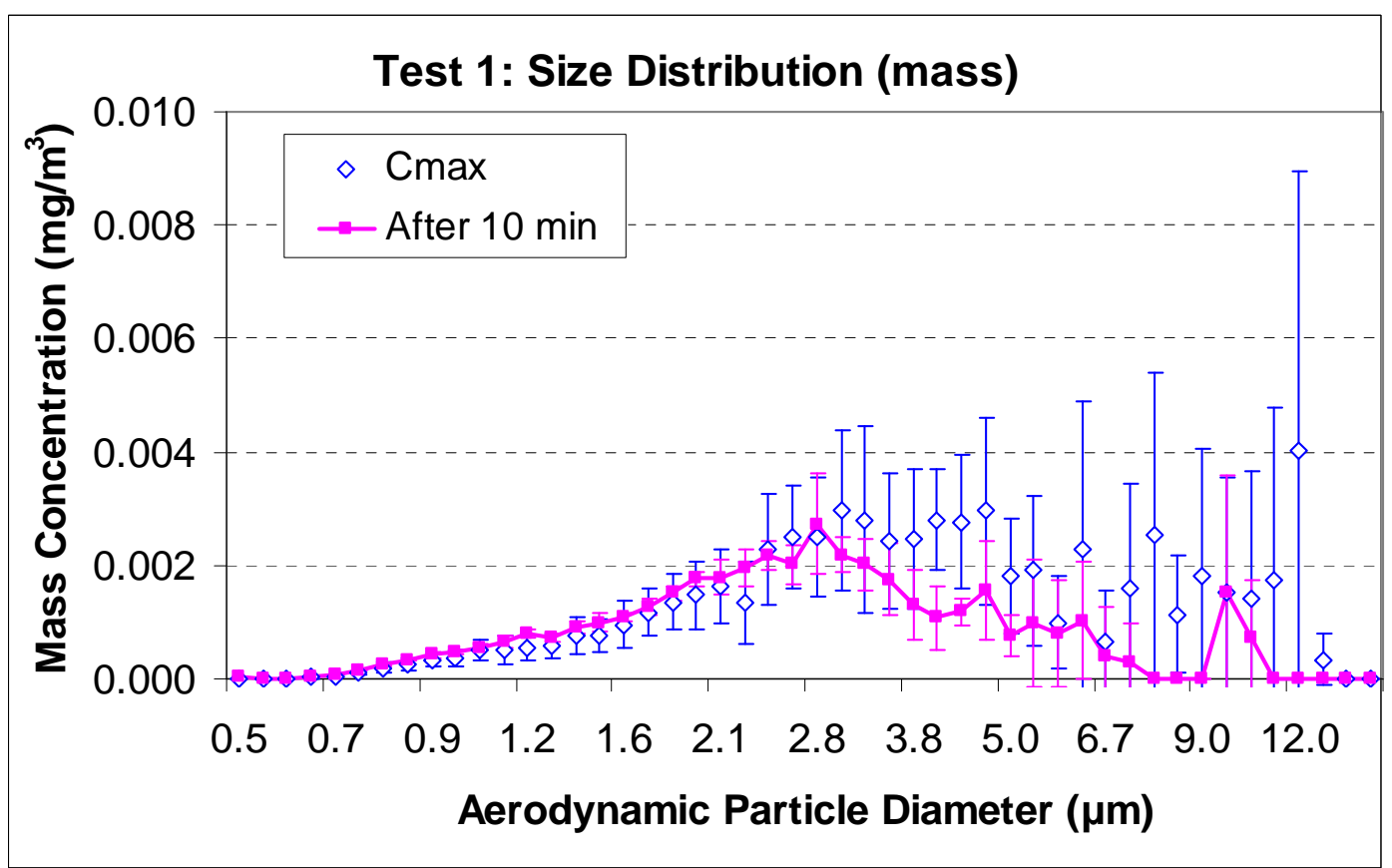

Figure A1-d. Particle mass concentration versus particle size (channel data) of Test 1 


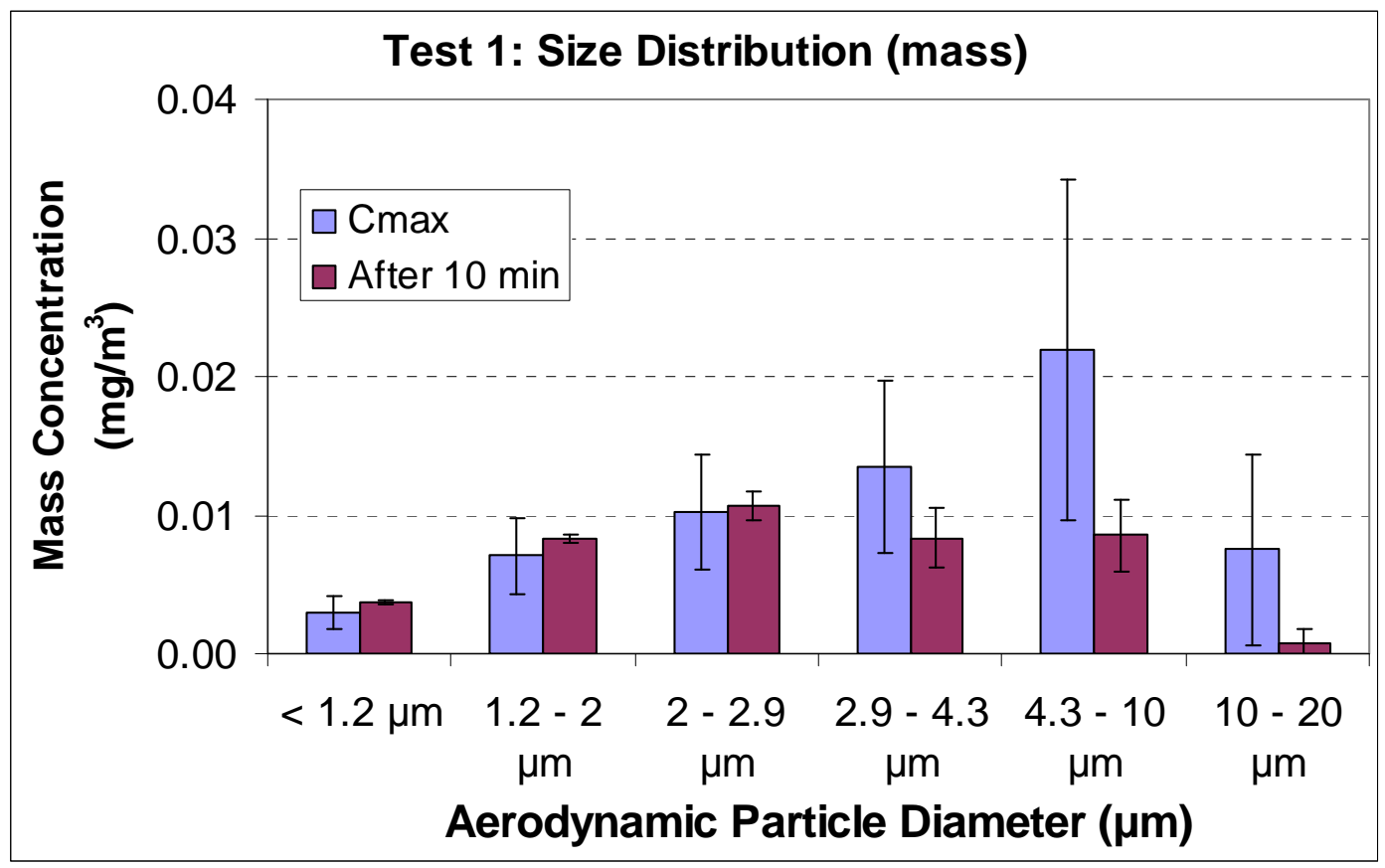

Figure A1-e. Particle mass concentration versus particle size of Test 1

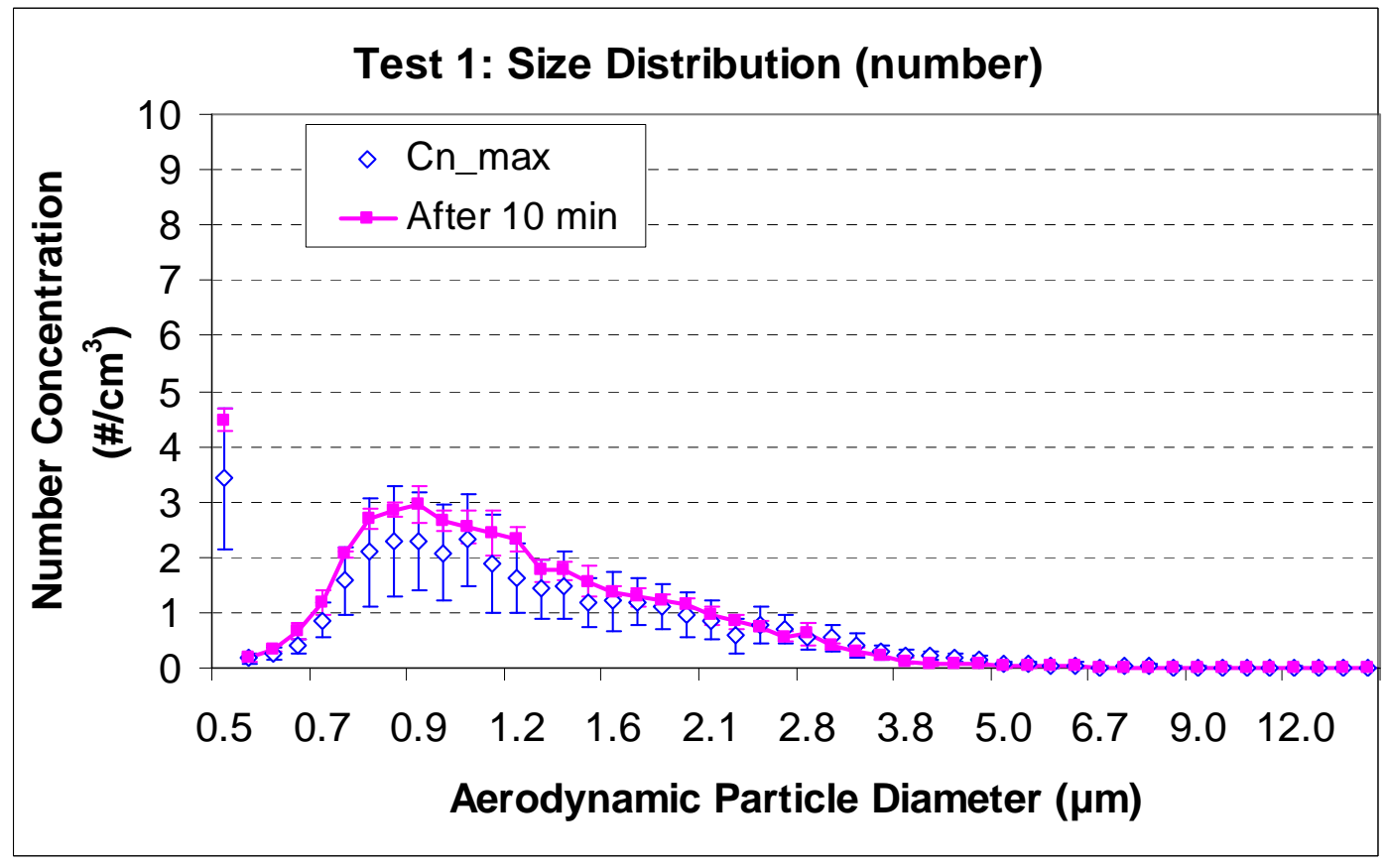

Figure A1-f. Particle number concentration versus particle size (channel data) of Test 1 


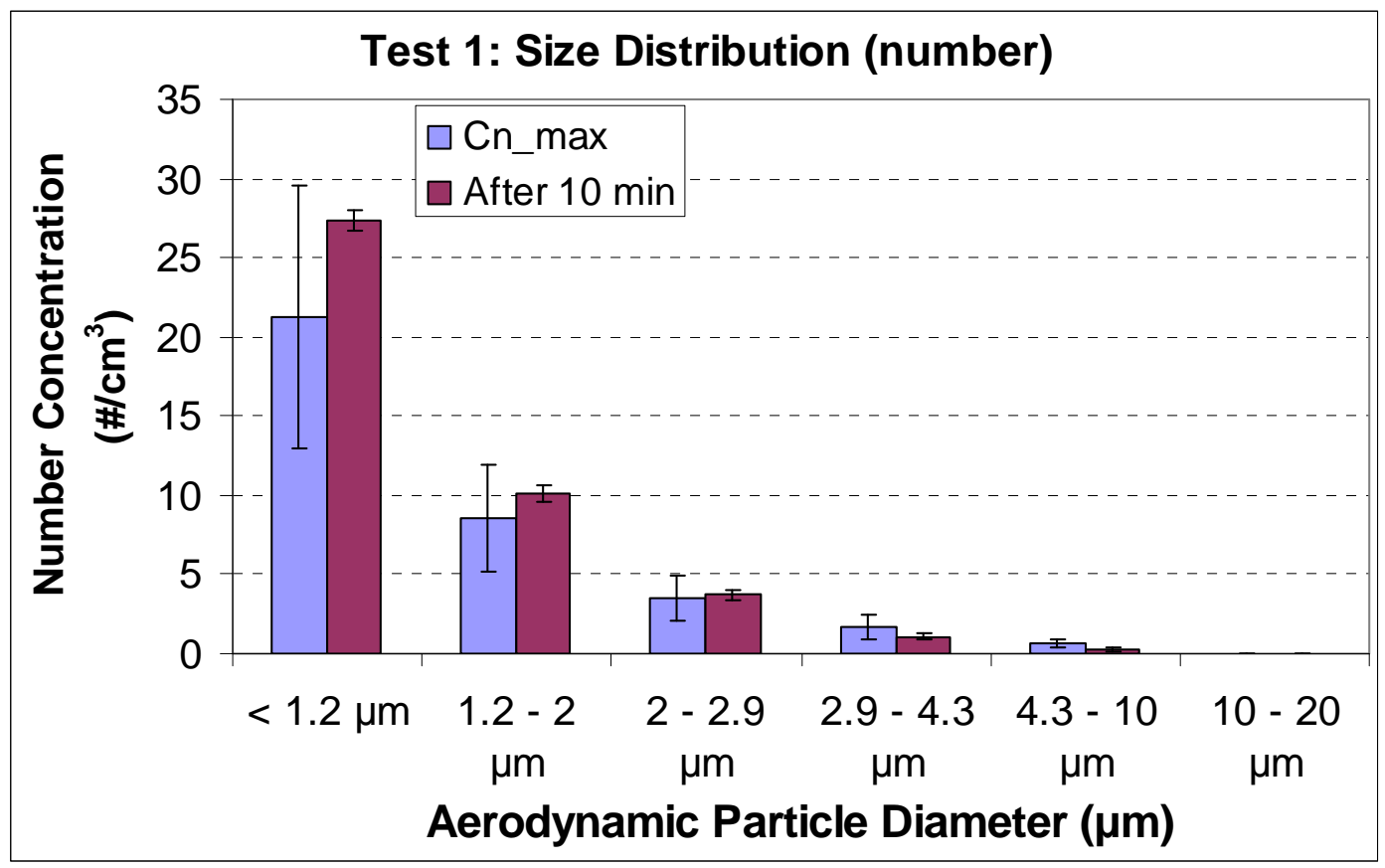

Figure A1-g. Particle number concentration versus particle size of Test 1

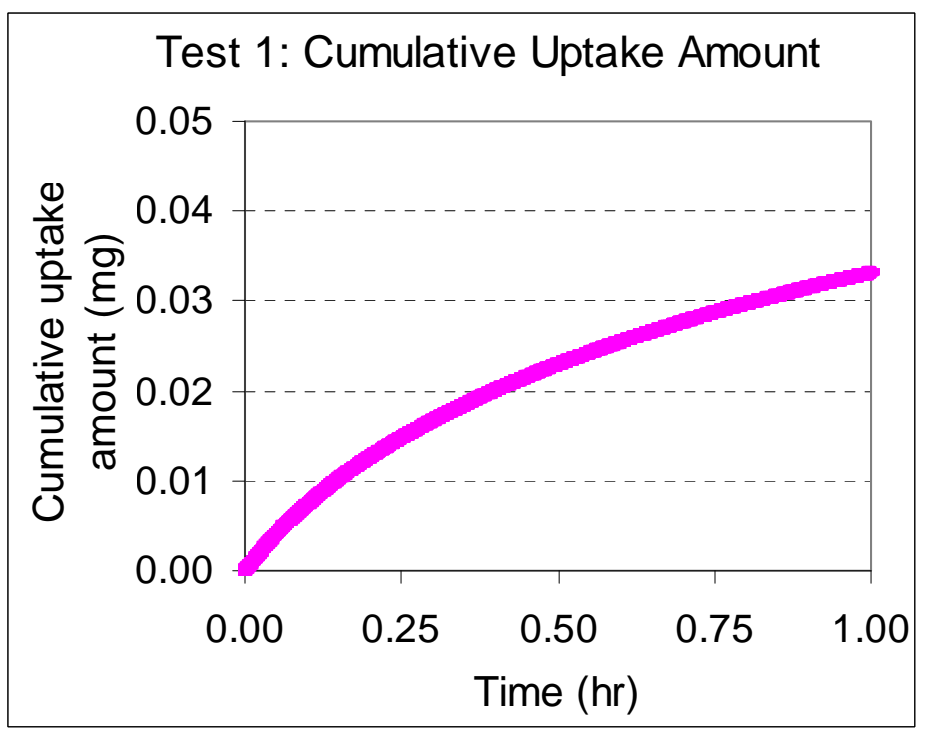

Figure A1-h. Cumulative uptake amount of particle mass of Test 1 
A3.2 Test 2

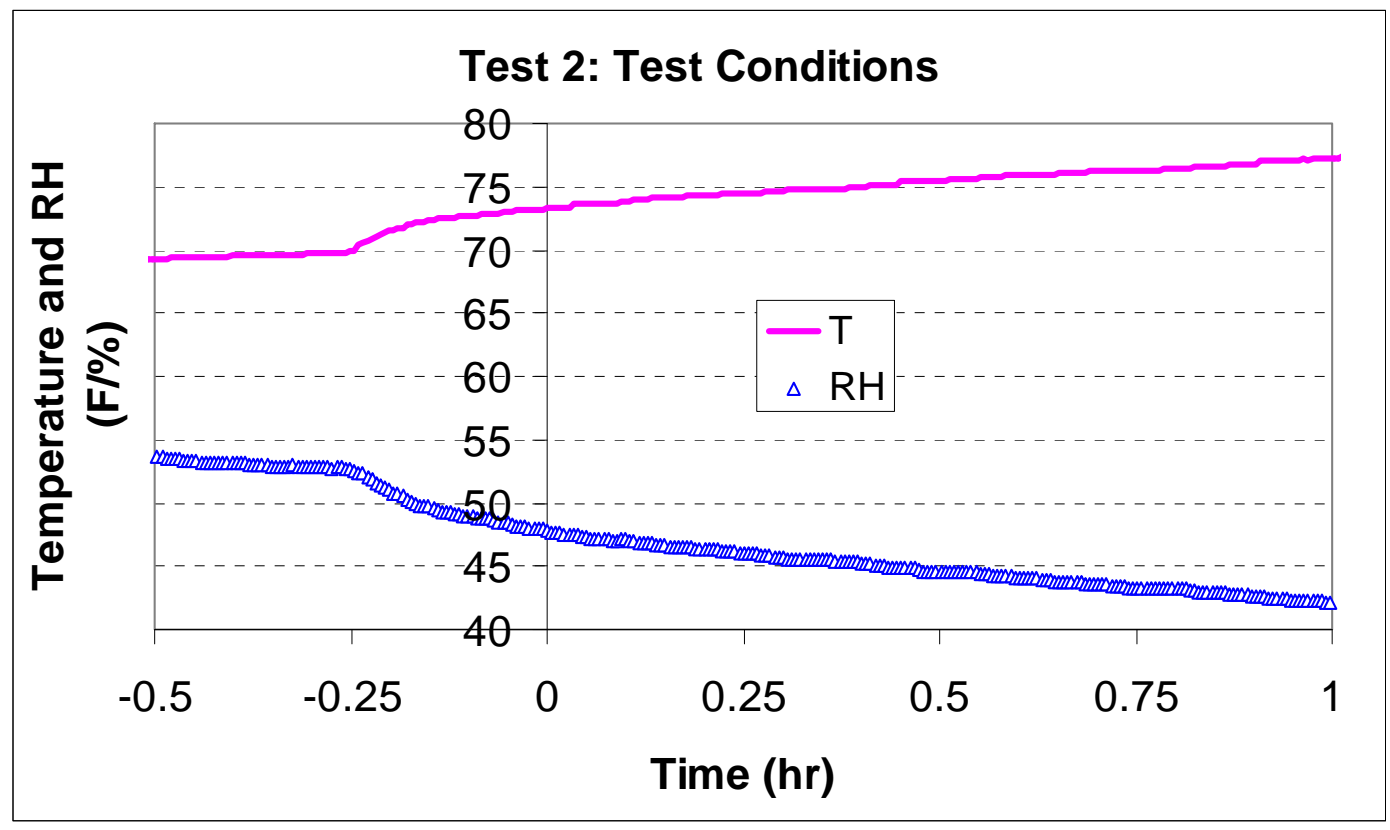

Figure A2-a. Chamber conditions during Test 2

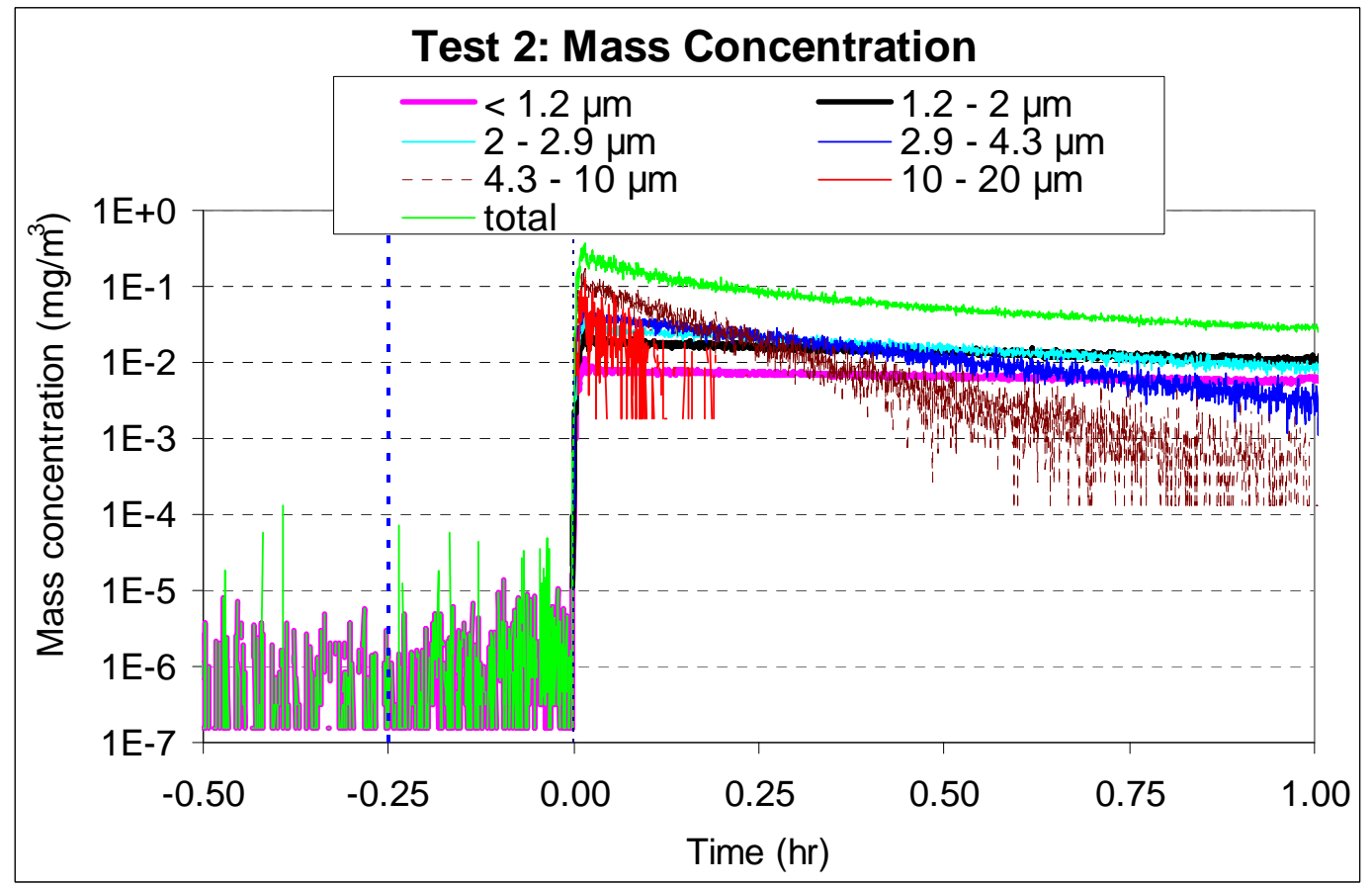

Figure A2-b. Particle mass concentration before and after the dropping of Test 2 


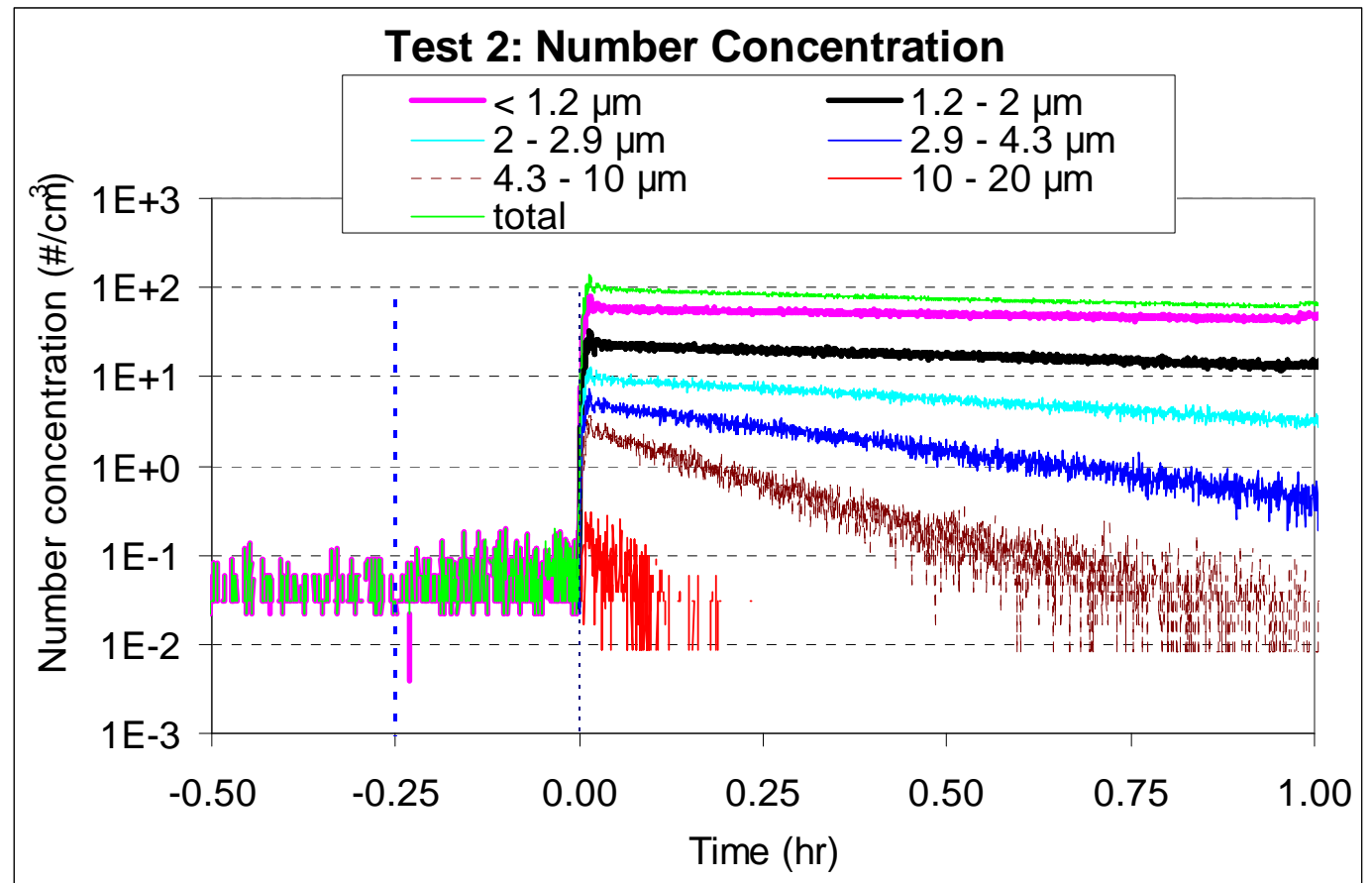

Figure A2-c. Particle number concentration before and after the dropping of Test 2

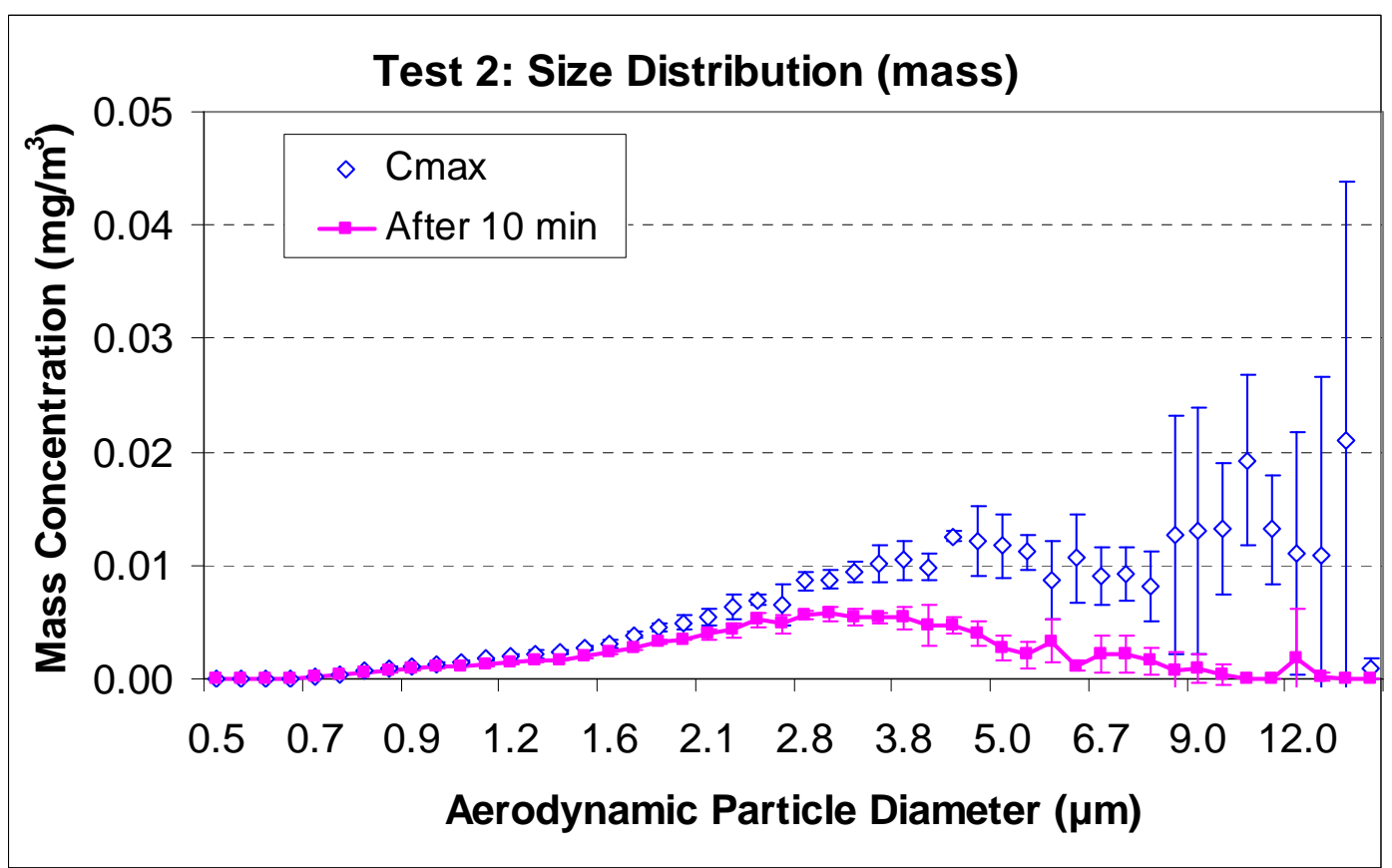

Figure A2-d. Particle mass concentration versus particle size (channel data) of Test 2 


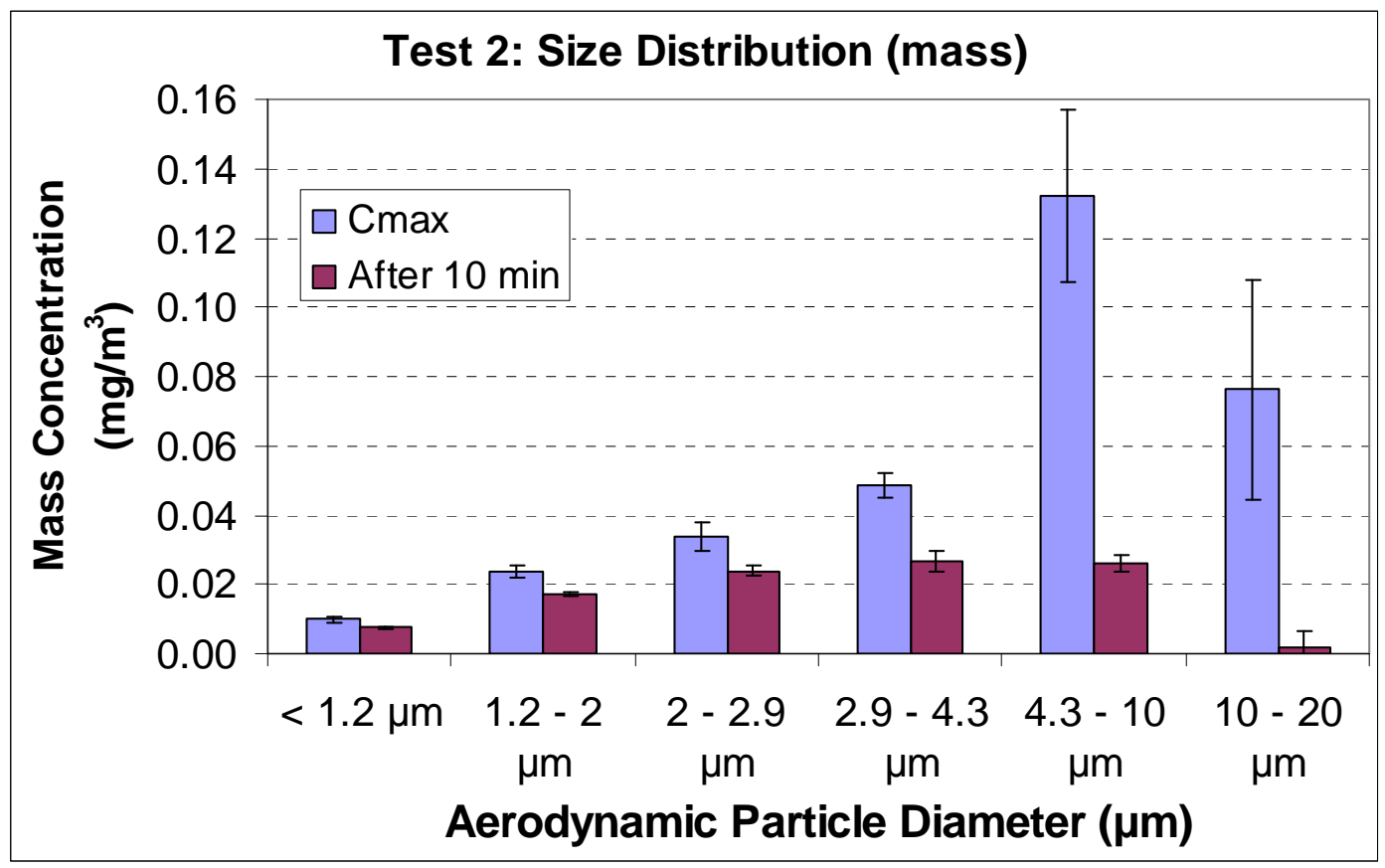

Figure A2-e. Particle mass concentration versus particle size of Test 2

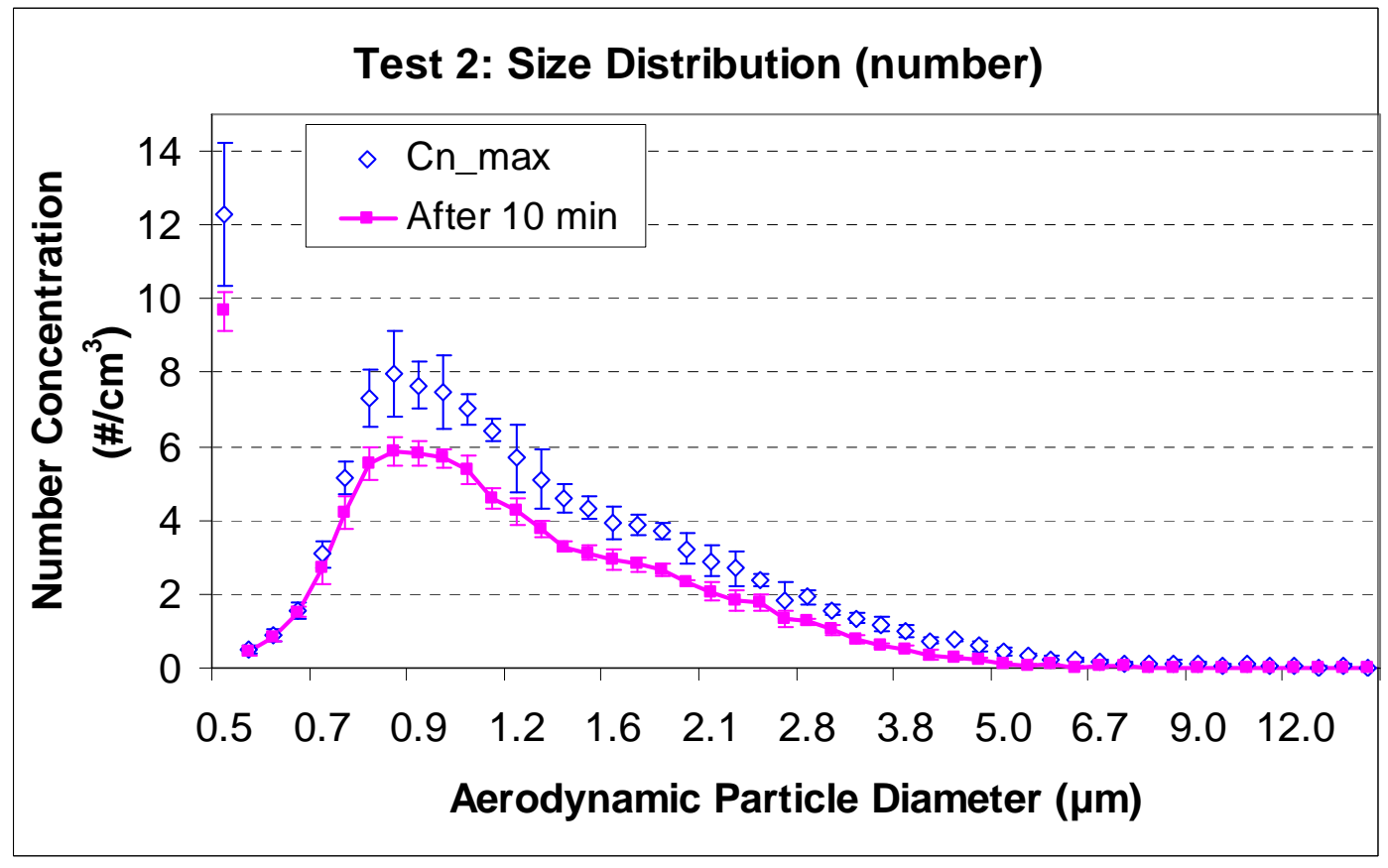

Figure A2-f. Particle number concentration versus particle size (channel data) of Test 2 


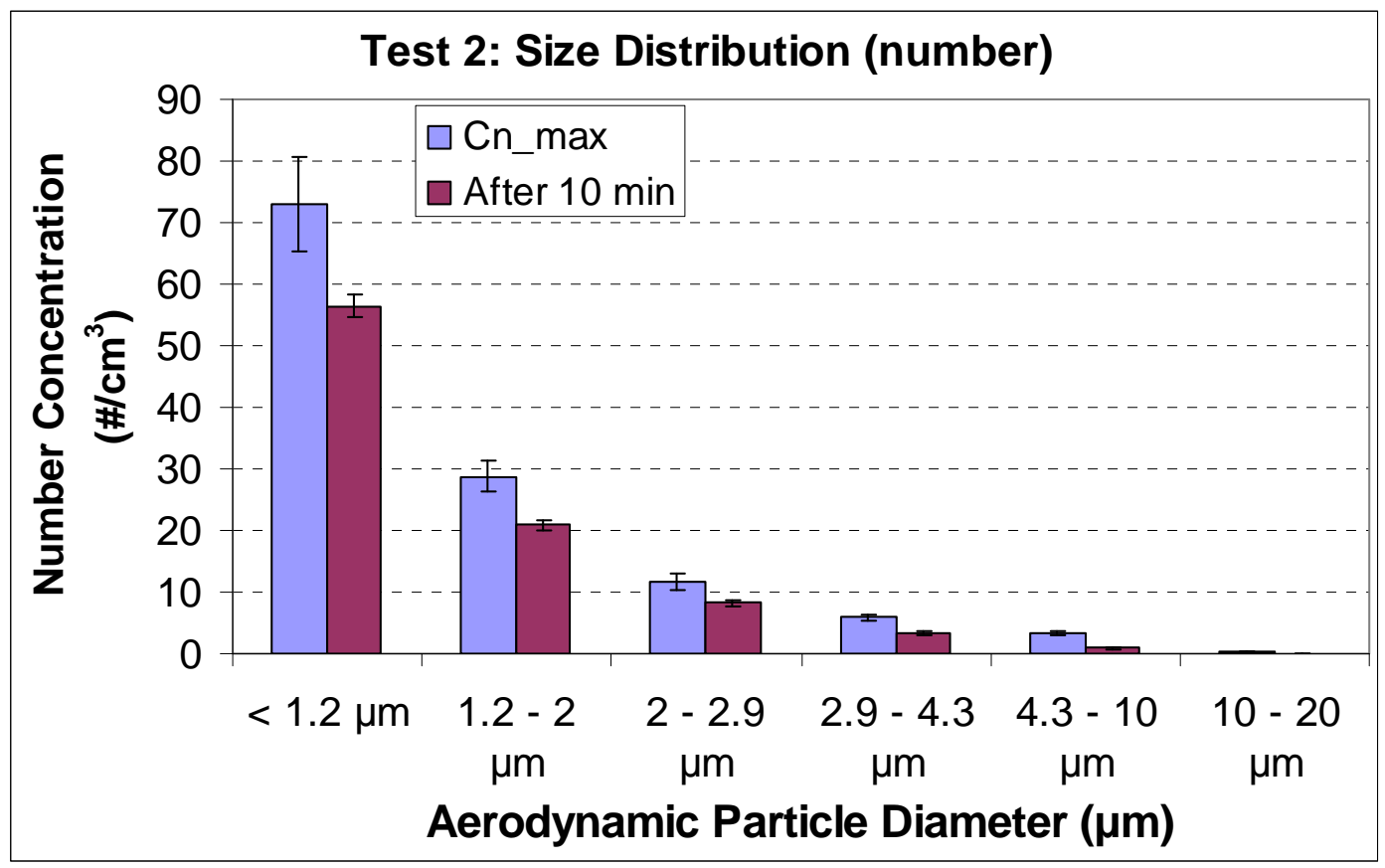

Figure A2-g. Particle number concentration versus particle size of Test 2

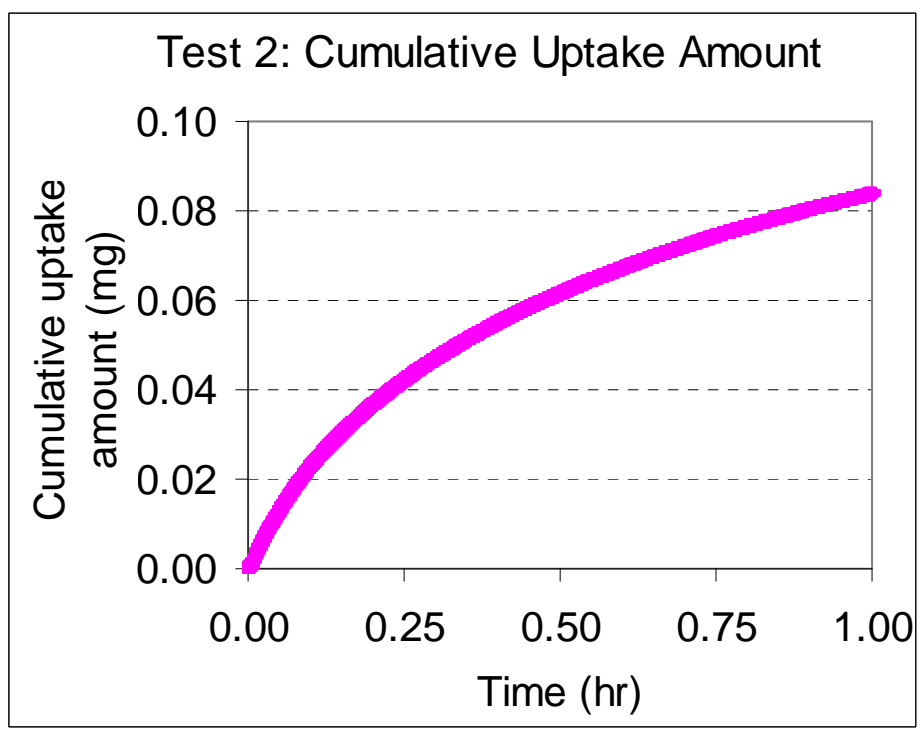

Figure A2-h. Cumulative uptake amount of particle mass of Test 2 


\section{A3.3 Test 3}

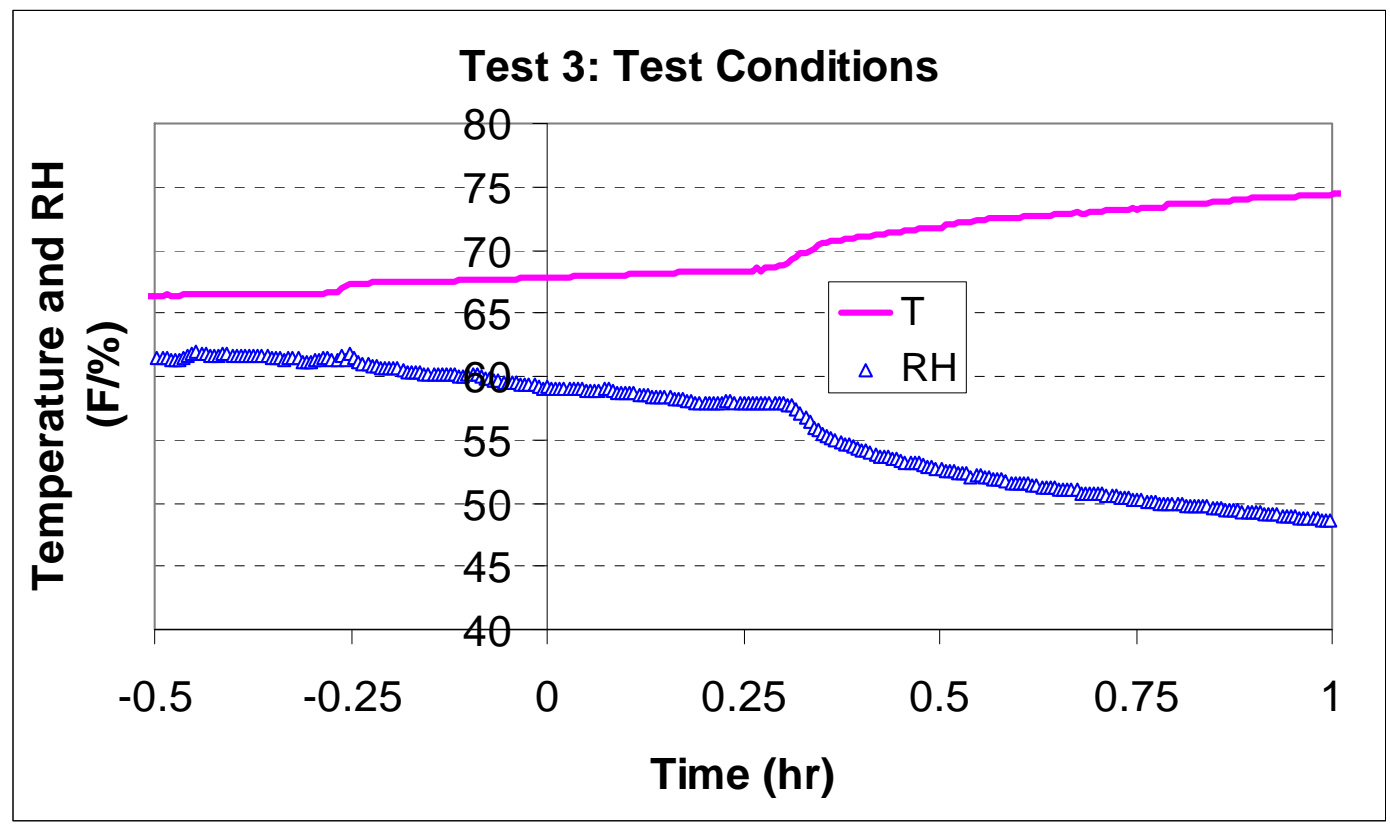

Figure A3-a. Chamber conditions during Test 3

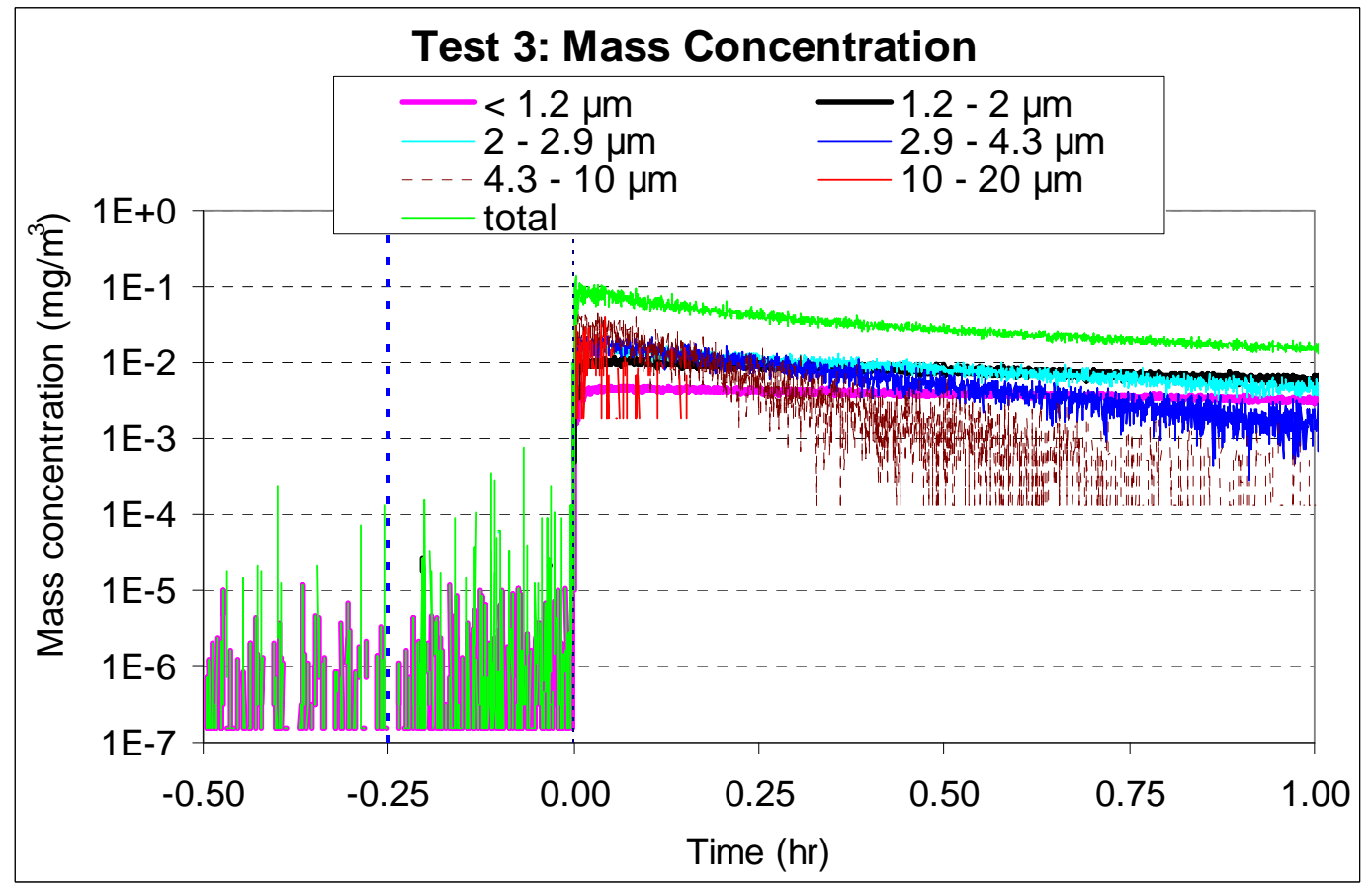

Figure A3-b. Particle mass concentration before and after the dropping of Test 3 


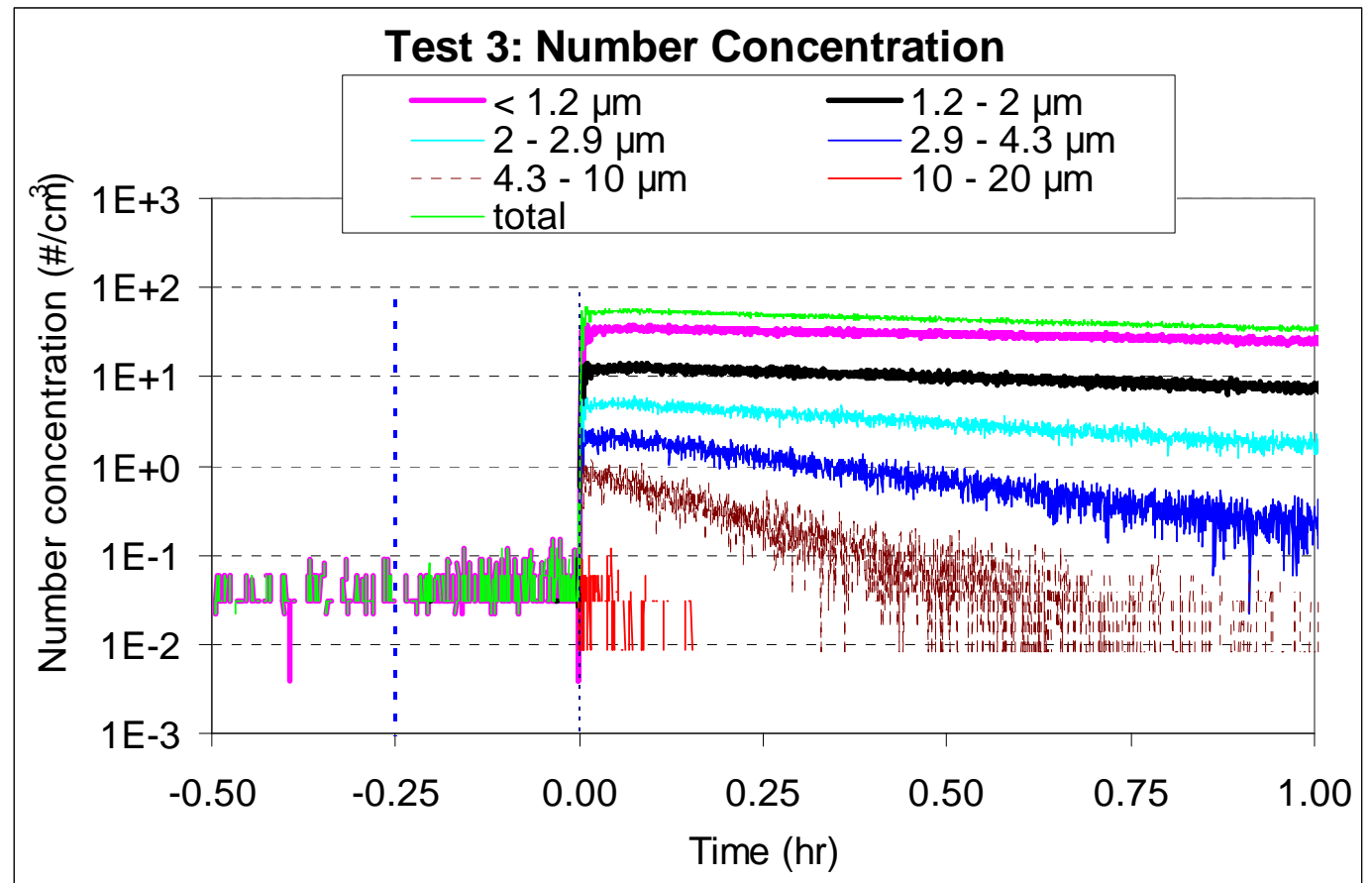

Figure A3-c. Particle number concentration before and after the dropping of Test 3

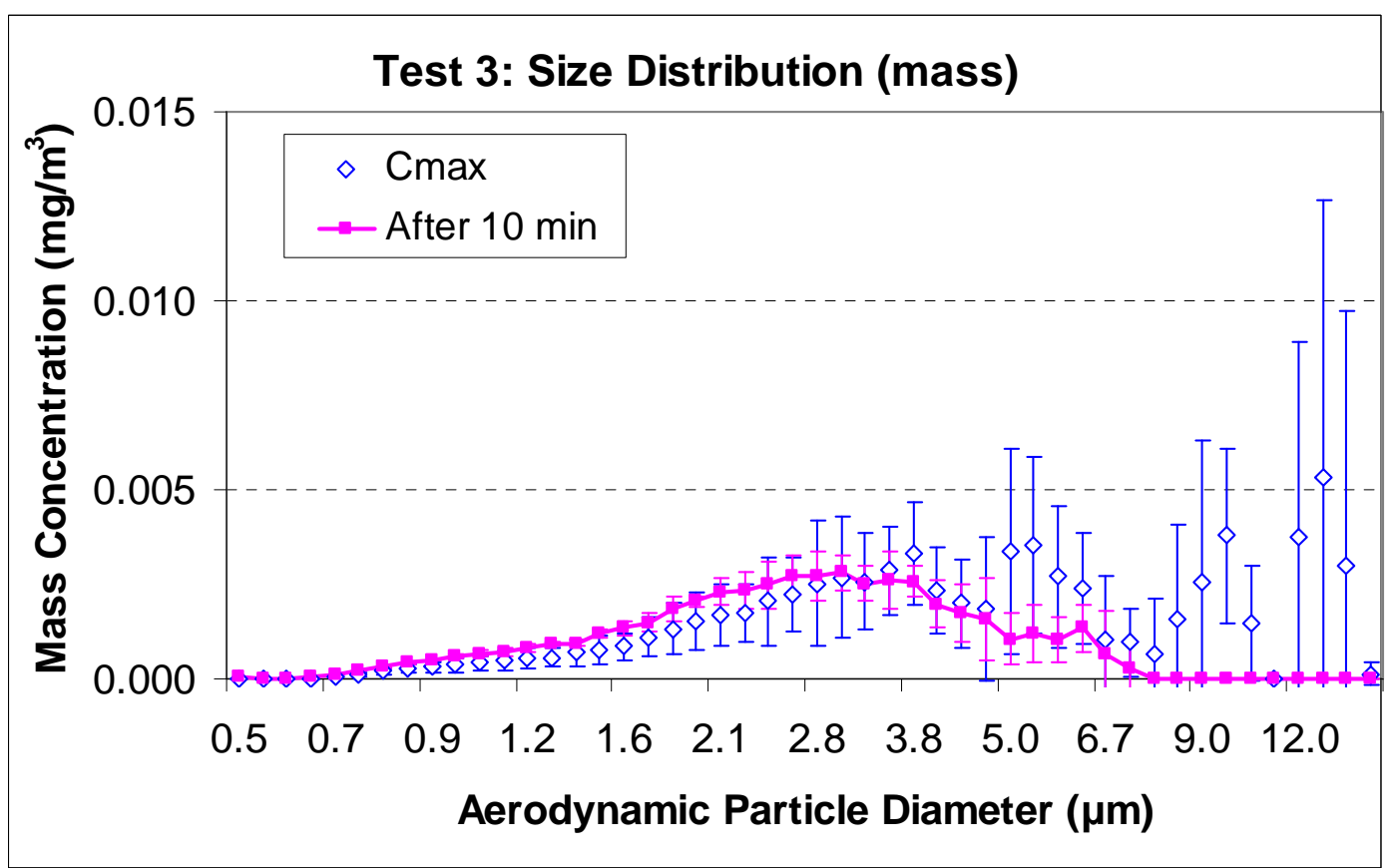

Figure A3-d. Particle mass concentration versus particle size (channel data) of Test 3 


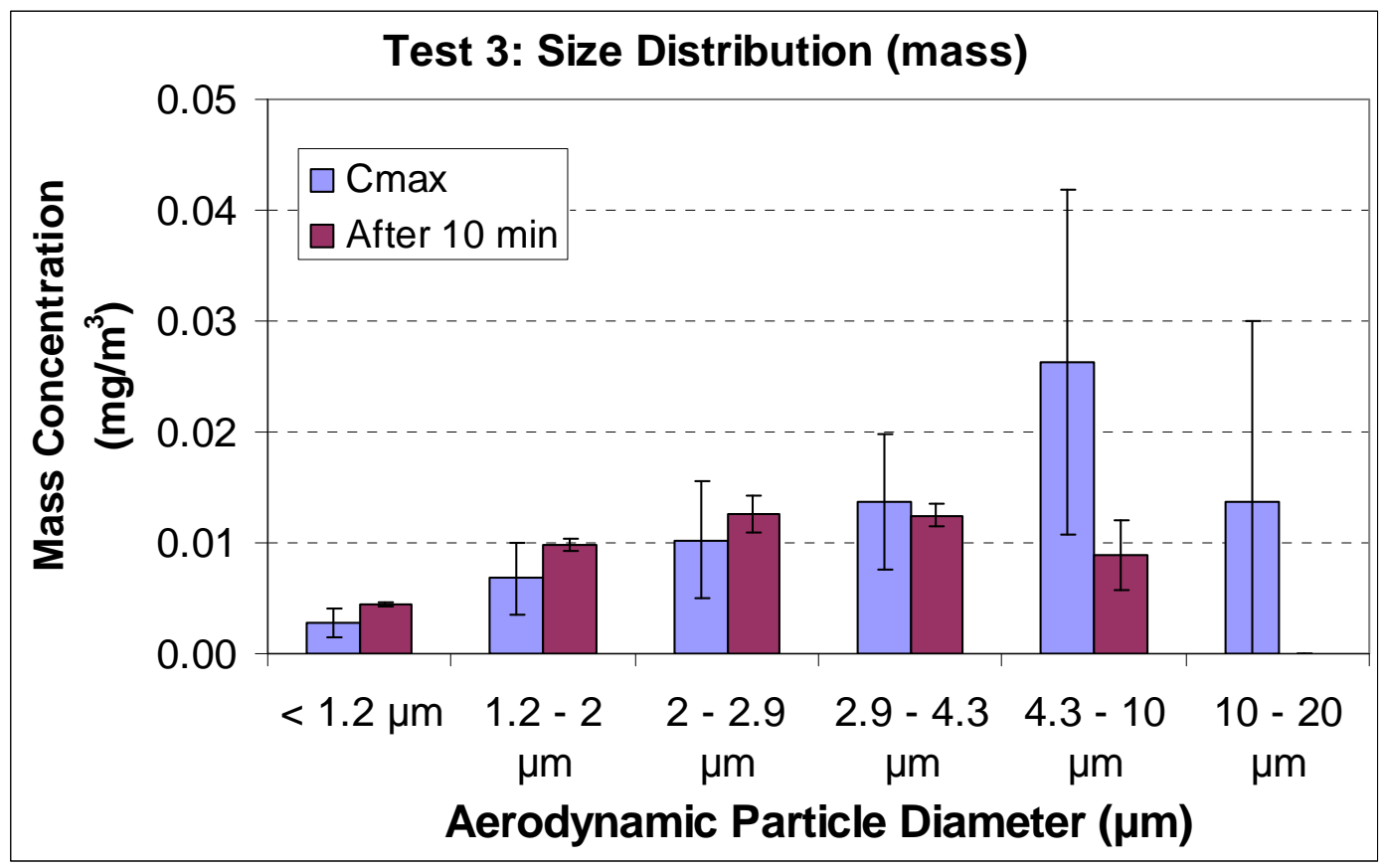

Figure A3-e. Particle mass concentration versus particle size of Test 3

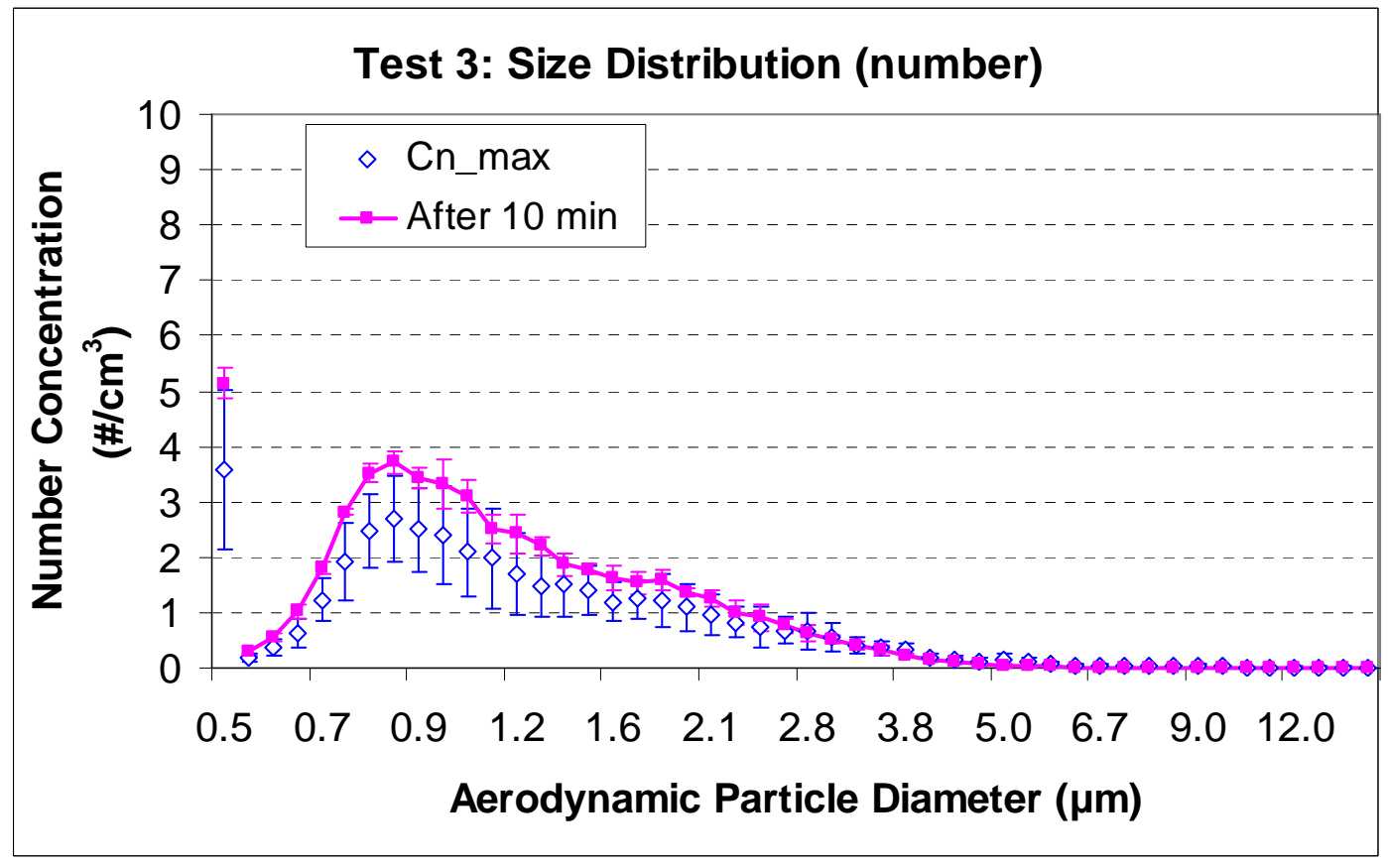

Figure A3-f. Particle number concentration versus particle size (channel data) of Test 3 


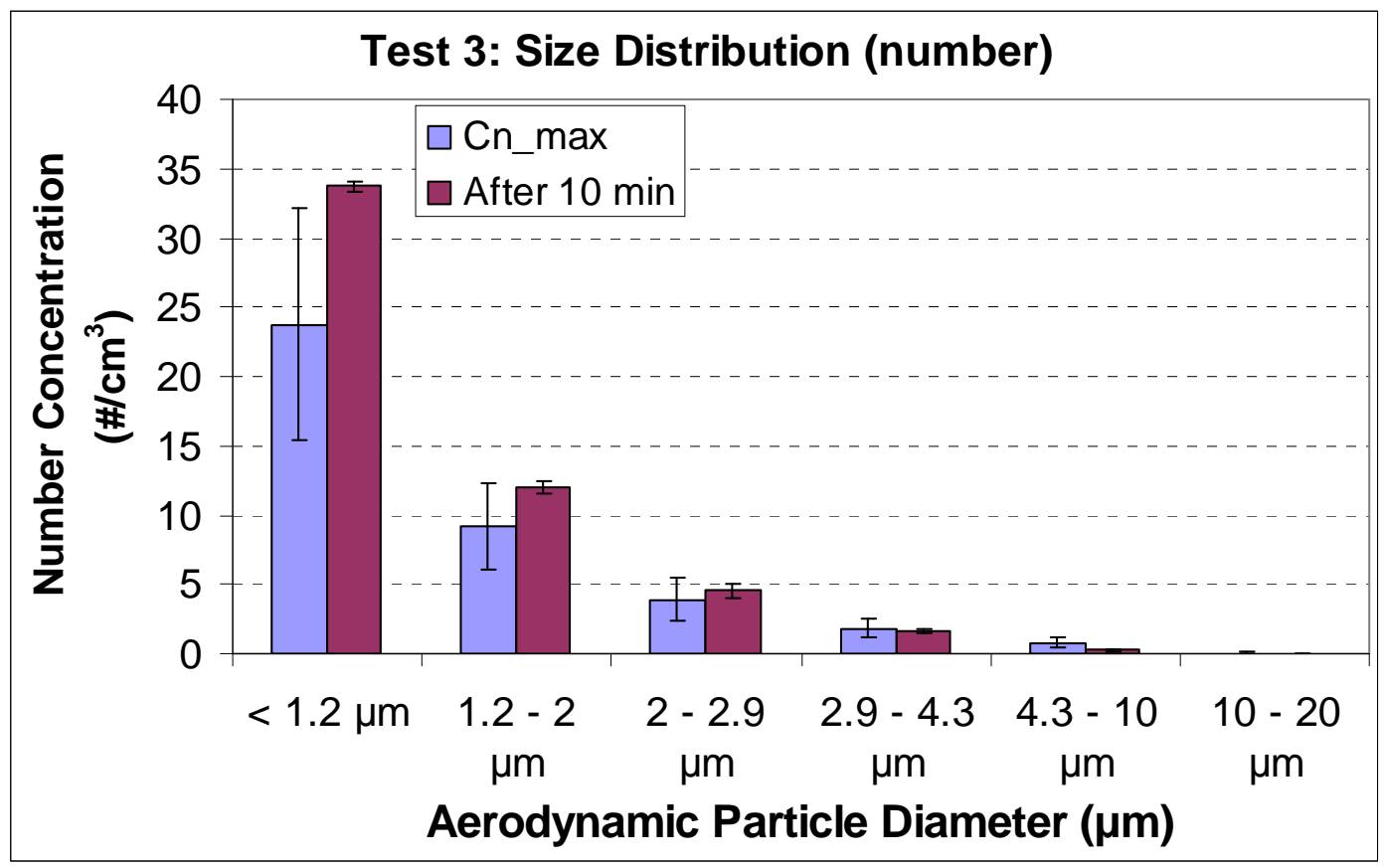

Figure A3-g. Particle number concentration versus particle size of Test 3

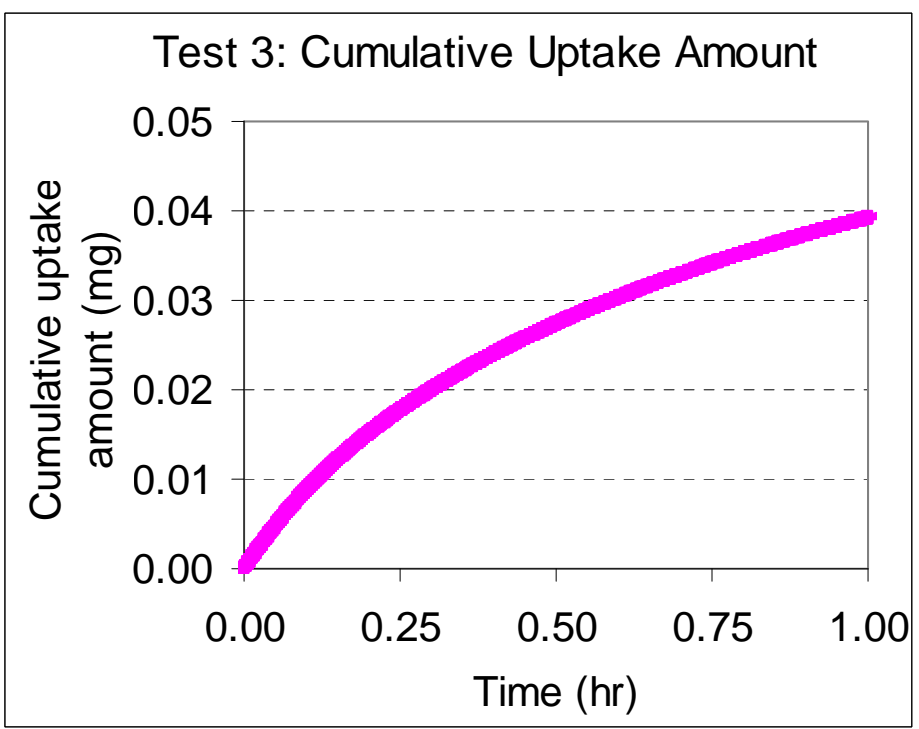

Figure A3-h. Cumulative uptake amount of particle mass of Test 3 
A3.4 Test 4

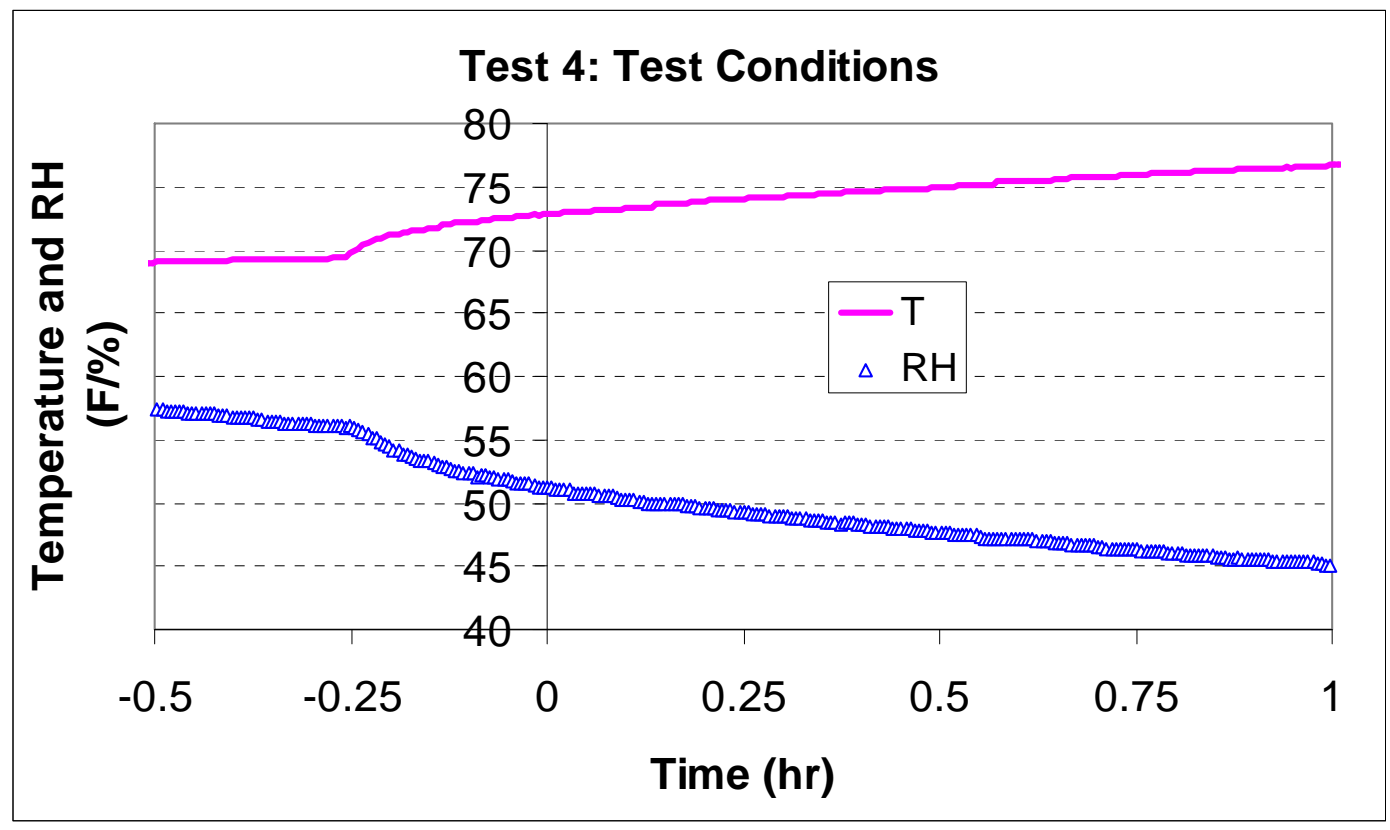

Figure A4-a. Chamber conditions during Test 4

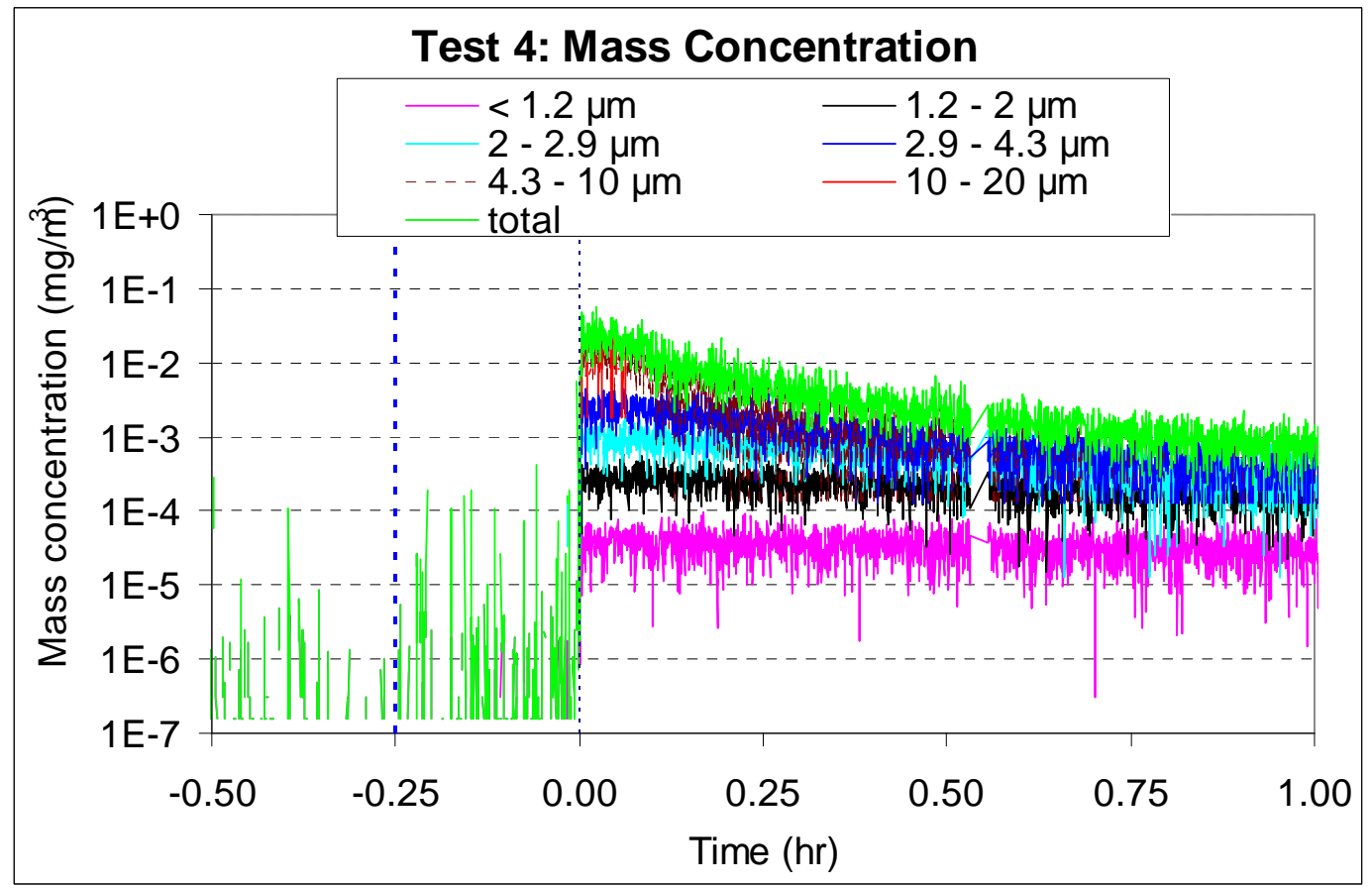

Figure A4-b. Particle mass concentration before and after the dropping of Test 4 


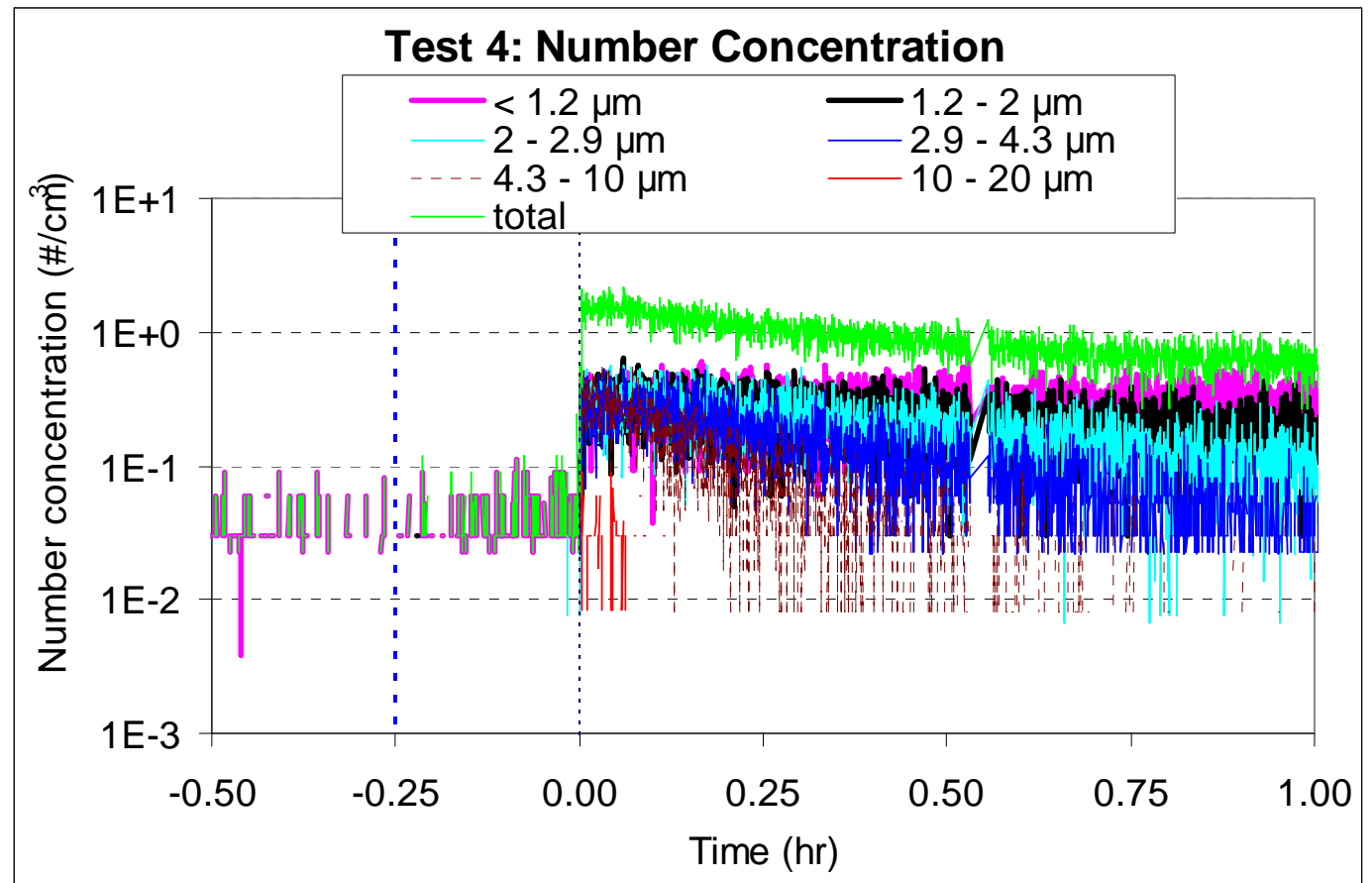

Figure A4-c. Particle number concentration before and after the dropping of Test 4

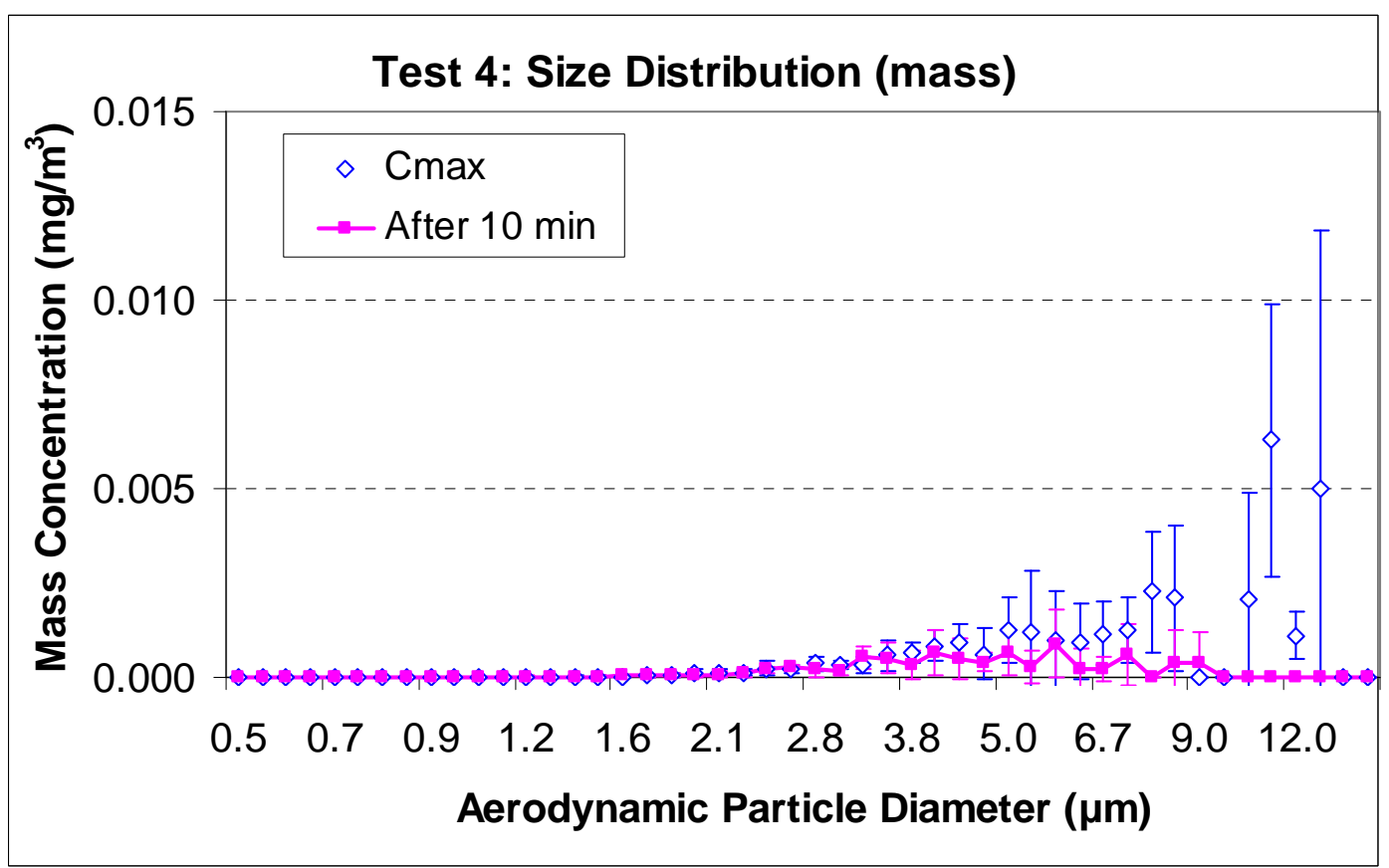

Figure A4-d. Particle mass concentration versus particle size (channel data) of Test 4 


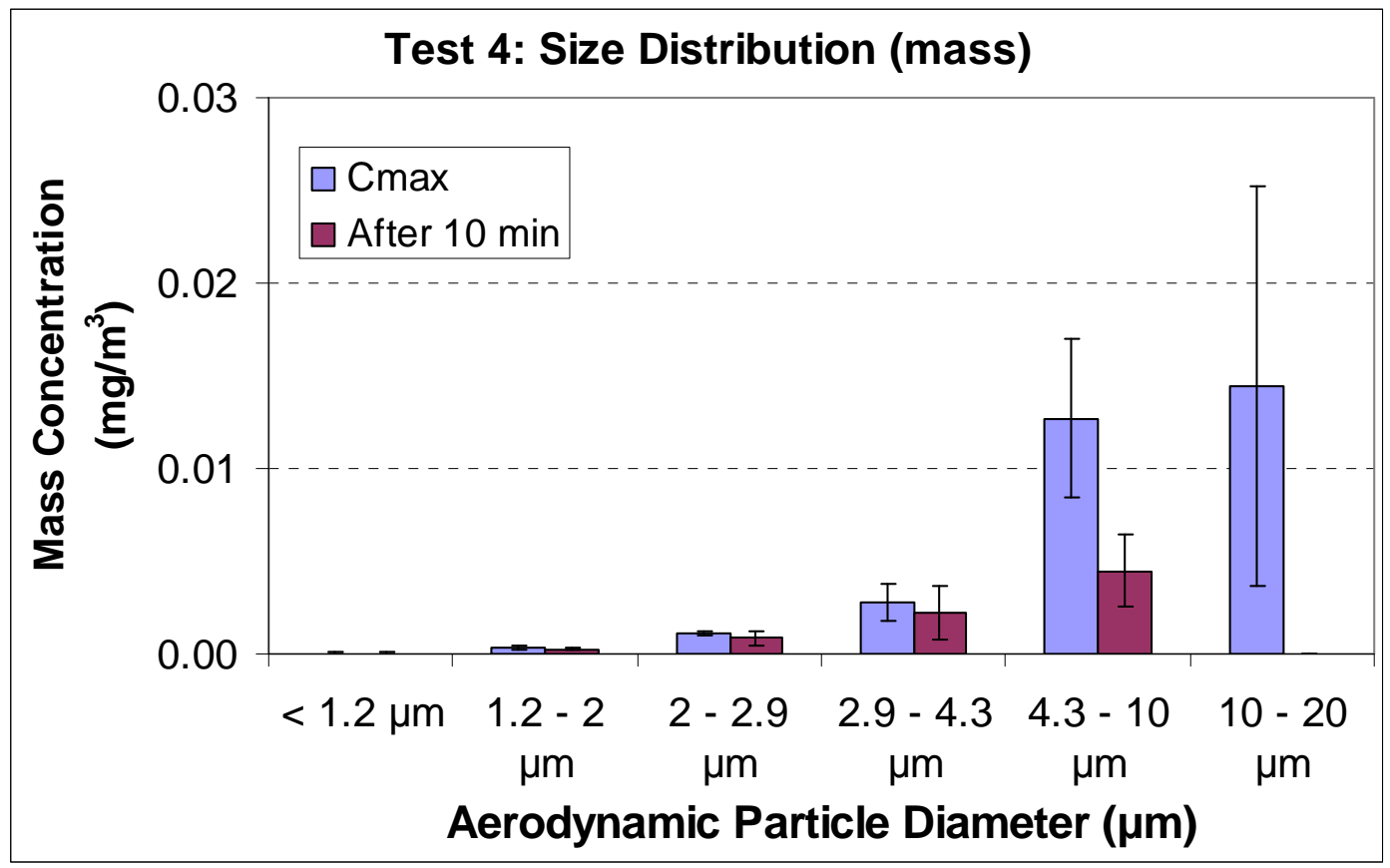

Figure A4-e. Particle mass concentration versus particle size of Test 4

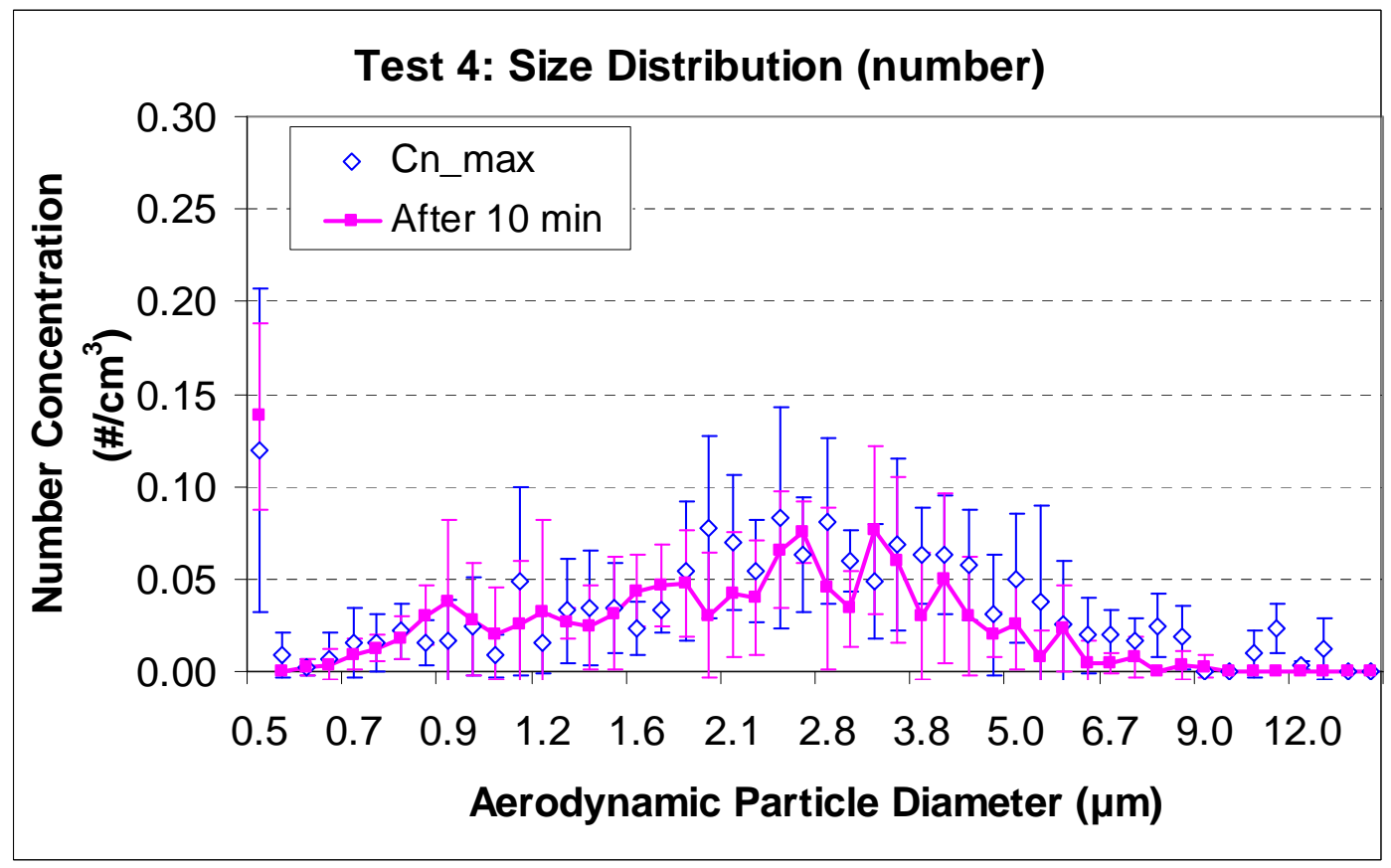

Figure A4-f. Particle number concentration versus particle size (channel data) of Test 4 


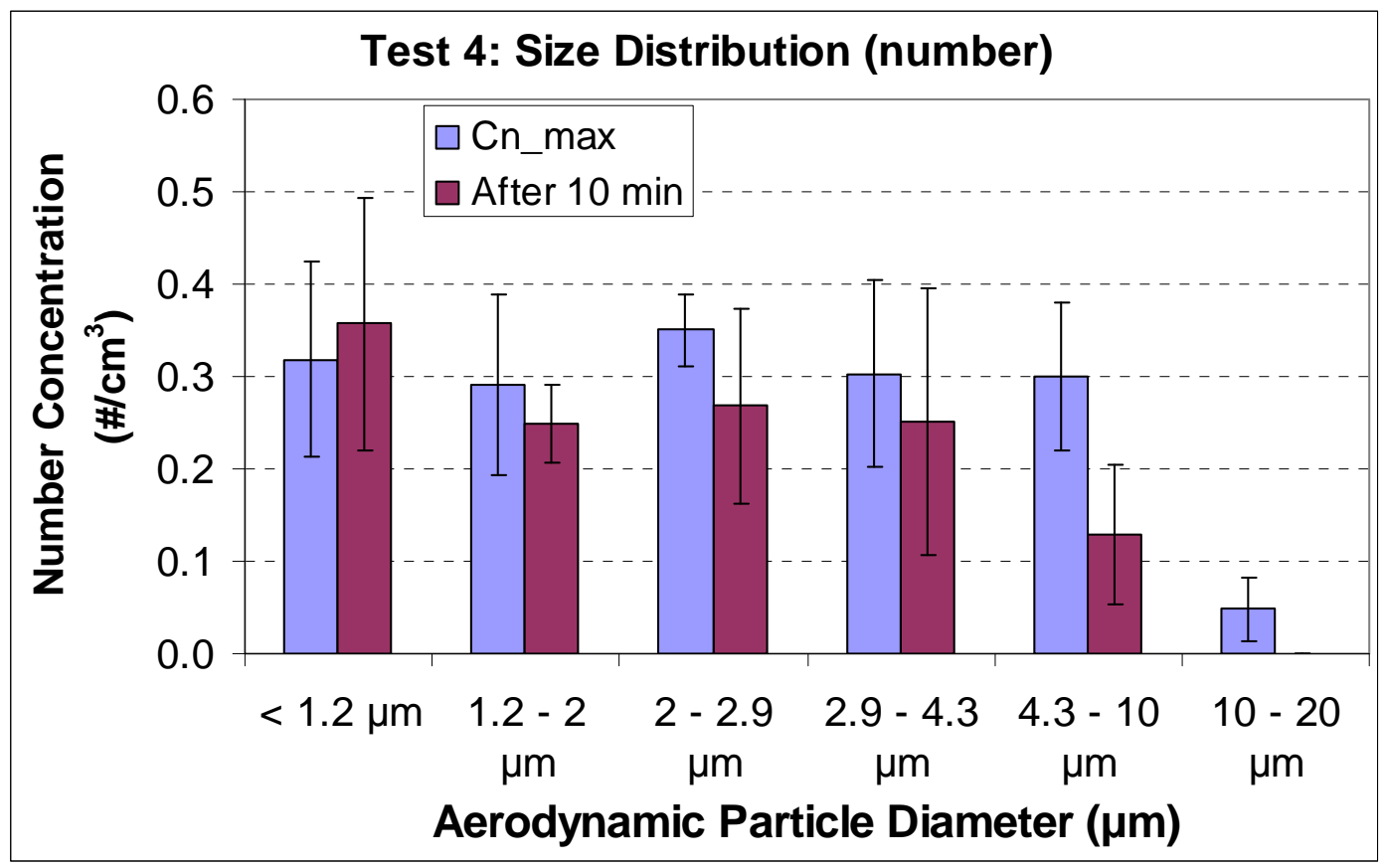

Figure A4-g. Particle number concentration versus particle size of Test 4

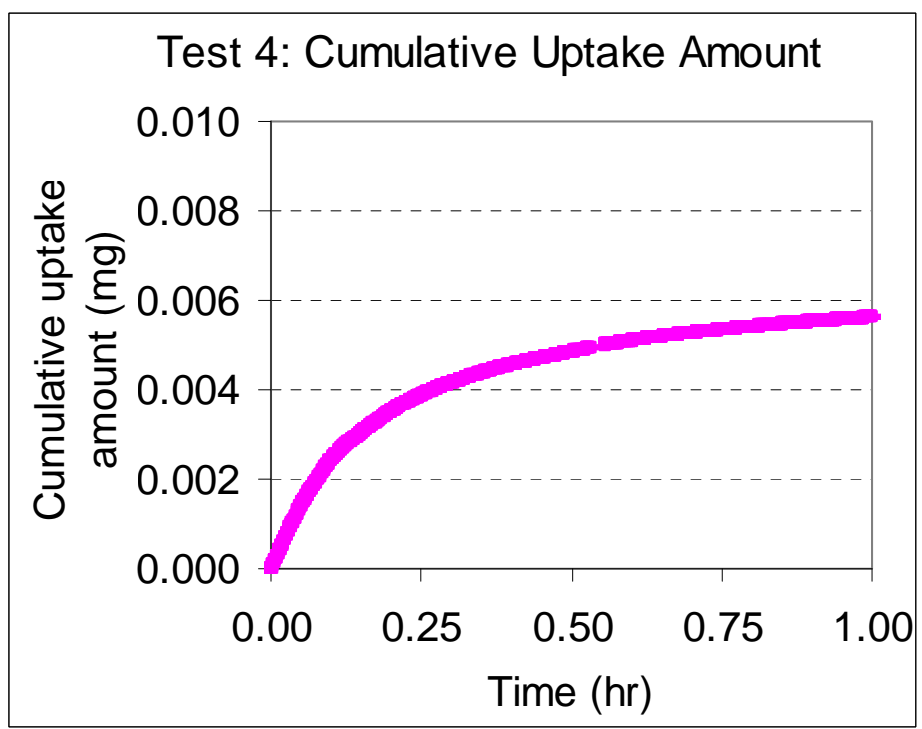

Figure A4-h. Cumulative uptake amount of particle mass of Test 4 
A3.5 Test 5

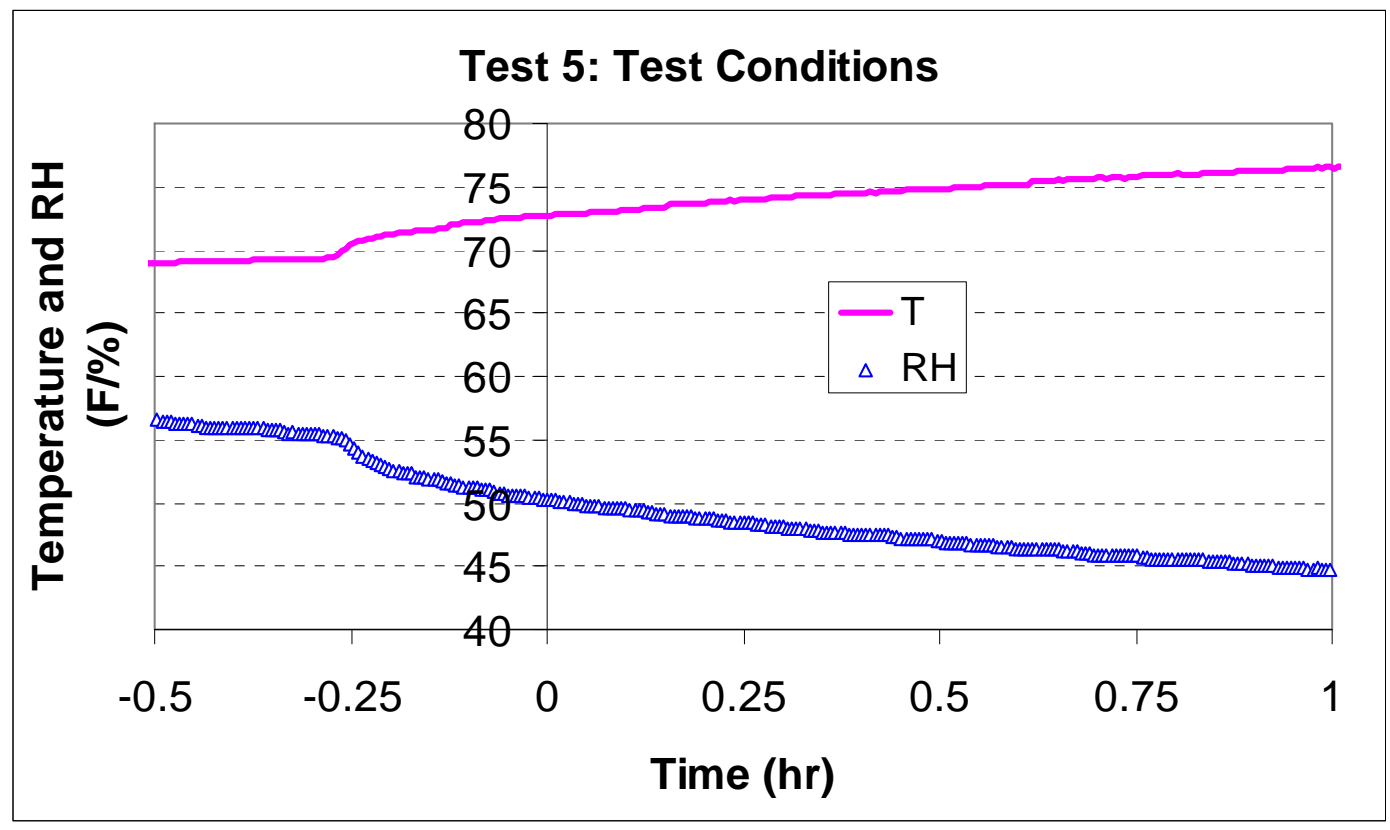

Figure A5-a. Chamber conditions during Test 5

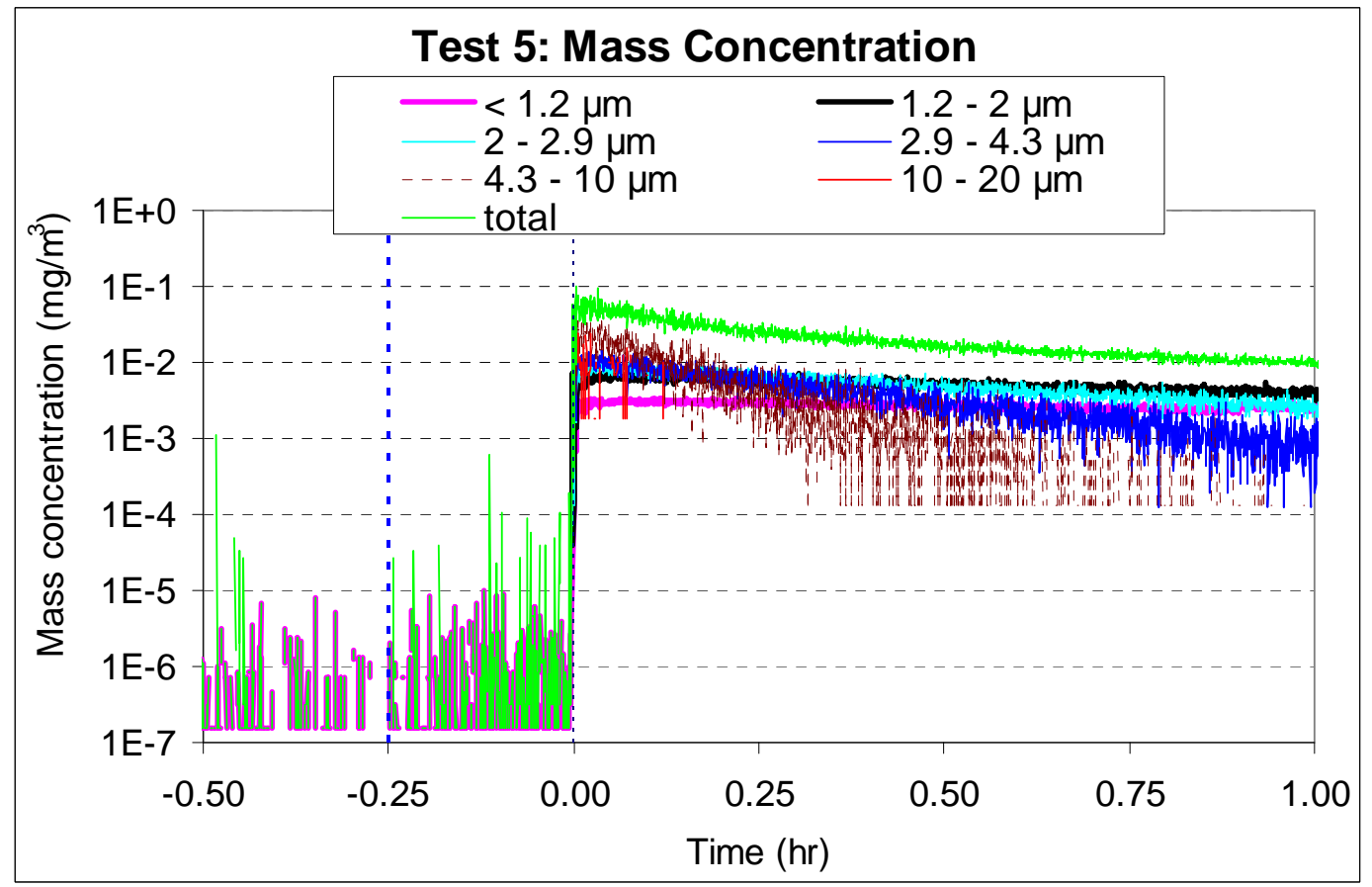

Figure A5-b. Particle mass concentration before and after the dropping of Test 5 


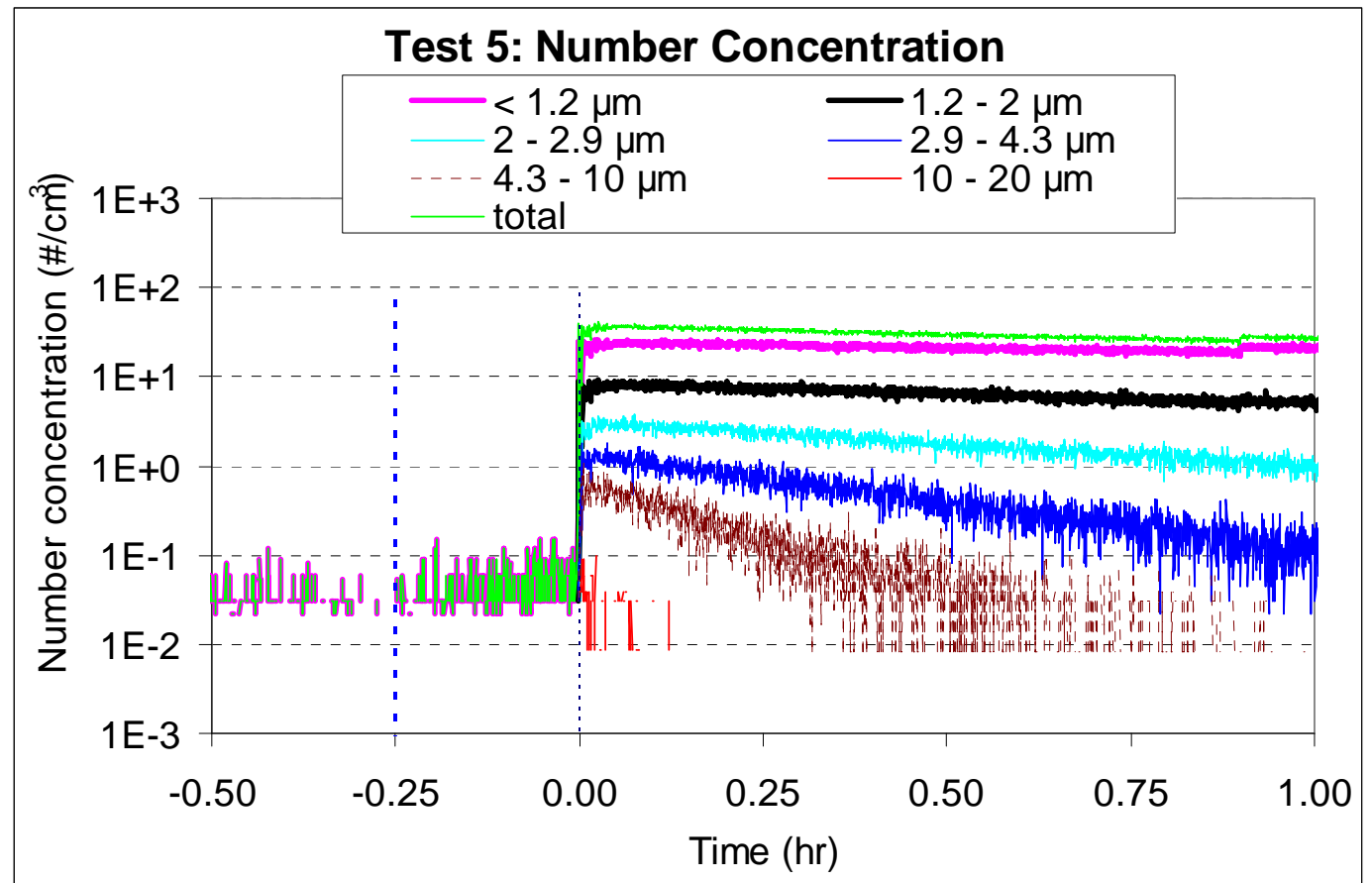

Figure A5-c. Particle number concentration before and after the dropping of Test 5

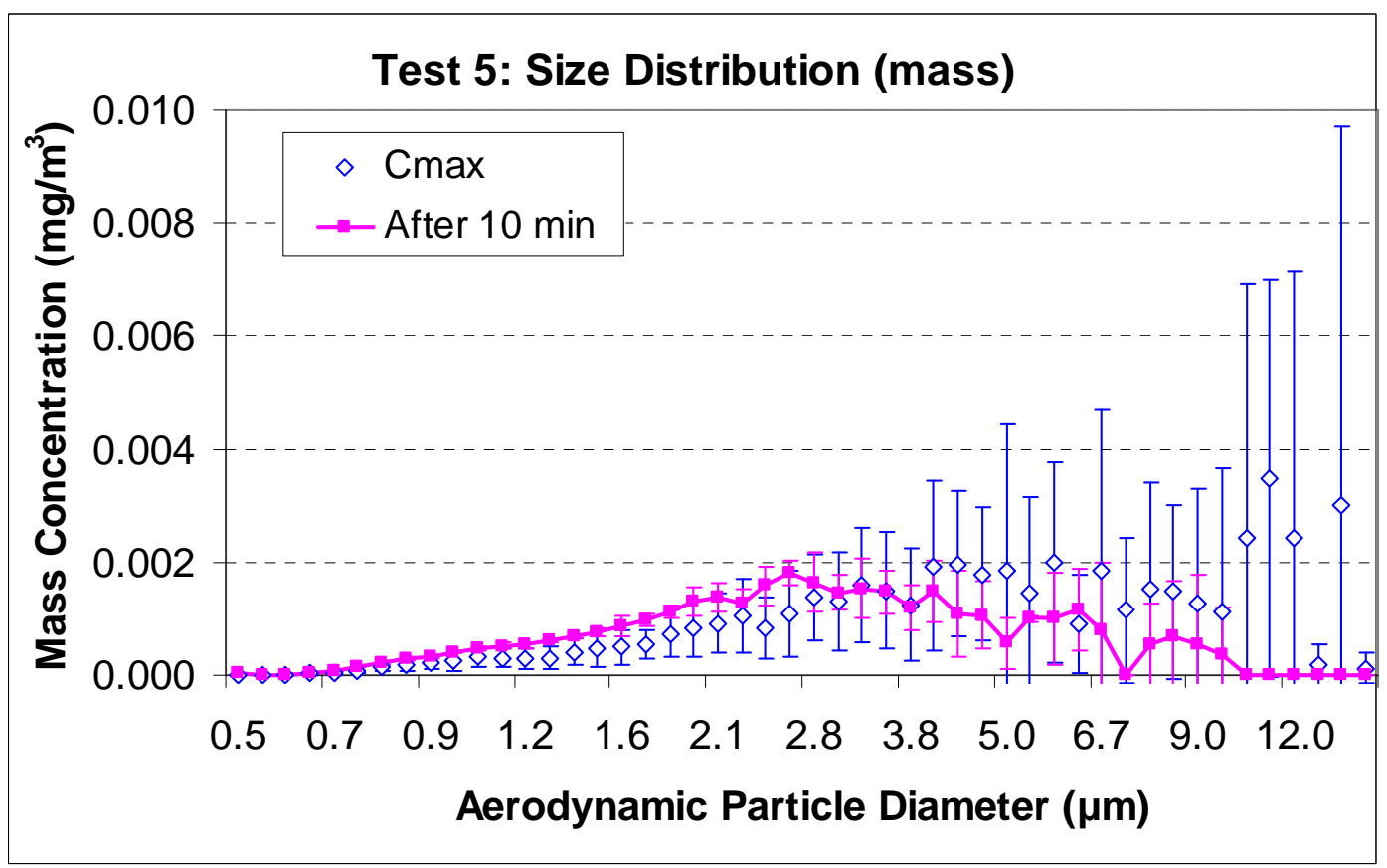

Figure A5-d. Particle mass concentration versus particle size (channel data) of Test 5 


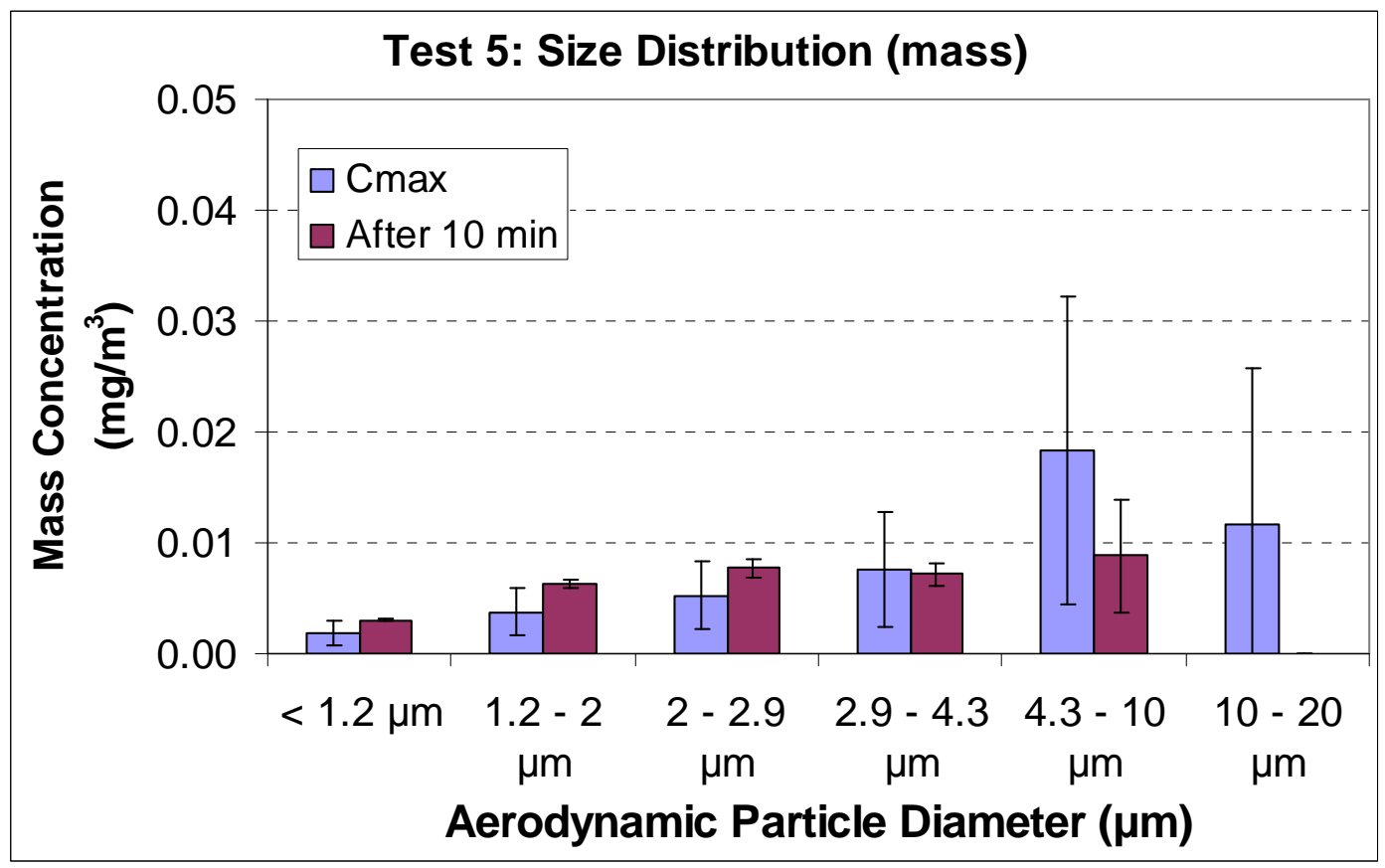

Figure A5-e. Particle mass concentration versus particle size of Test 5

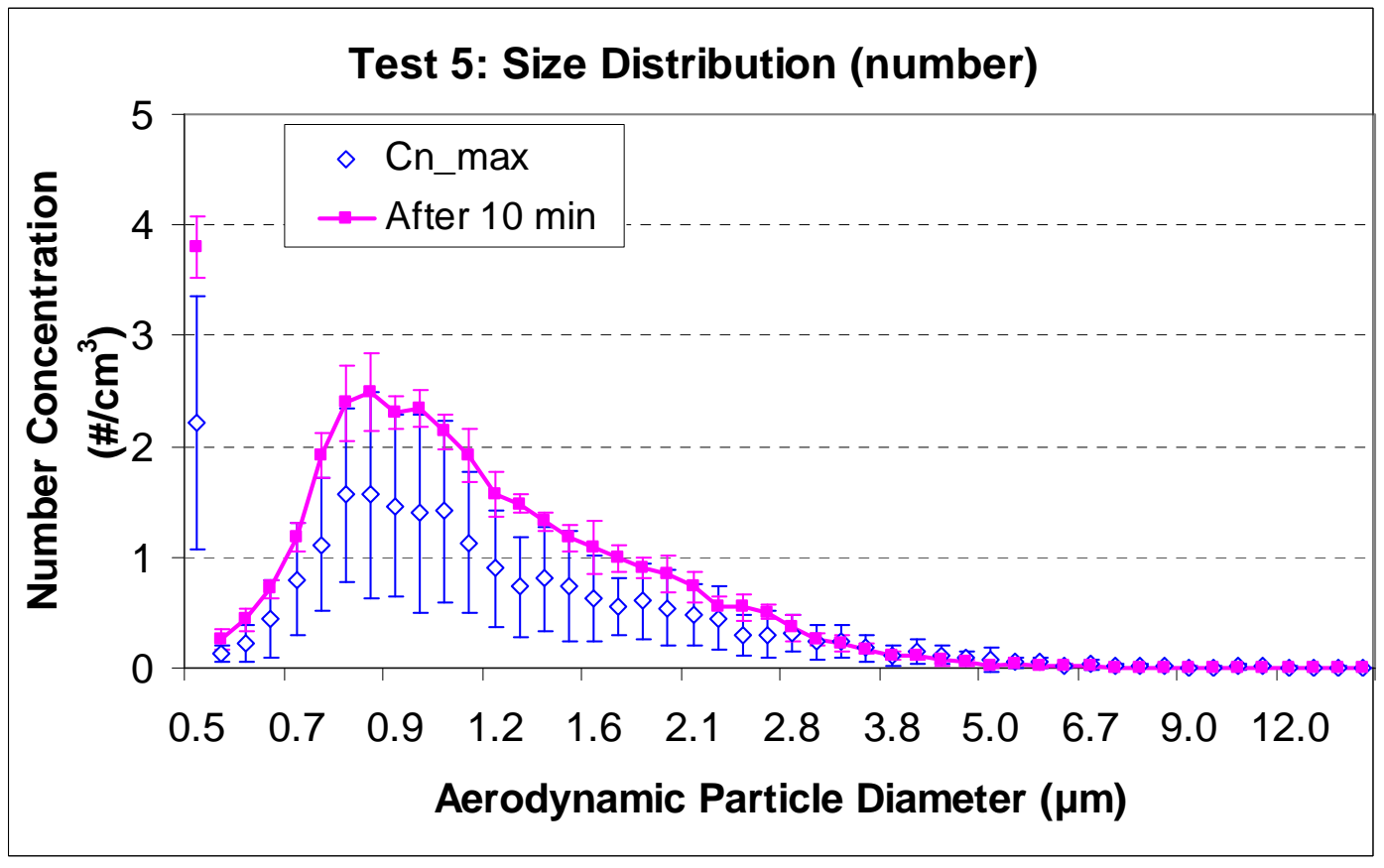

Figure A5-f. Particle number concentration versus particle size (channel data) of Test 5 


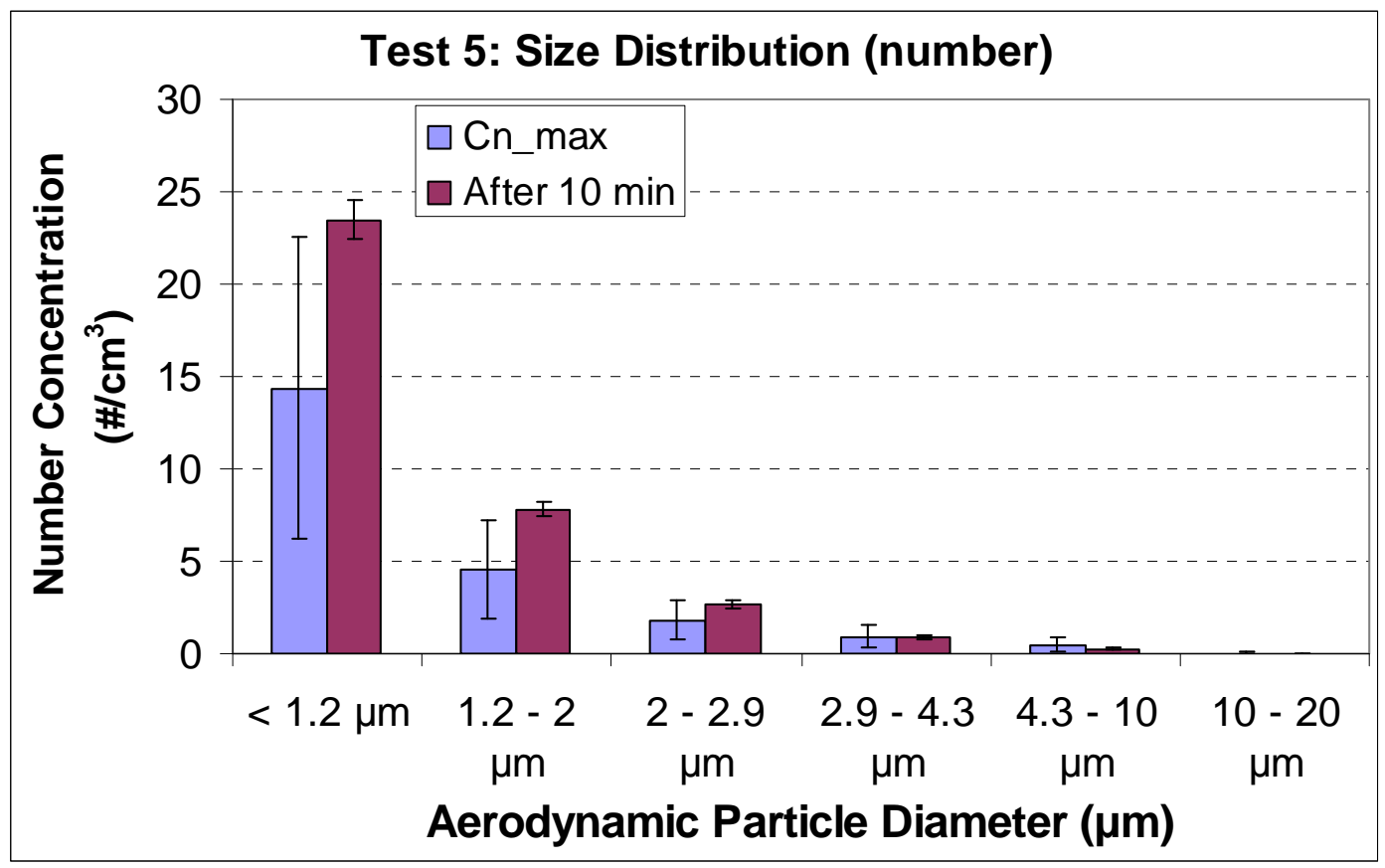

Figure A5-g. Particle number concentration versus particle size of Test 5

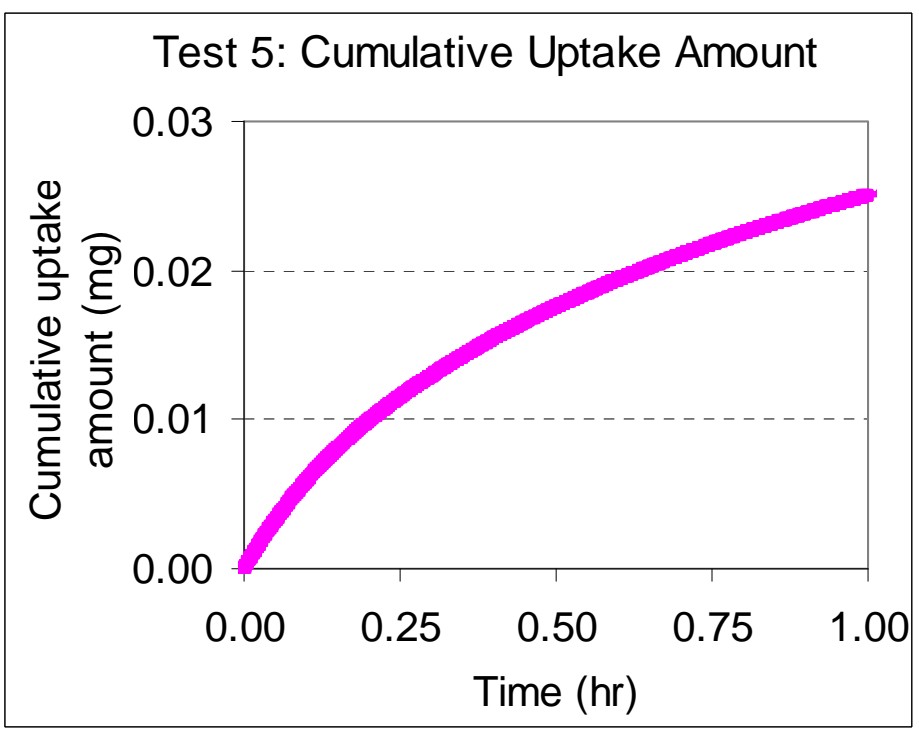

Figure A5-h. Cumulative uptake amount of particle mass of Test 5 
A3.6 Test 6

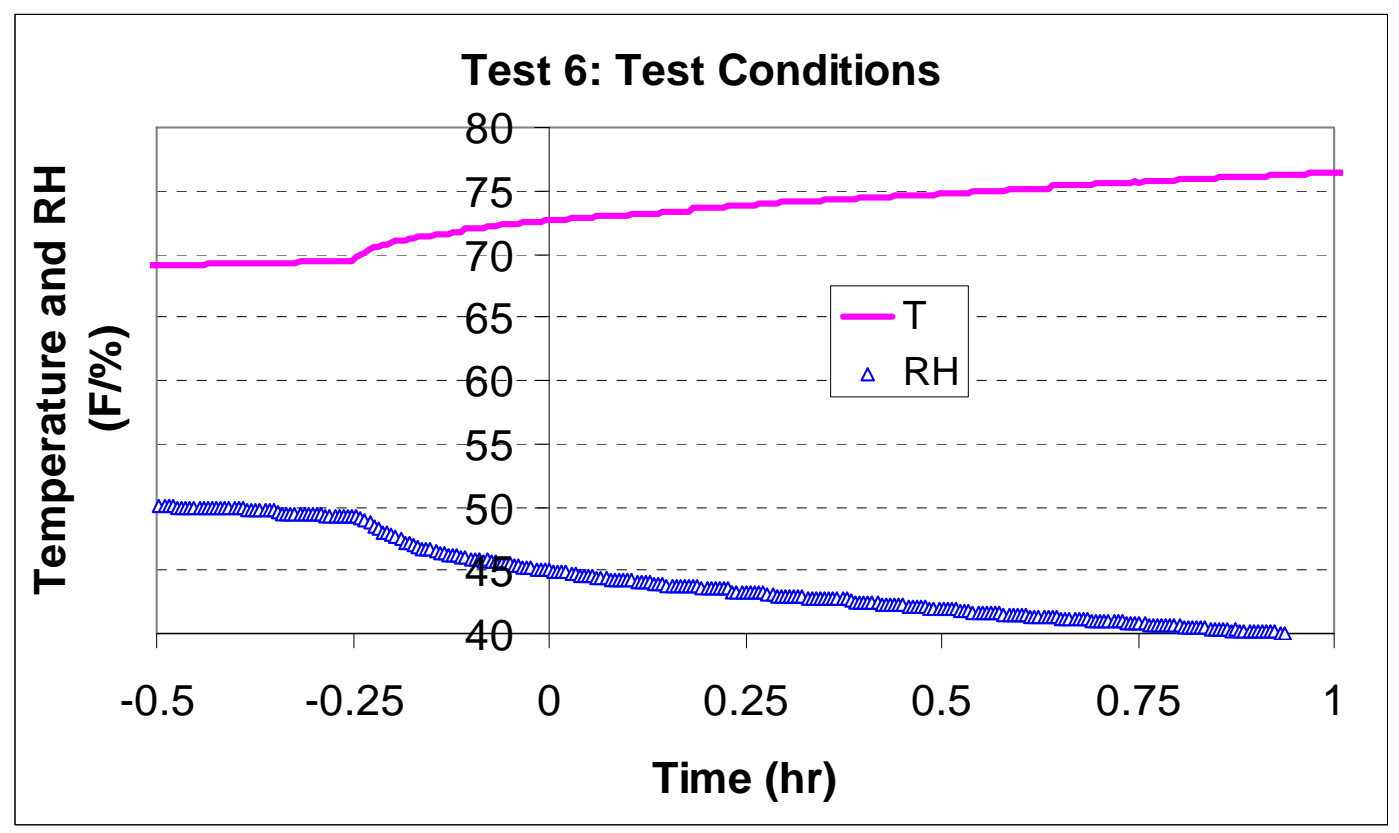

Figure A6-a. Chamber conditions during Test 6

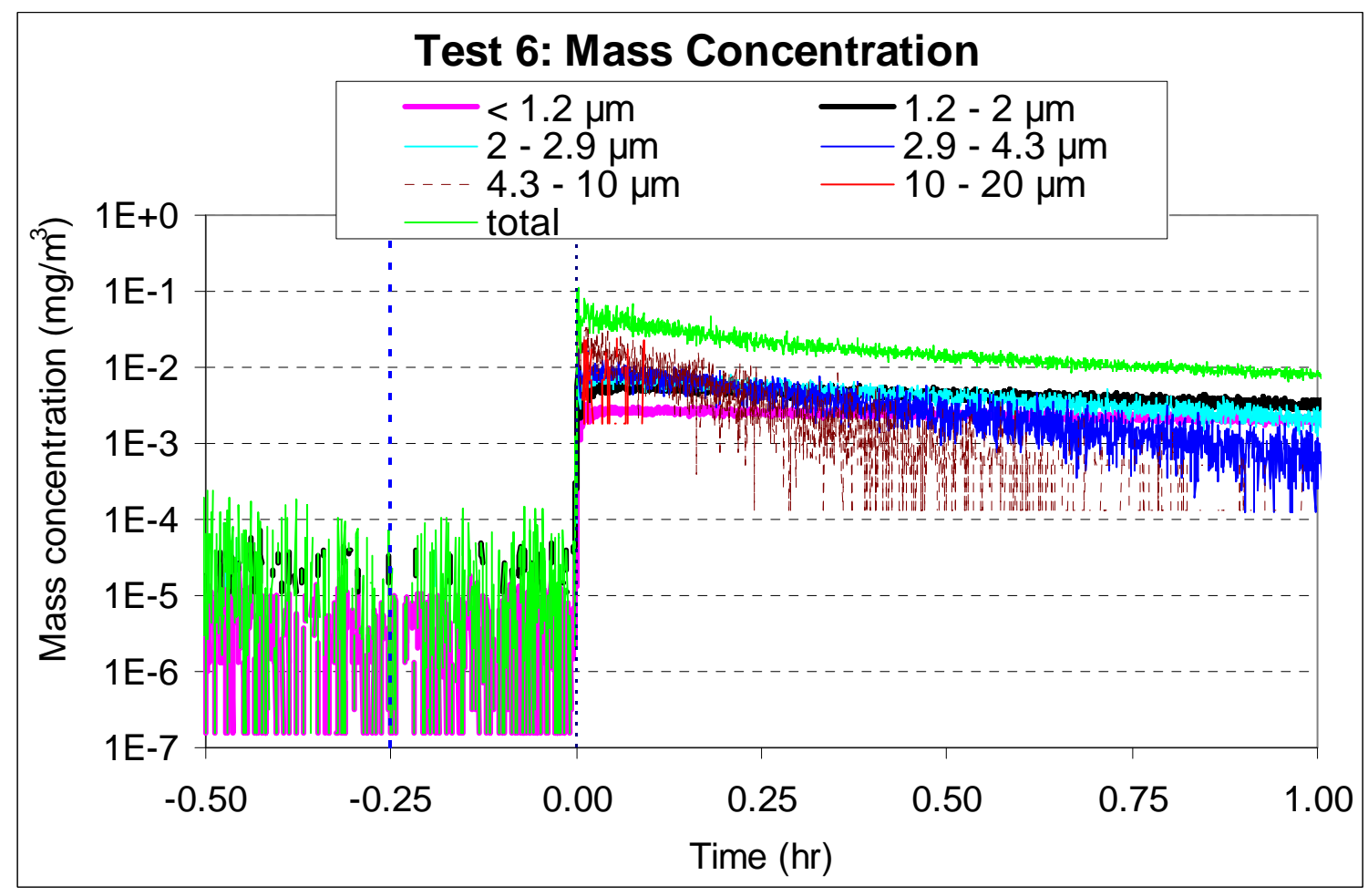

Figure A6-b. Particle mass concentration before and after the dropping of Test 6 


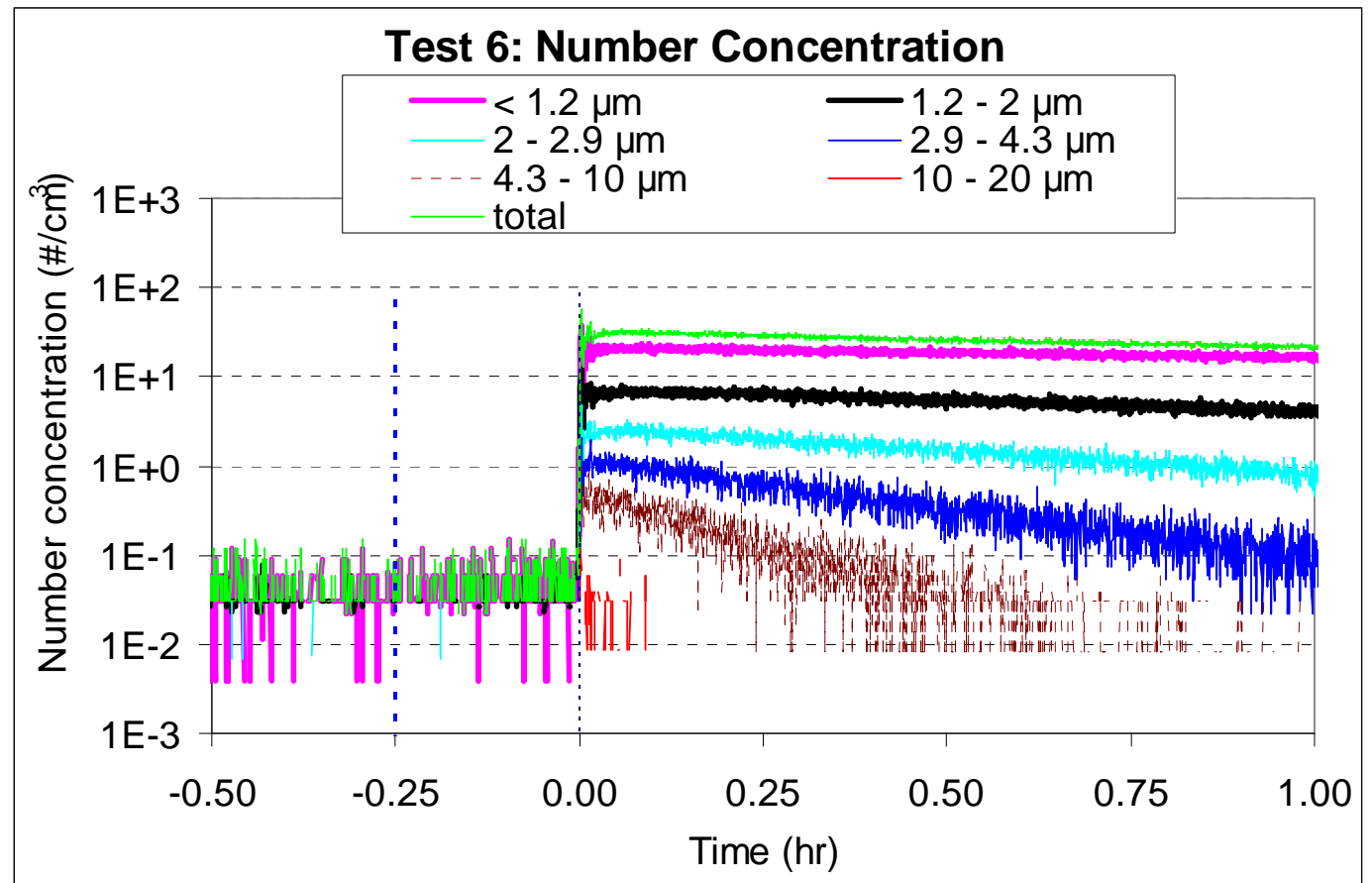

Figure A6-c. Particle number concentration before and after the dropping of Test 6

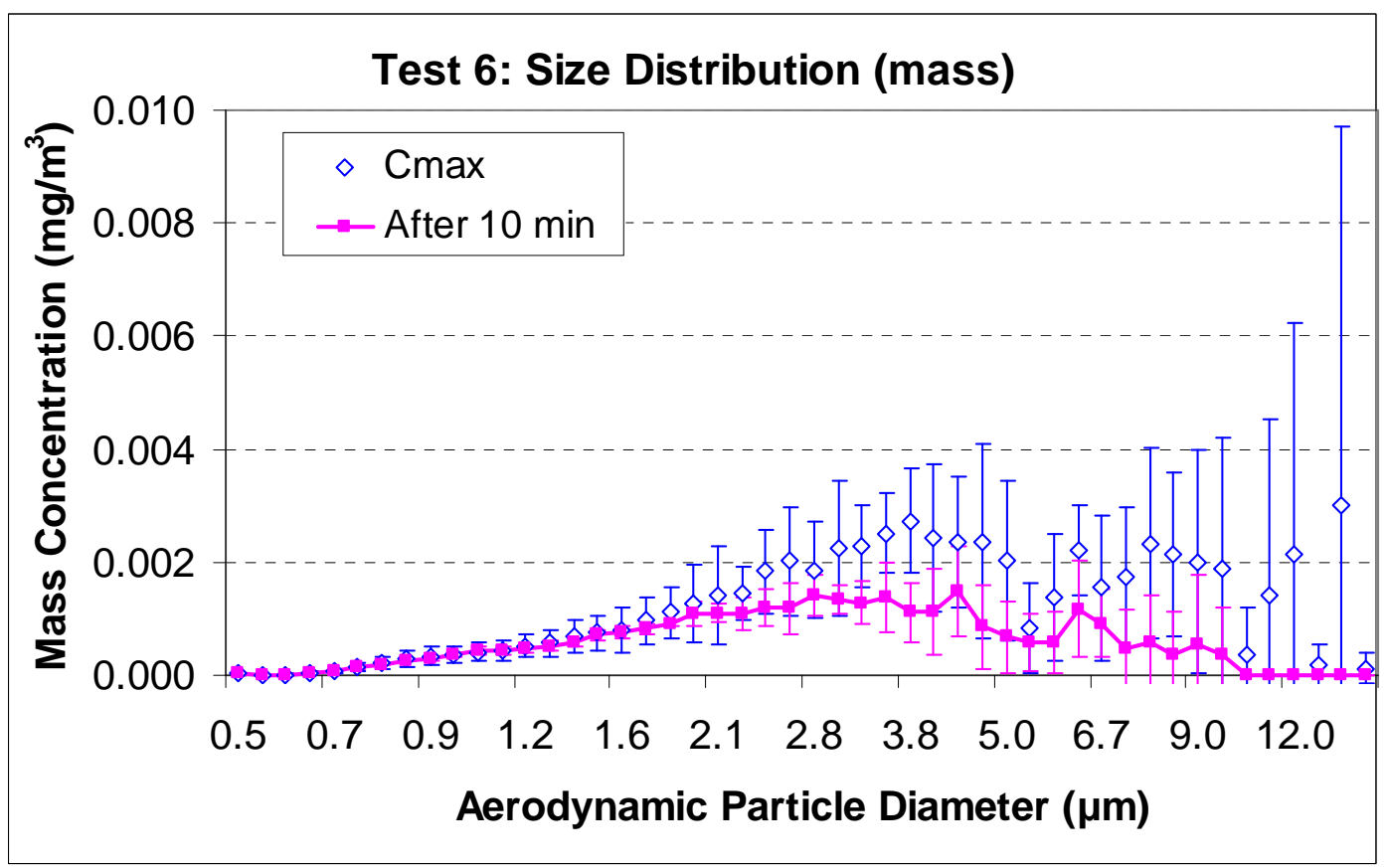

Figure A6-d. Particle mass concentration versus particle size (channel data) of Test 6 


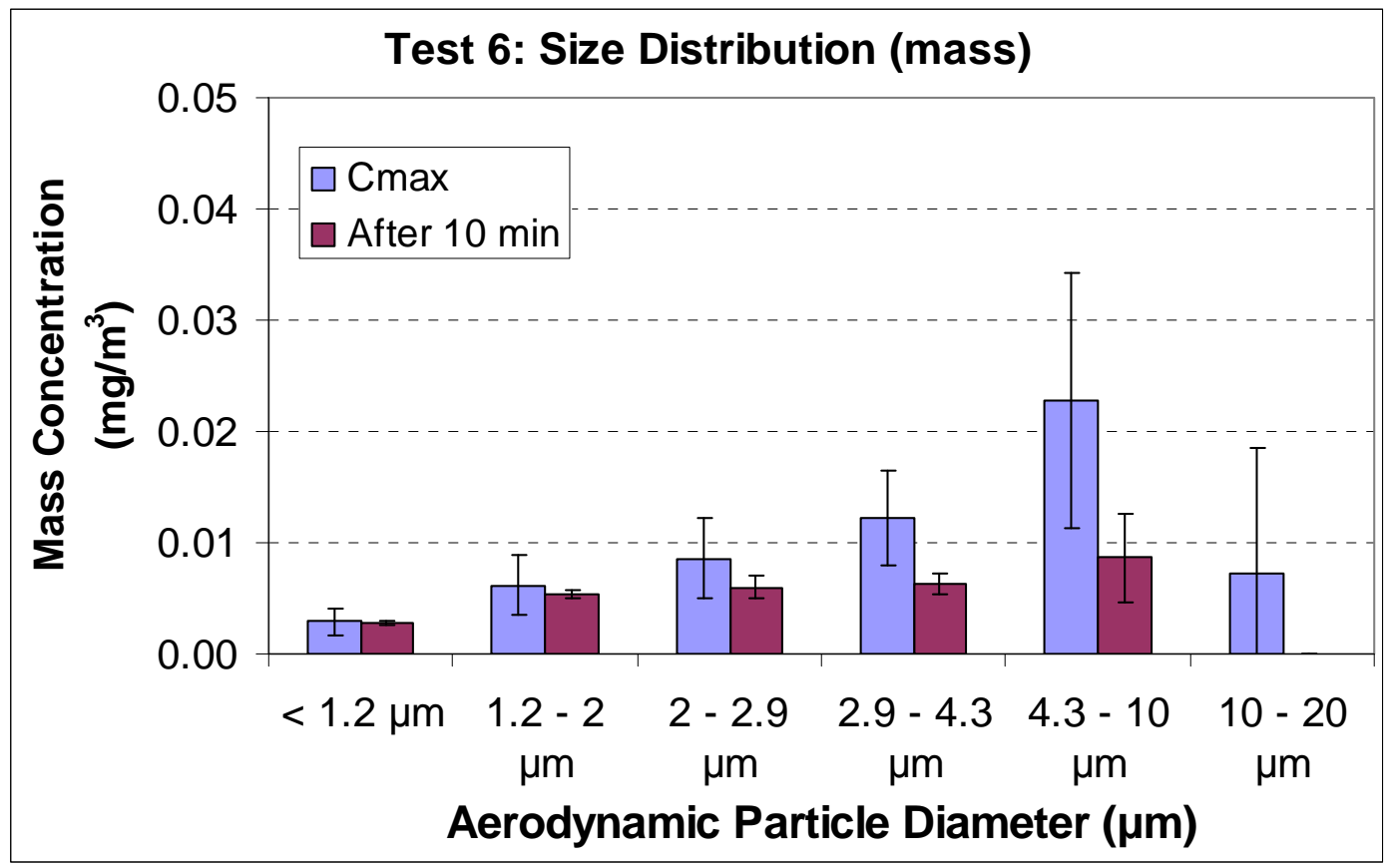

Figure A6-e. Particle mass concentration versus particle size of Test 6

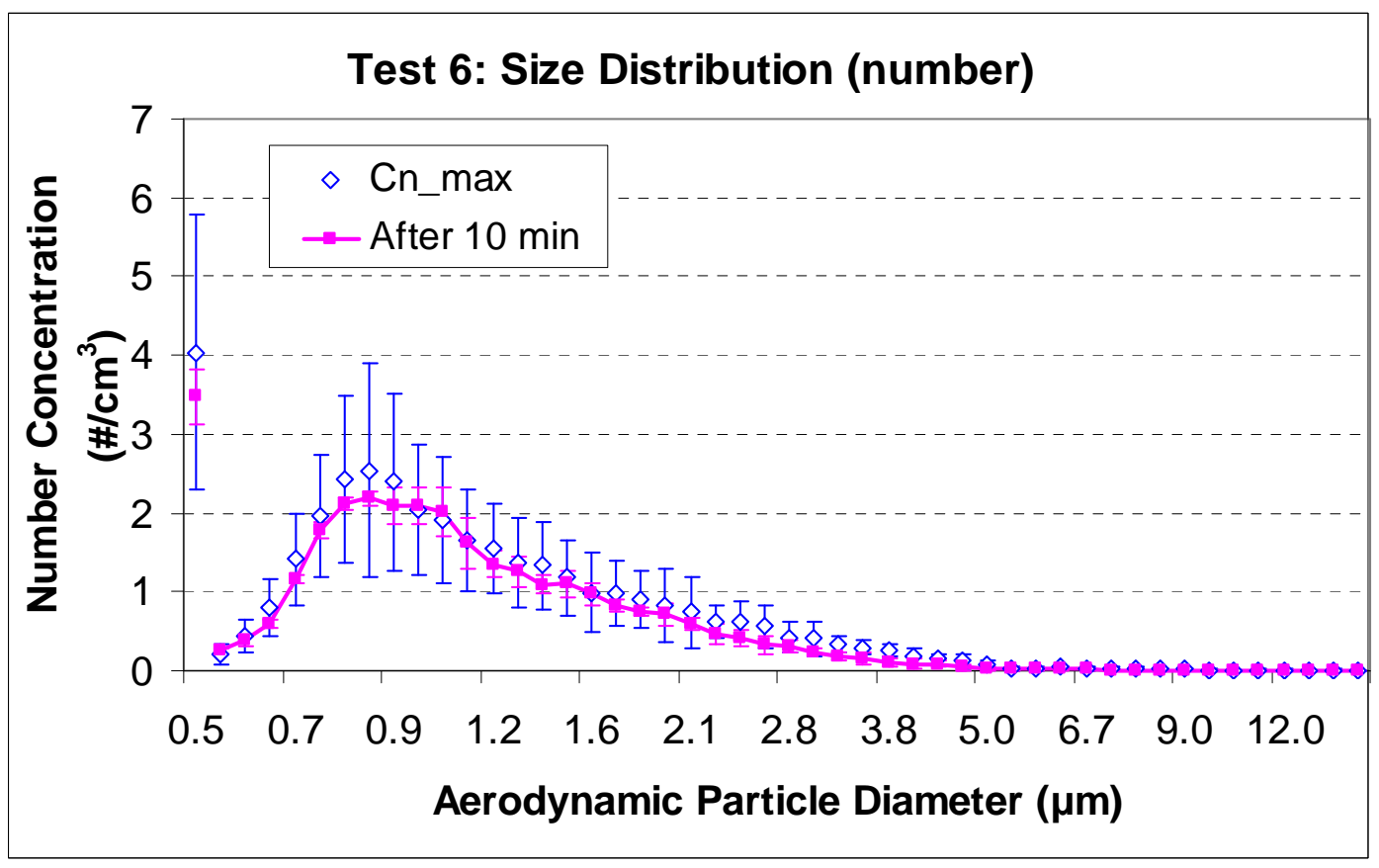

Figure A6-f. Particle number concentration versus particle size (channel data) of Test 6 


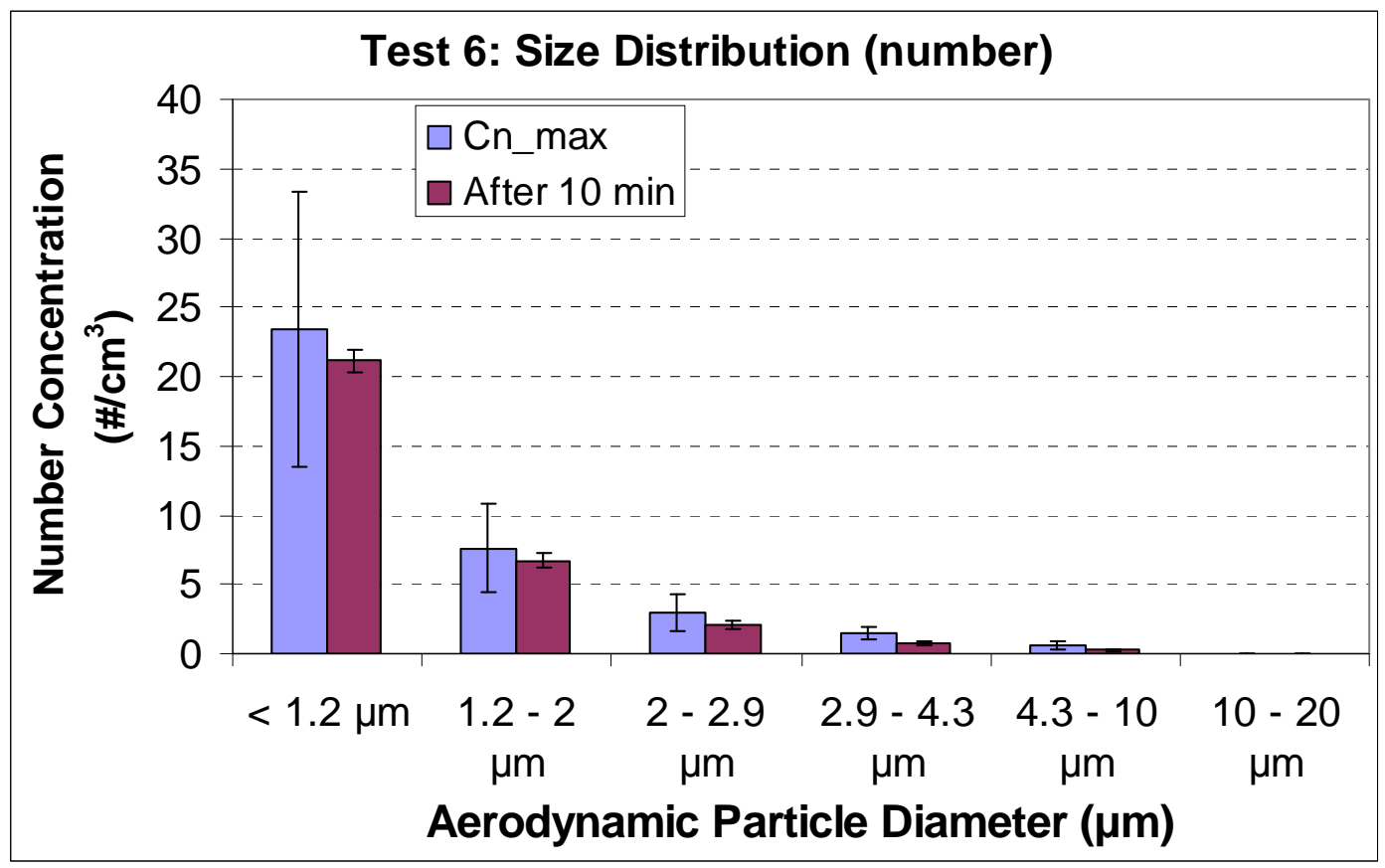

Figure A6-g. Particle number concentration versus particle size of Test 6

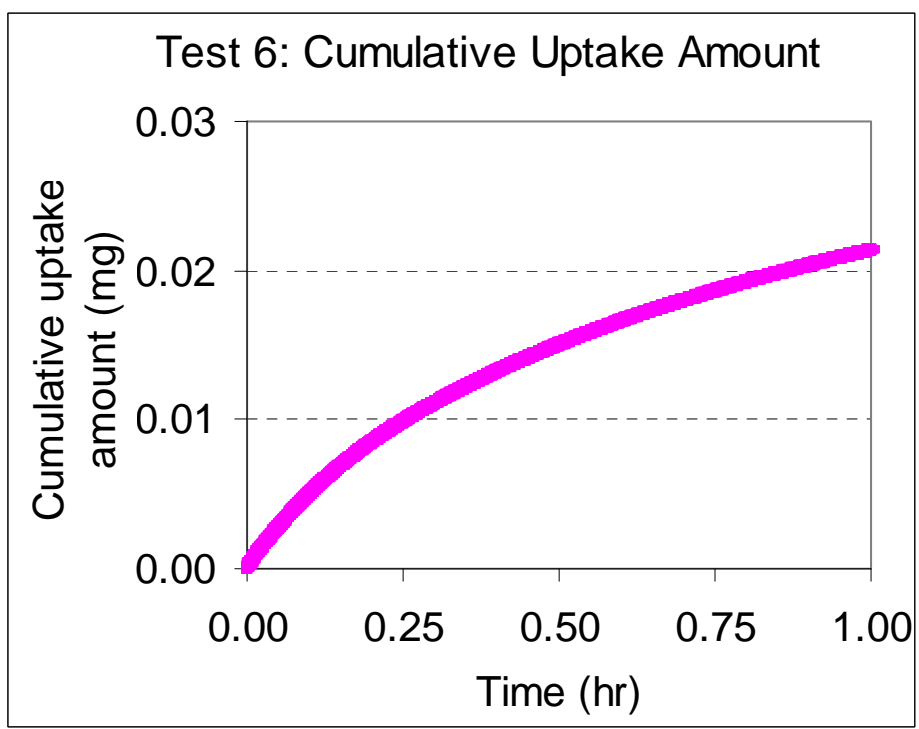

Figure A6-h. Cumulative uptake amount of particle mass of Test 6 
A3.7 Test 7

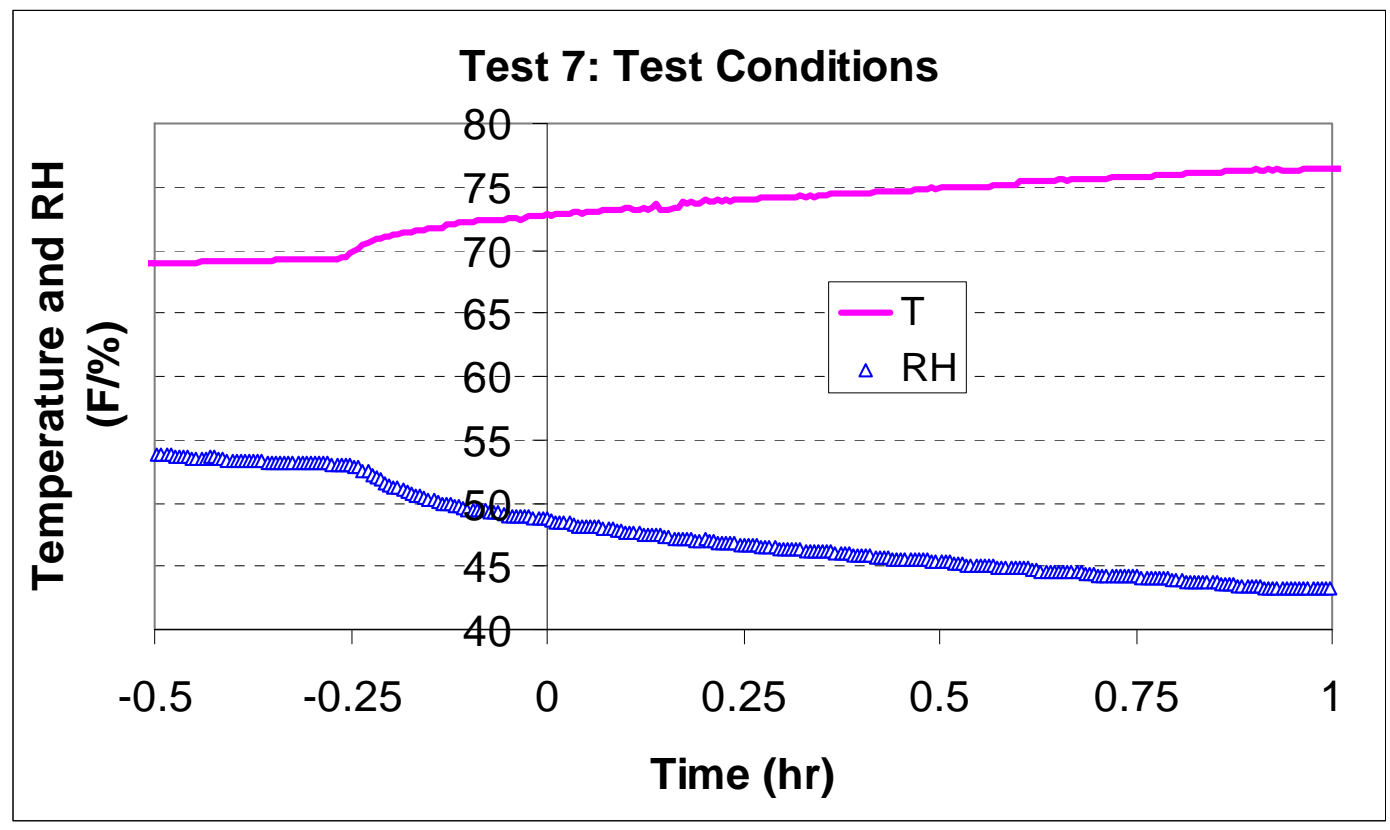

Figure A7-a. Chamber conditions during Test 7

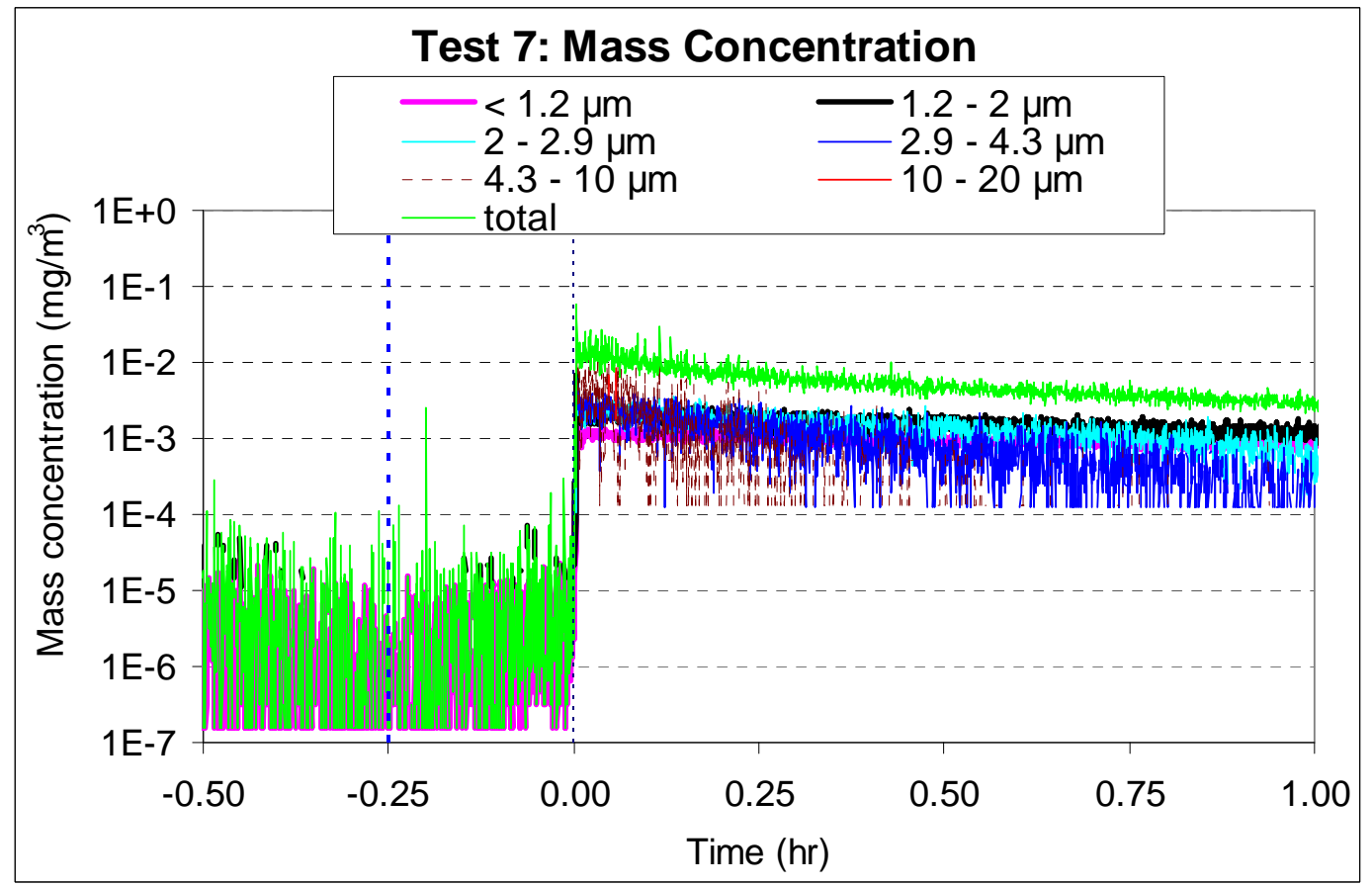

Figure A7-b. Particle mass concentration before and after the dropping of Test 7 


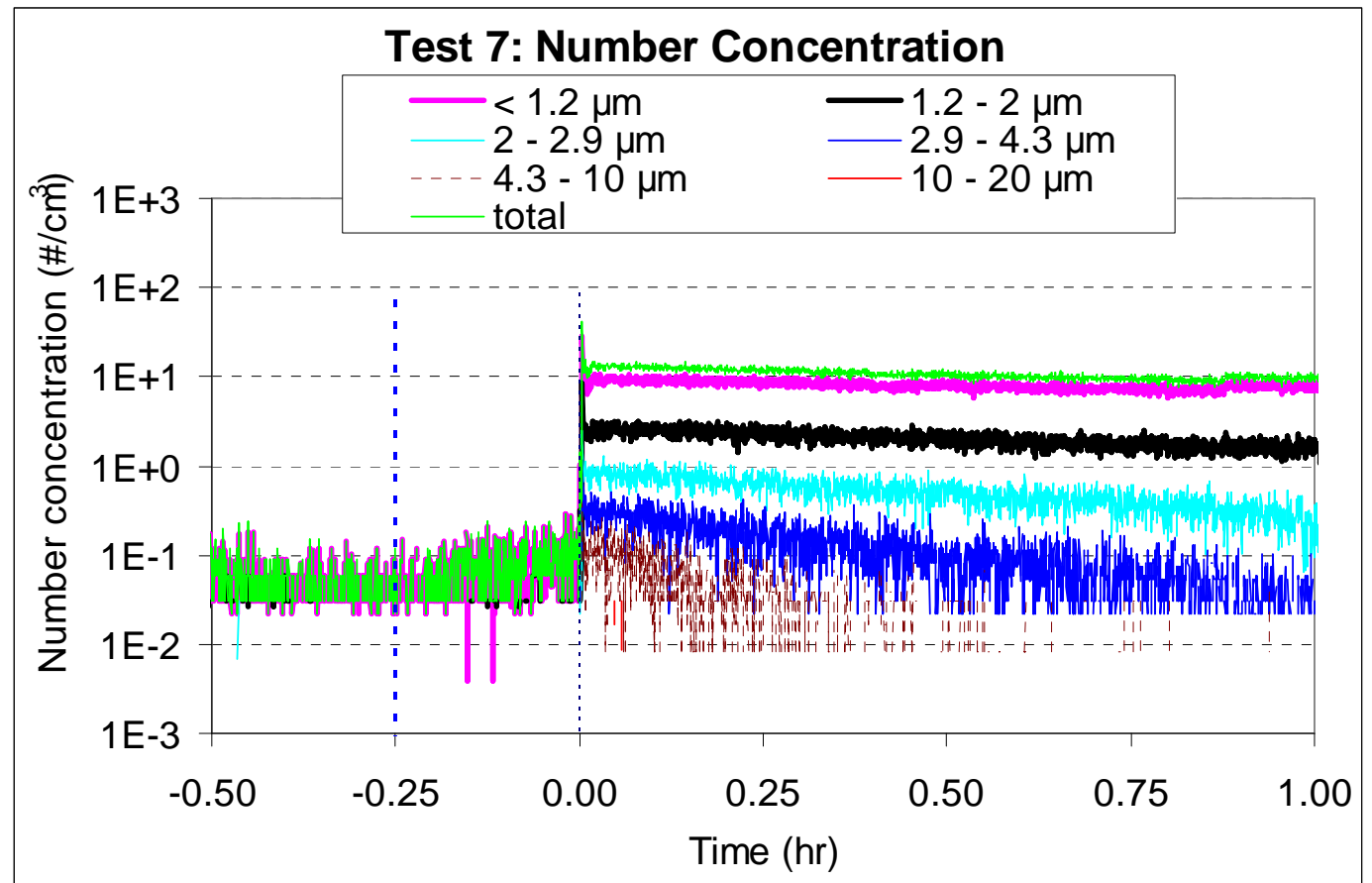

Figure A7-c. Particle number concentration before and after the dropping of Test 7

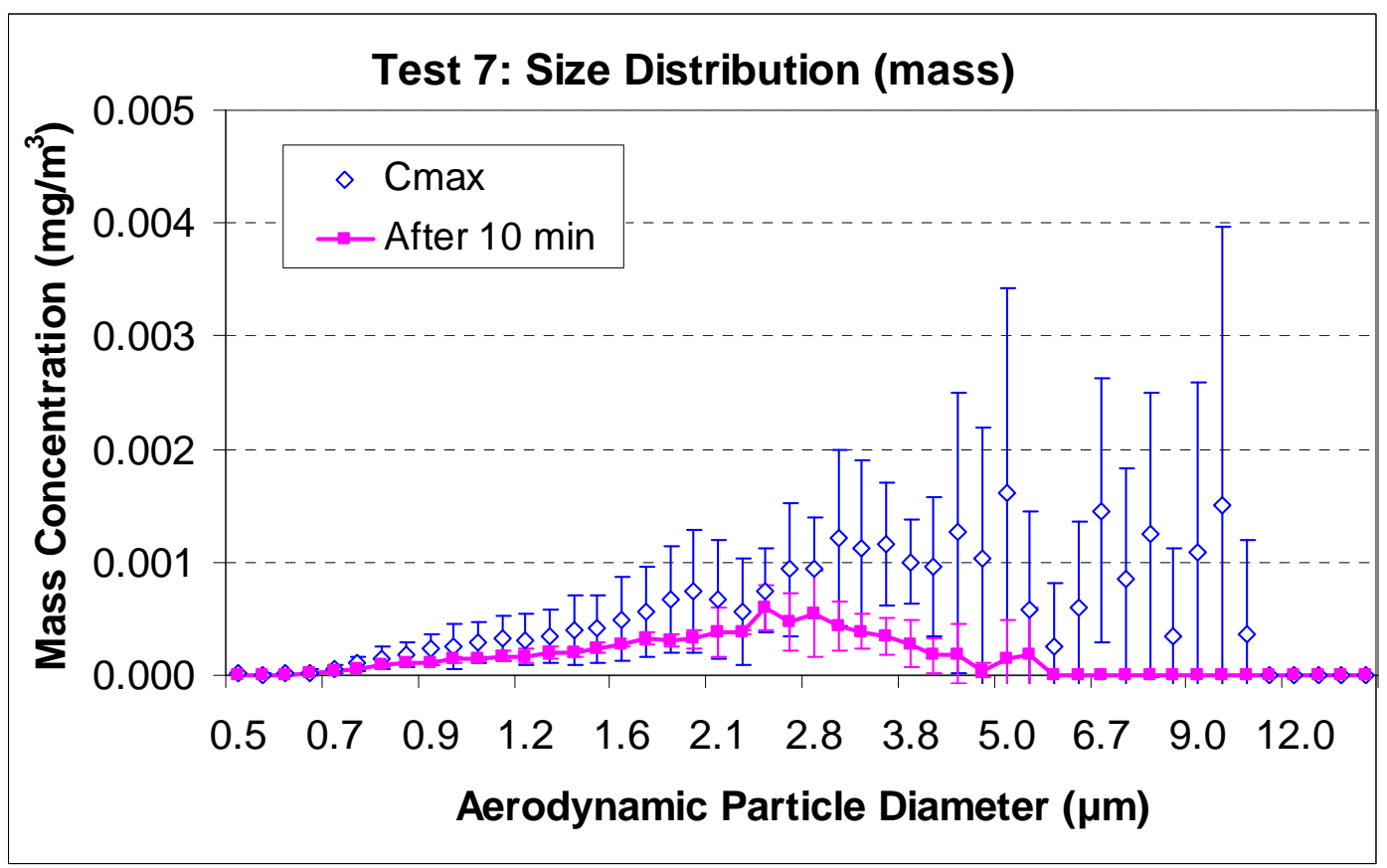

Figure A7-d. Particle mass concentration versus particle size (channel data) of Test 7 


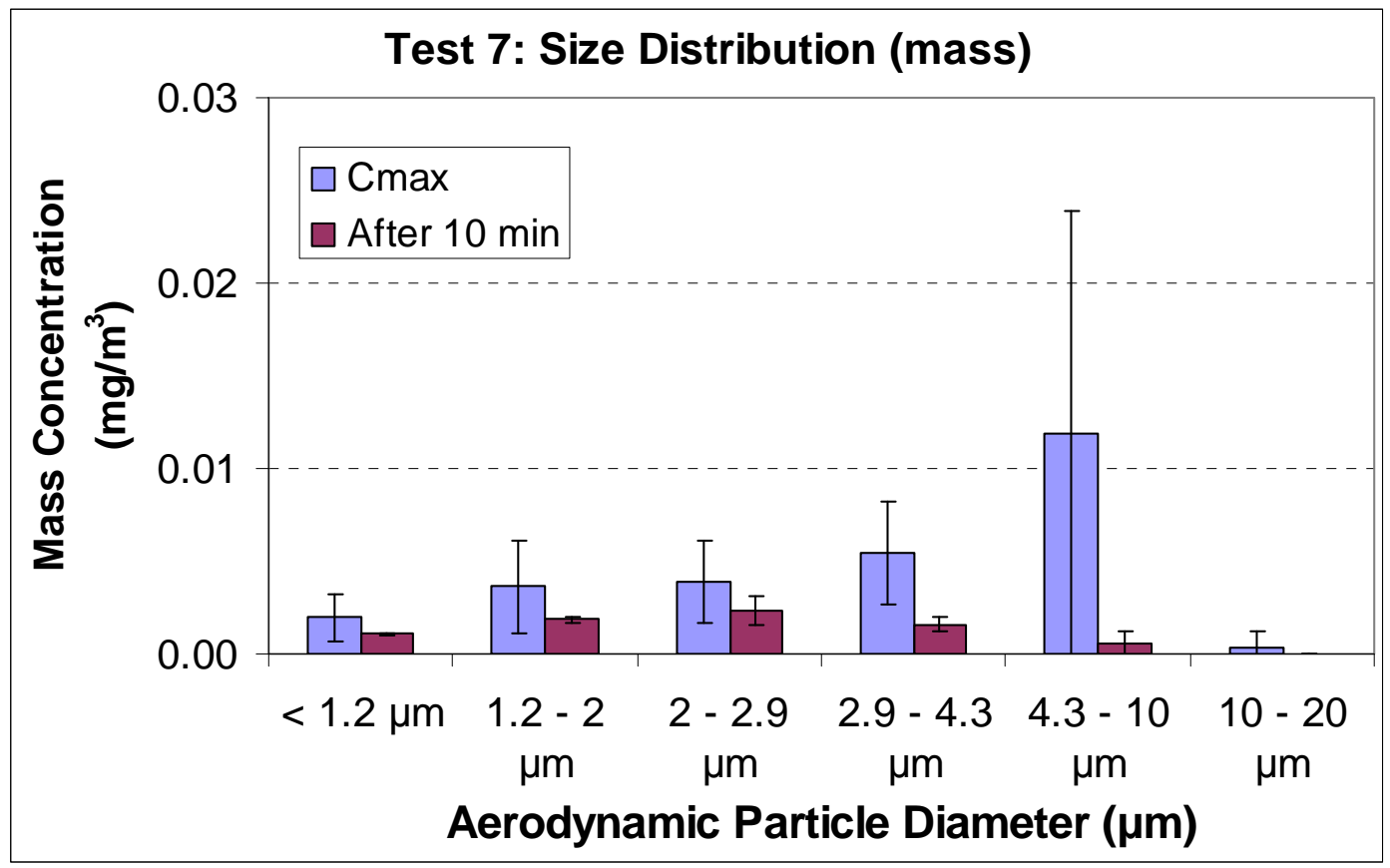

Figure A7-e. Particle mass concentration versus particle size of Test 7

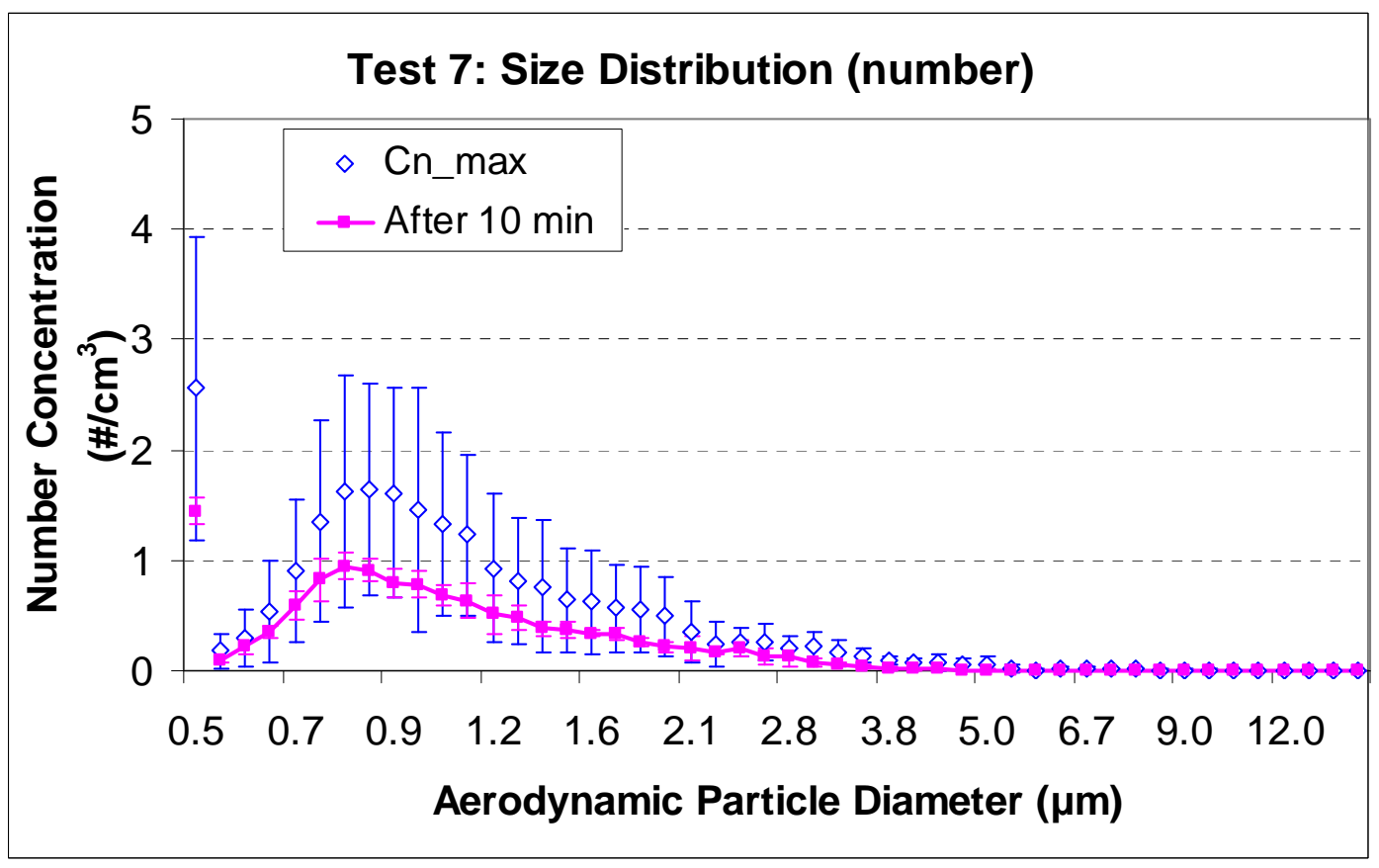

Figure A7-f. Particle number concentration versus particle size (channel data) of Test 7 


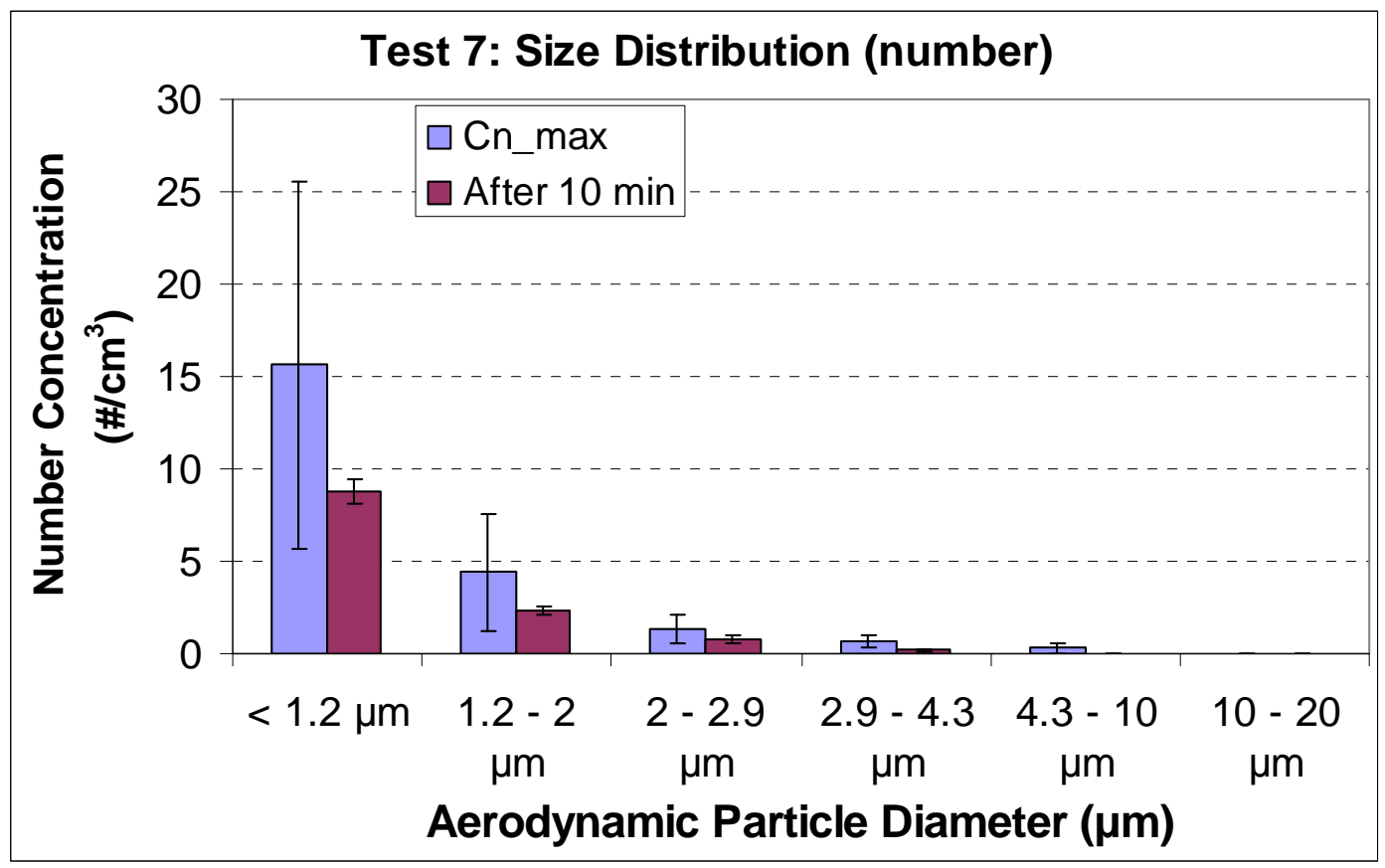

Figure A7-g. Particle number concentration versus particle size of Test 7

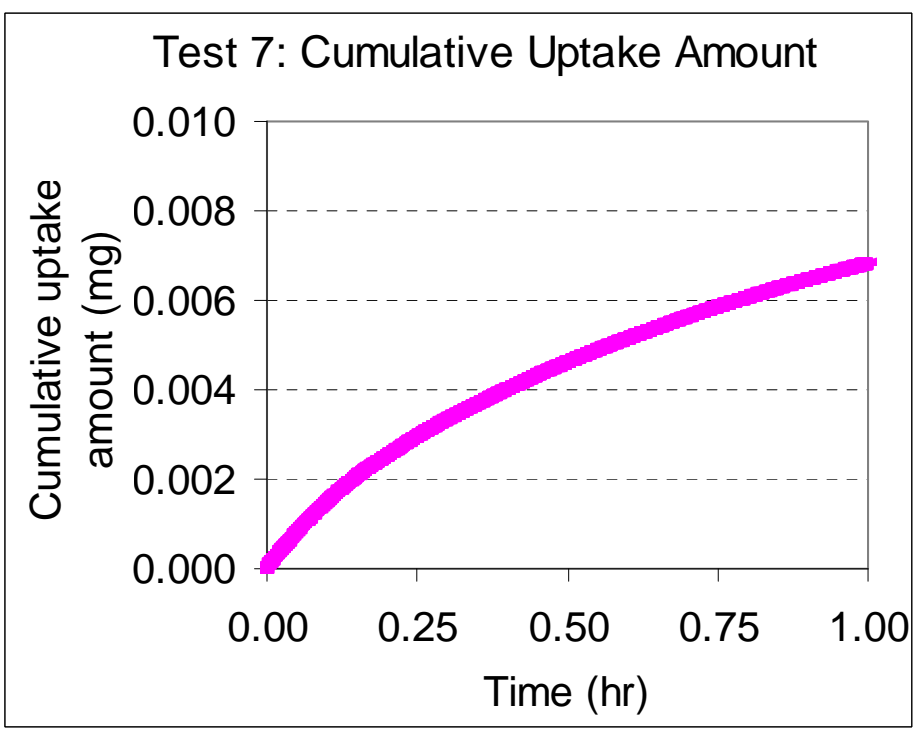

Figure A7-h. Cumulative uptake amount of particle mass of Test 7 
A3.8 Test 8

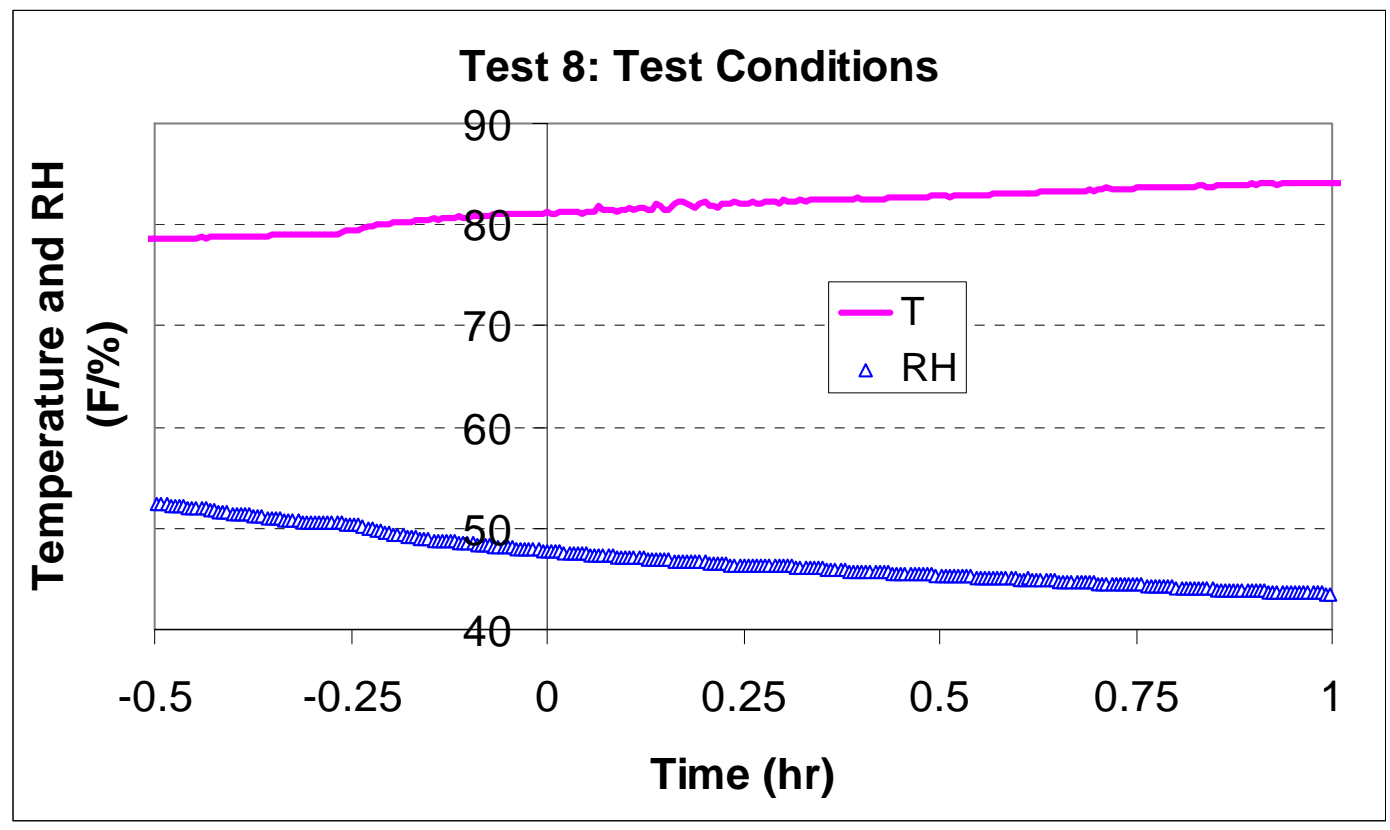

Figure A8-a. Chamber conditions during Test 8

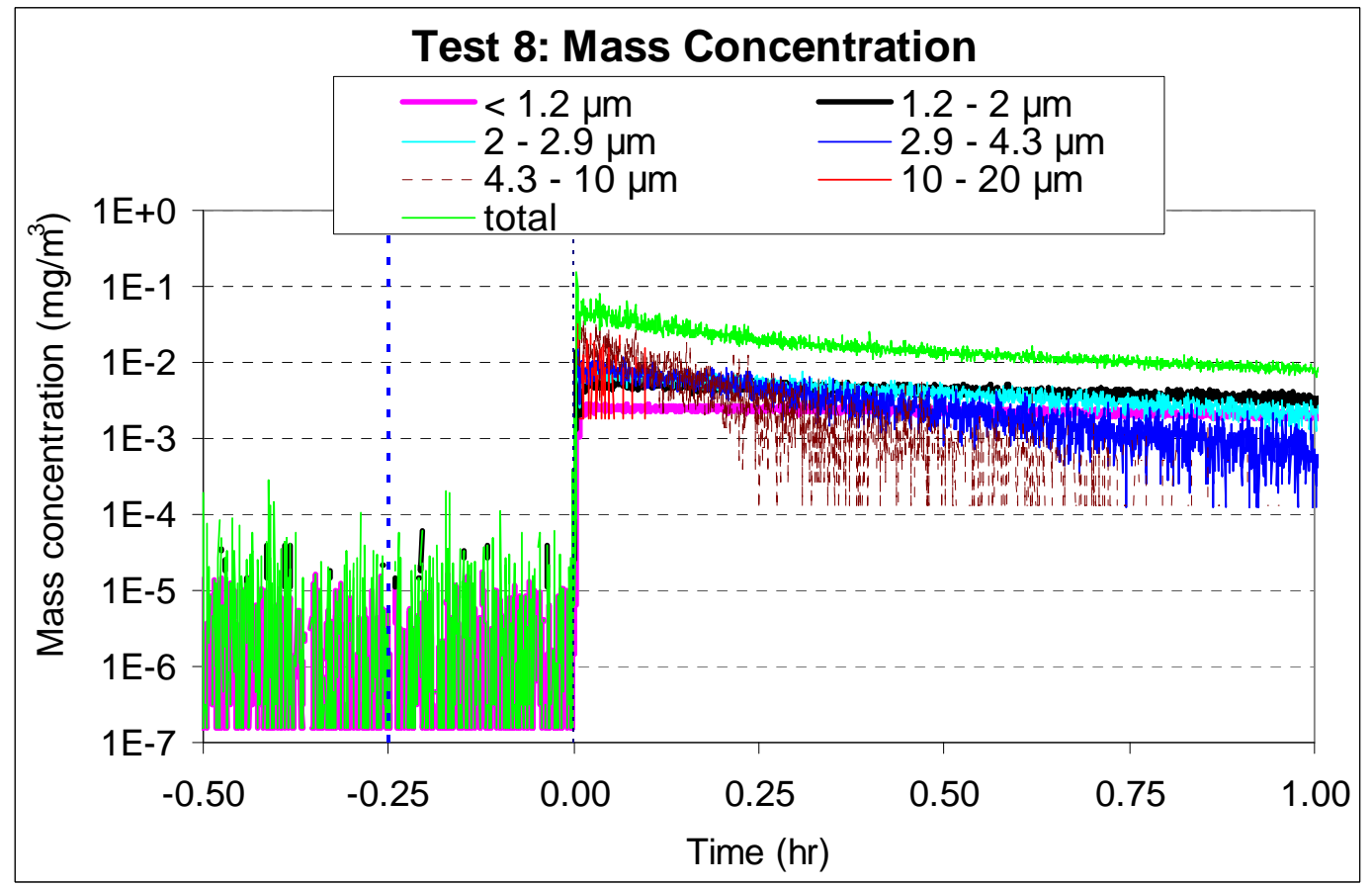

Figure A8-b. Particle mass concentration before and after the dropping of Test 8 


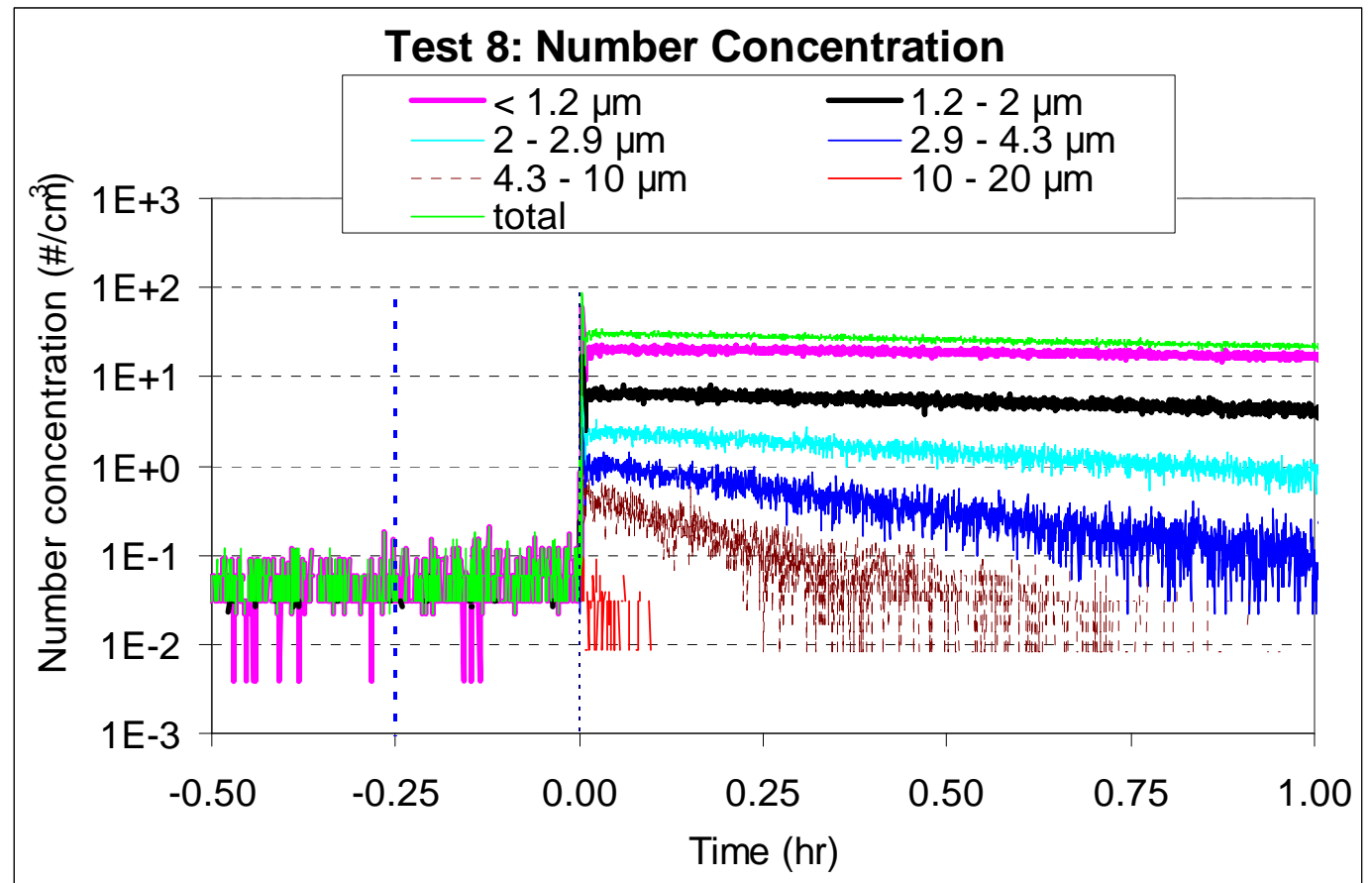

Figure A8-c. Particle number concentration before and after the dropping of Test 8

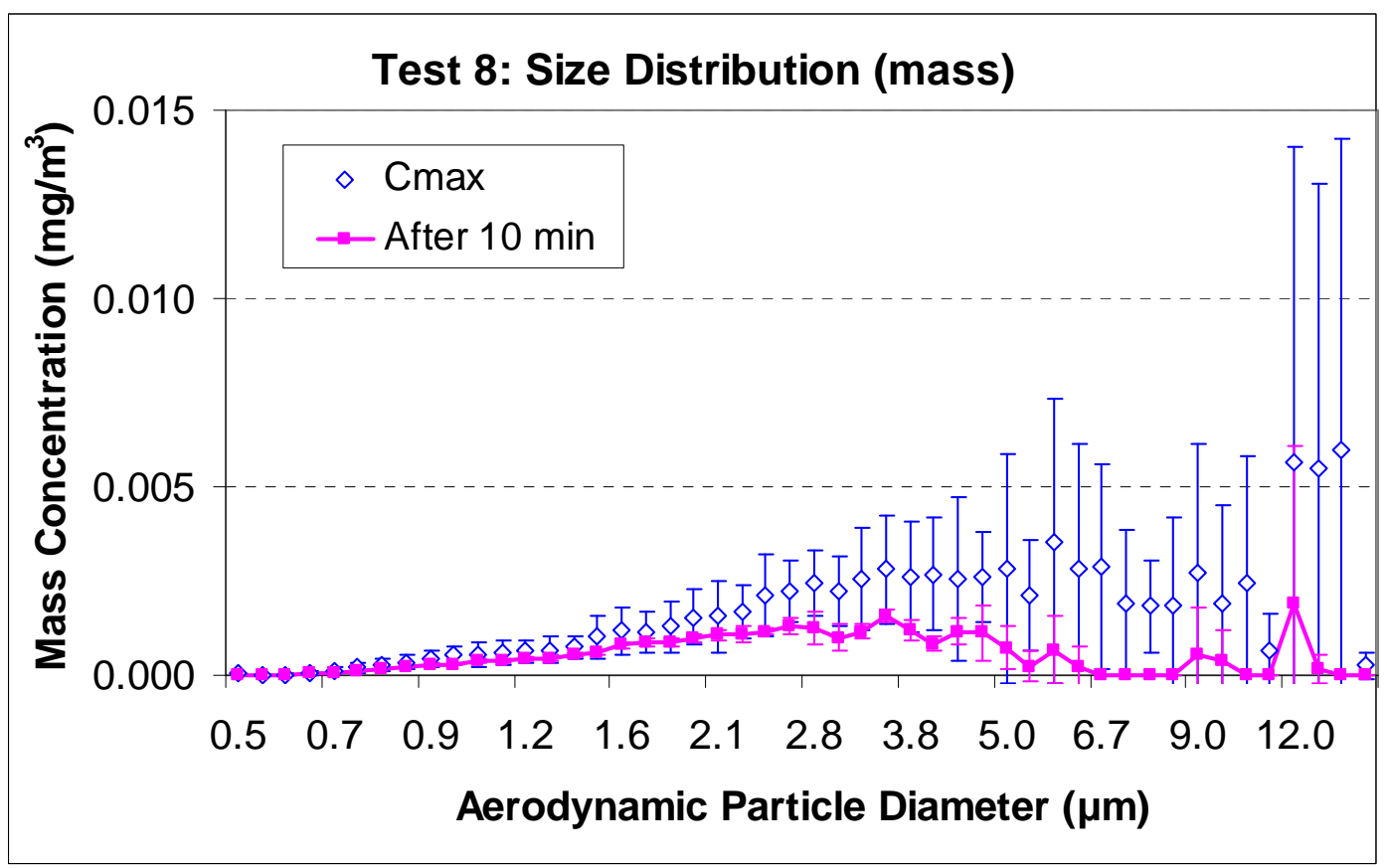

Figure A8-d. Particle mass concentration versus particle size (channel data) of Test 8 


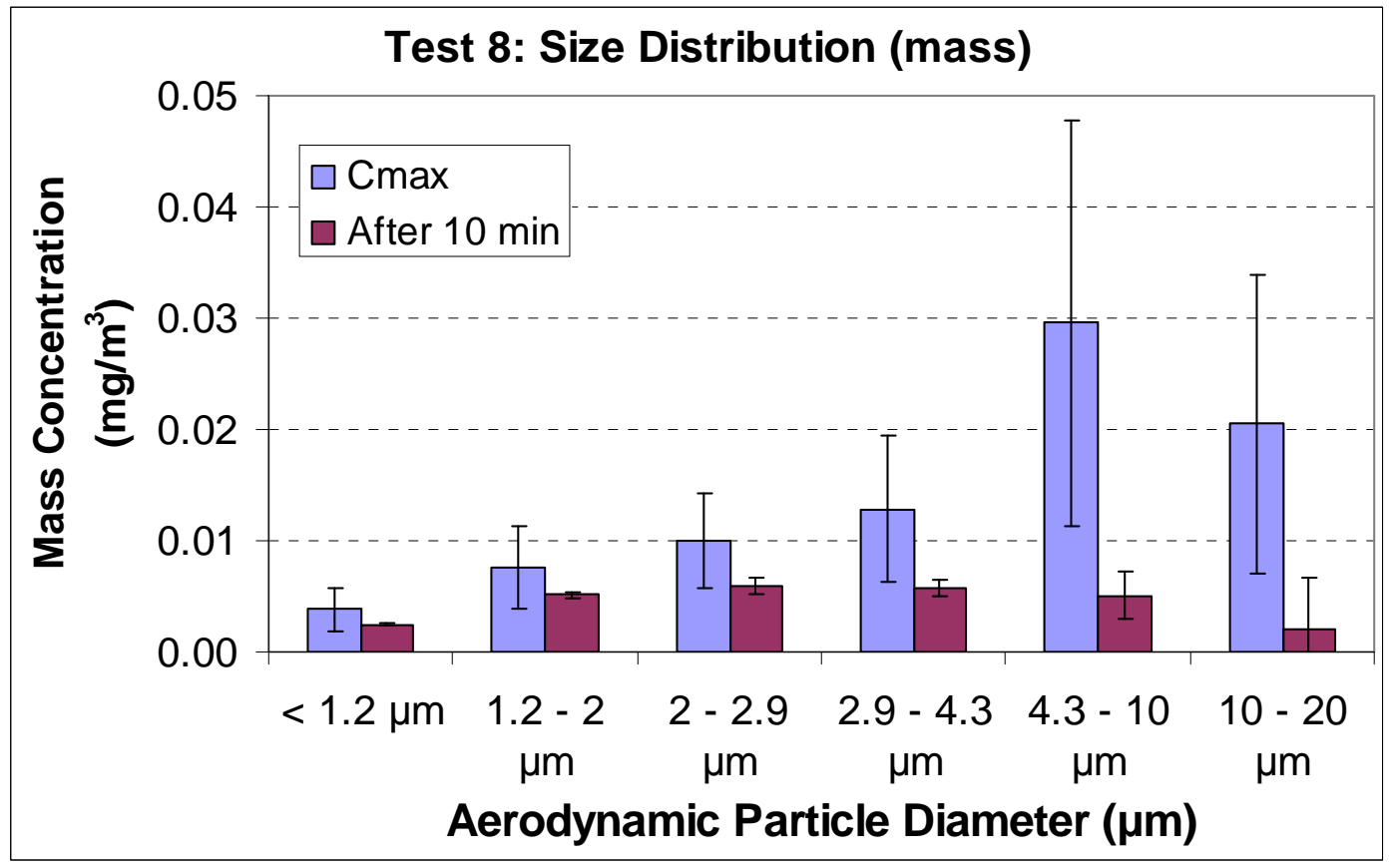

Figure A8-e. Particle mass concentration versus particle size of Test 8

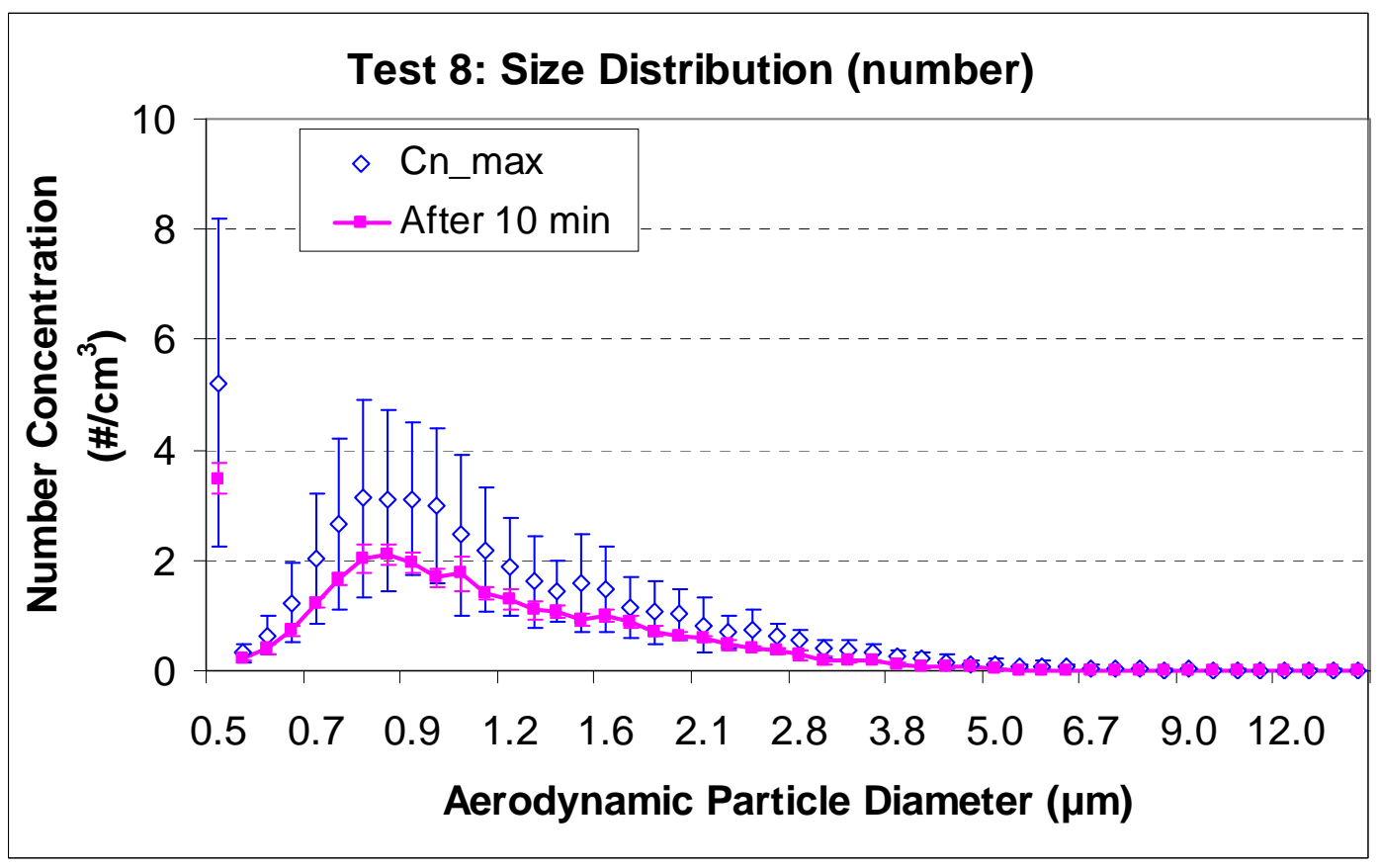

Figure A8-f. Particle number concentration versus particle size (channel data) of Test 8 


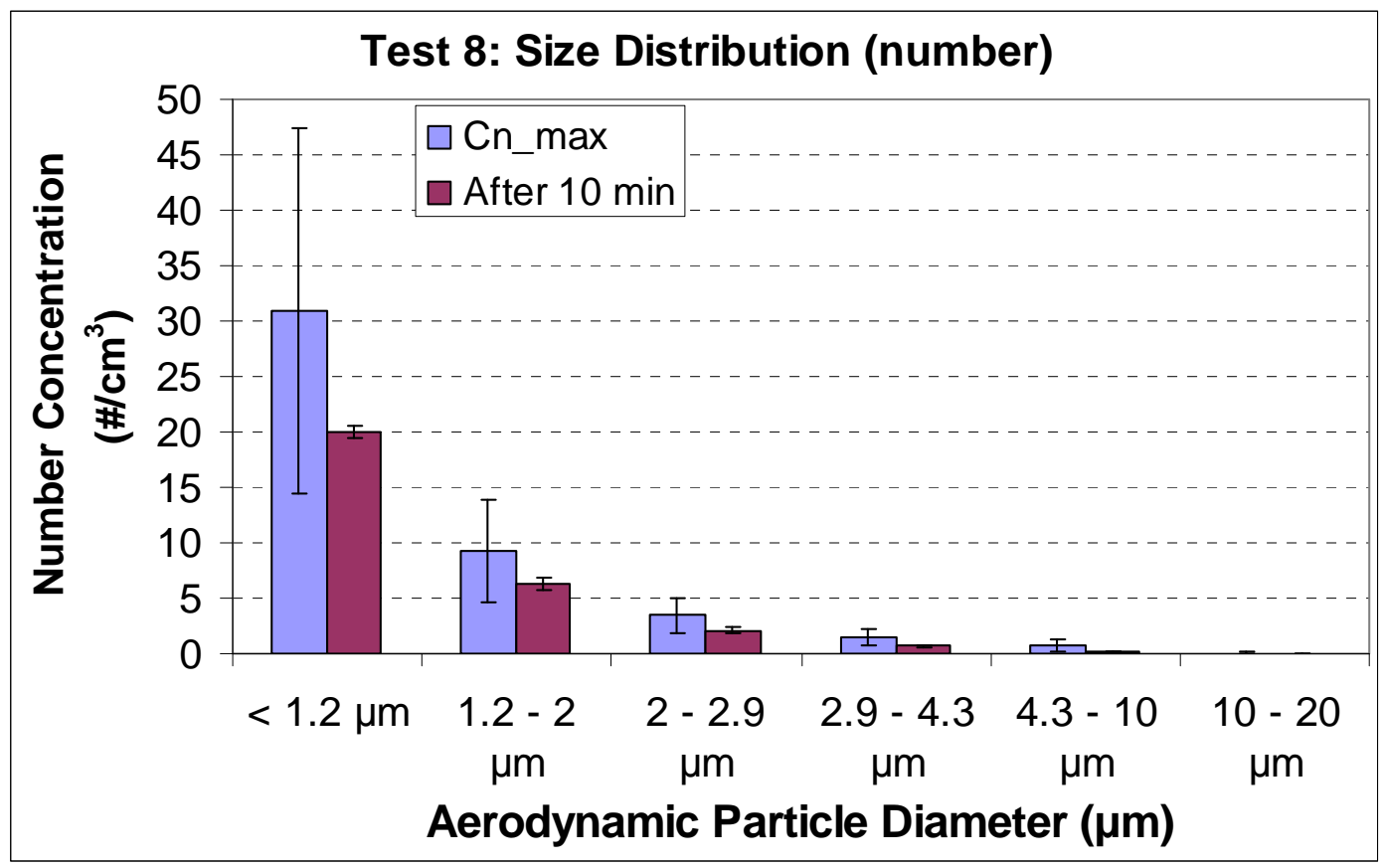

Figure A8-g. Particle number concentration versus particle size of Test 8

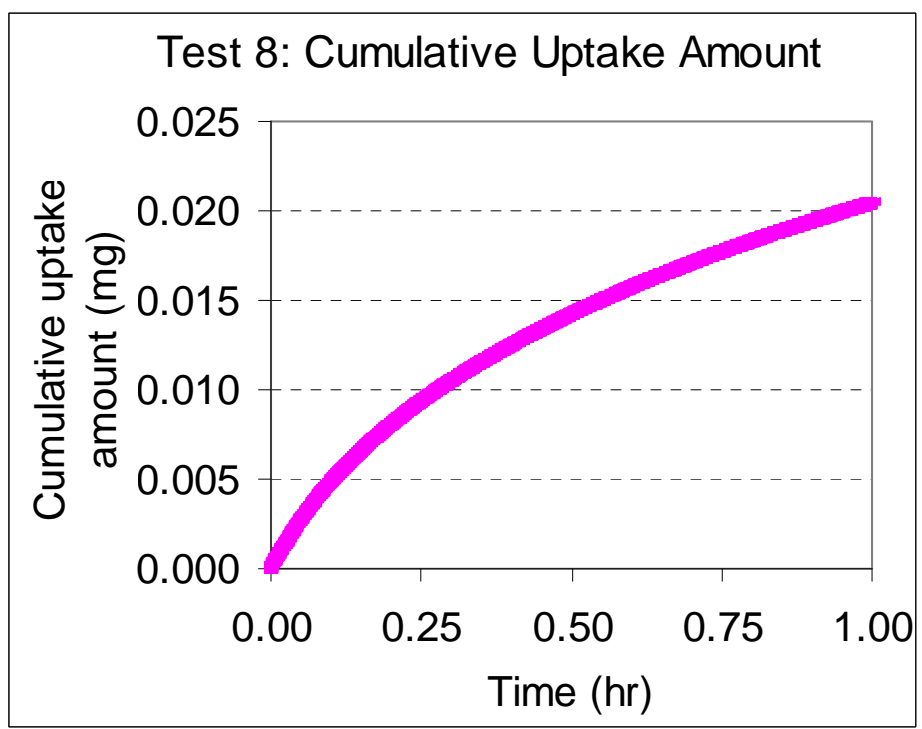

Figure A8-h. Cumulative uptake amount of particle mass of Test 8 


\section{APPENDIX 4: RELATED DOCUMENTS}

\section{A4.1 Aerodynamic Diameter and Stokes Correction}

Note: The following paragraph is adapted from the manual of APS 3321 (TSI Inc.)

Surface area, volume and mass calculations are based on geometric diameter of particles $\left(D_{p}\right)$ while the APS measures the aerodynamic diameter of particles $\left(D_{a}\right)$

The relationship between $D_{a}$ and $D_{p}$ is

$$
D_{a}=D_{p} \sqrt{\frac{\rho}{\rho_{0}}}
$$

Where $\rho_{0}$ is the unit density $\left(1 \mathrm{~g} / \mathrm{cm}^{3}\right)$

According to this relationship, for a fixed aerodynamic size distribution measured by the APS, the total mass $m$ decreases to $m / \sqrt{N}$ when particle density $\rho$ increases to $N \cdot \rho$.

$$
\frac{m_{1}}{m_{2}}=\frac{\frac{1}{6} \pi \rho_{1} D_{p 1}^{3}}{\frac{1}{6} \pi \rho_{2} D_{p 2}^{3}}=\frac{\frac{1}{6} \pi \rho_{1}\left(D_{a} \sqrt{\frac{\rho_{0}}{\rho_{1}}}\right)^{3}}{\frac{1}{6} \pi \rho_{2}\left(D_{a} \sqrt{\frac{\rho_{0}}{\rho_{2}}}\right)^{3}}=\frac{\frac{1}{6} \pi N \rho_{2}\left(D_{a} \sqrt{\frac{\rho_{0}}{N \rho_{2}}}\right)^{3}}{\frac{1}{6} \pi \rho_{2}\left(D_{a} \sqrt{\frac{\rho_{0}}{\rho_{2}}}\right)^{3}}=\frac{1}{\sqrt{N}}
$$

Stokes correction should be applied while sampling particles with density below 0.9 $\mathrm{g} / \mathrm{cm}^{3}$ or above $1.1 \mathrm{~g} / \mathrm{cm}^{3}$.

The APS spectrometers are calibrated using Polystyrene Latex (PSL) spheres of density close to $1.05 \mathrm{~g} / \mathrm{cm}^{3}$. In addition, the APS does not measure the aerodynamic size of particles in still air (the classical definition of aerodynamic size) but in a flow velocity of approximately $150 \mathrm{~m} / \mathrm{s}$. This means that the particle Reynolds numbers are outside the stokes regime $(\mathrm{R}>0.5)$. For particle densities other than unity, the particles will be incorrectly sized smaller for densities blow unity and sized larger for densities above unity. The magnitude of this difference increases for larger particle sizes. For example, a particle of density 0.8 can be underestimated by as much as $5 \%$ and a particle of density 2 can be overestimated by as much as $10 \%$.

If the density of the particles is known, the non-stokes error can be corrected using equations from the paper by Hwachi Wang and Walter John (1987), "Particle density correction for the aerodynamic particle sizer", Aerosol science and Technology 6(2): 191-198. 
$D_{a 2}=D_{a 1}\left[\frac{6+R_{2}^{2 / 3}}{6+R_{1}^{2 / 3}}\right]^{1 / 2}$

$D_{a 2}$ : corrected aerodynamic diameter $(\mu \mathrm{m})$

$D_{a 1}$ : uncorrected aerodynamic diameter $(\mu \mathrm{m})$

$R_{1}$ and $R_{2}$ are functions of air density, air viscosity, calibration particle density, air velocity, average particle velocity and actual particle density supplied by user. 


\section{A4.2 Calibration Certificate of APS 3321 (TSI Inc.)}

TSI.

Particle Intrument Division

Mailing Addres: P.O. Bor 64394 St. Paul, MN 55164 USA

Shipping Address: 500 Candigan Road Shoreview. MN 55/26 USA

Phome: 1-800-677-2708 or (651)490-283H FAX. (651)490-3860

\section{Certificate of Calibration}

TSI model 332

Date of Calibration: May 25, 2010

Serial Number:

1290

$\begin{array}{lccc} & \text { Diameter }(\mu \mathrm{m}) & \text { Median Bin Density }(\mathrm{g} / \mathrm{ml}) \\ \text { Particle \#1 } & .350 & 205.2 & 1.05 \\ \text { Particle \#2 } & .400 & 206.6 & 1.05 \\ \text { Particle \#3 } & .519 & 212.6 & 1.05 \\ \text { Particle \#4 } & .707 & 224.1 & 1.05 \\ \text { Particle \#5 } & .993 & 244.5 & 1.05 \\ \text { Particle \#6 } & 1.998 & 309.7 & 1.05 \\ \text { Particle \#7 } & 4.98 & 477.7 & 1.05 \\ \text { Particle \#8 } & 7.02 & 577.3 & 1.05 \\ \text { Particle \#9 } & 10.00 & 691.9 & 1.05 \\ \text { Particle \#10 } & 15.02 & 860.8 & 1.05 \\ \text { Particle \#11 } & 20.00 & 1015.3 & 1.05\end{array}$

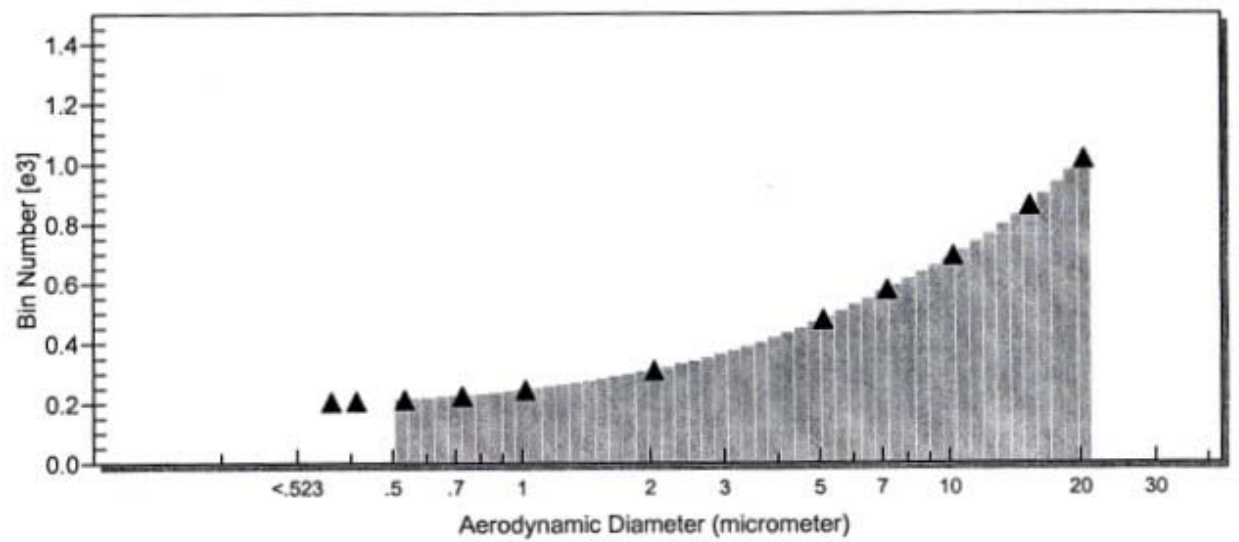

IS/ Incorporated does hereby certify that all materials, components, and workmanship used in the manufacture of this equipment are in strict accordance with the applicable specifications agreed upon by TS/ and the eustomer and with all pablished specifications. All performance and acceptance test were successfully conducted according to required specifications. TSI Incorporated certifies

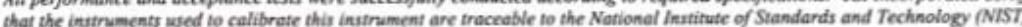
where applicable, and internal TS/ calibration standardr where NIST standards do not exist.

Calibrated by: Lerry Bemeth 


\section{A4.2 Calibration Certificate of APS 3321 (TSI Inc.) Continued}

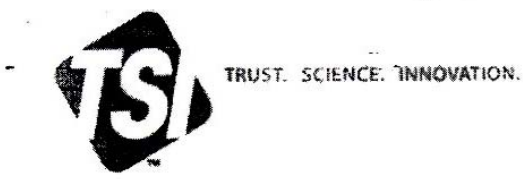

500 Cardigan Road, Shoreview, MN 55126 U.S.A. E-mail: answers@tsi.com Telephone: +1 651-490-2811 Toll Free: 1-800-874-2811 Fax: +1 651-490-3824

\section{APS 3320/3321 AS FOUND DATA}

Unit S/N 1290

Build Date: Dec, 2002

\section{Sizing at .993um}

Actual aerodynamic raw data bin: 240 with double pen Rs

Aerodynamic raw data bin last calibration: 235

Actual particle size APS reading@.993um: 1,16

$\%$ difference : $2 \%$

Flows

Actual sheath flow: $4,02 \mathrm{lpm} \quad$ Sheath Voltage: 10.0

Sheath flow last calibration: $4.01 \mathrm{lpm}$

$\%$ difference : $2 \%$

Actual Aerosol flow :, $950 \mathrm{lpm}$ Total Voltage: 10,3

Aerosol flow last calibration : $1,01 \mathrm{lpm}$

$\%$ difference: $\quad 6 \%$

COMMENTS :

Larry Bennett

Service Tech. TSI Inc. 


\section{A4.3 Physical Size Distribution Analysis of Tungsten Oxide (LOT \# Q1844) by Powder Technology Inc. (PTI)}

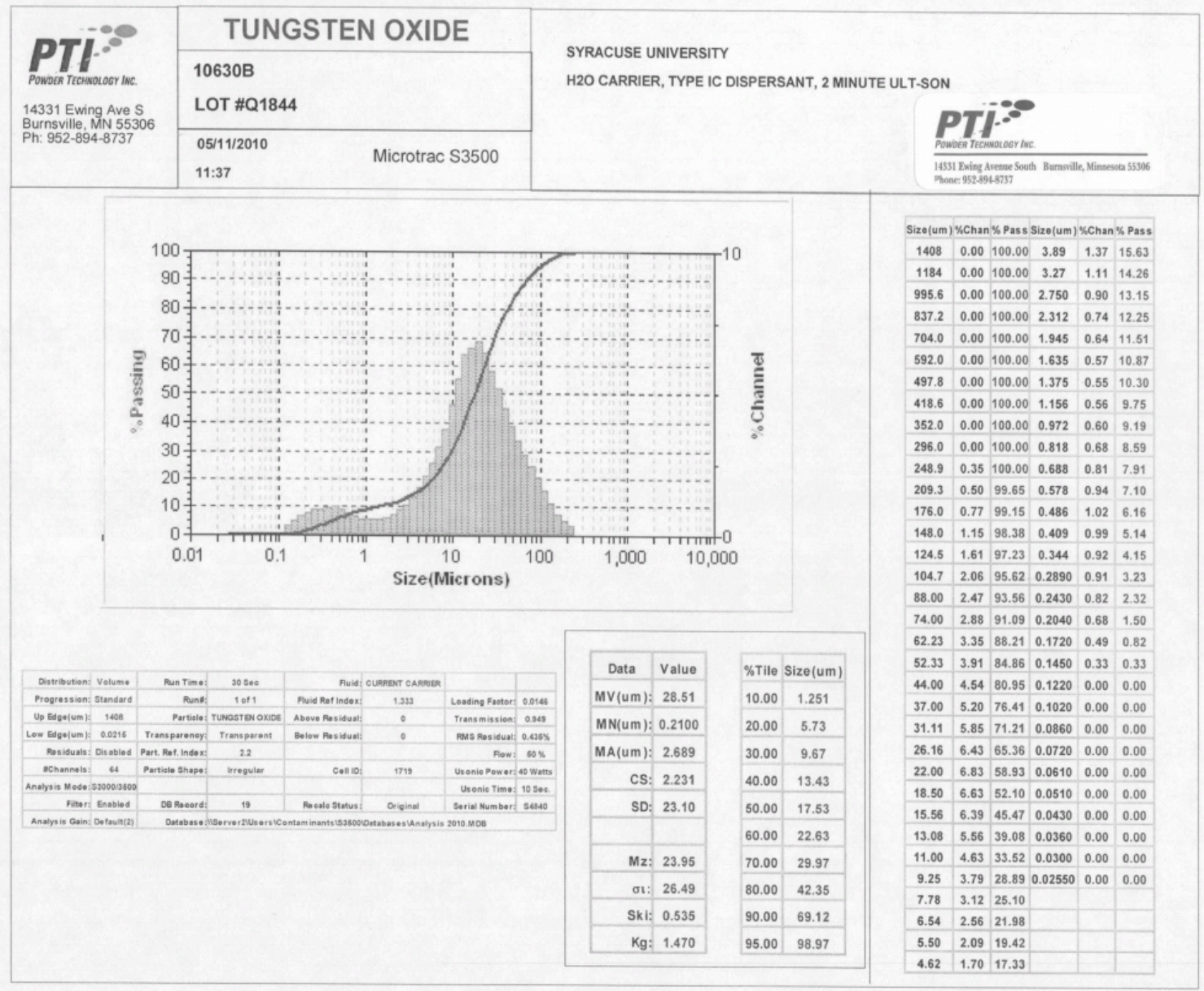




\section{A4.4 In-House Calibration of Veloci-Calc 8347 Air Velocity Meter (TSI Inc.)}

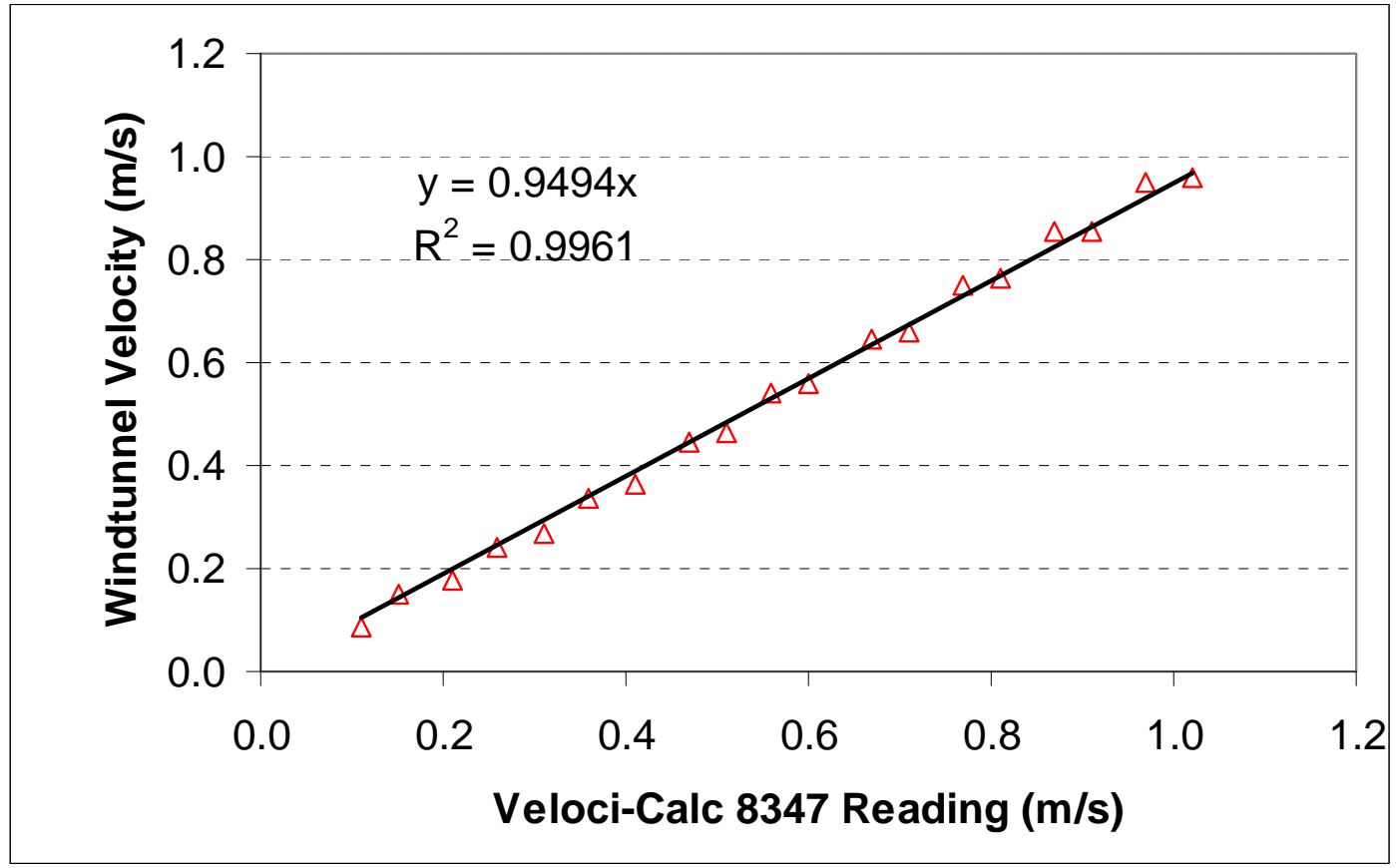

Note:

Calibration made on June 11, 2010

Calibration equipment:

1) Wind tunnel for calibration and dynamic tests Software: Automatic wind tunnel TunCal Ver 4.0

2) DP-Calc 8705 (TSI Inc.) 


\section{A4.5 Material Certification of Tungsten Oxide (ESPI Metals)}

\author{
ESPI Metals \\ 1050 Benson Way \\ Ashland, OR 97520 \\ USA \\ Voice: 8006382581 \\ Fax: $\quad 5414888313$
}

CERTIFICATION

Invoice Number: 24785

Invoice Date: Jun 2, 2010

Page:

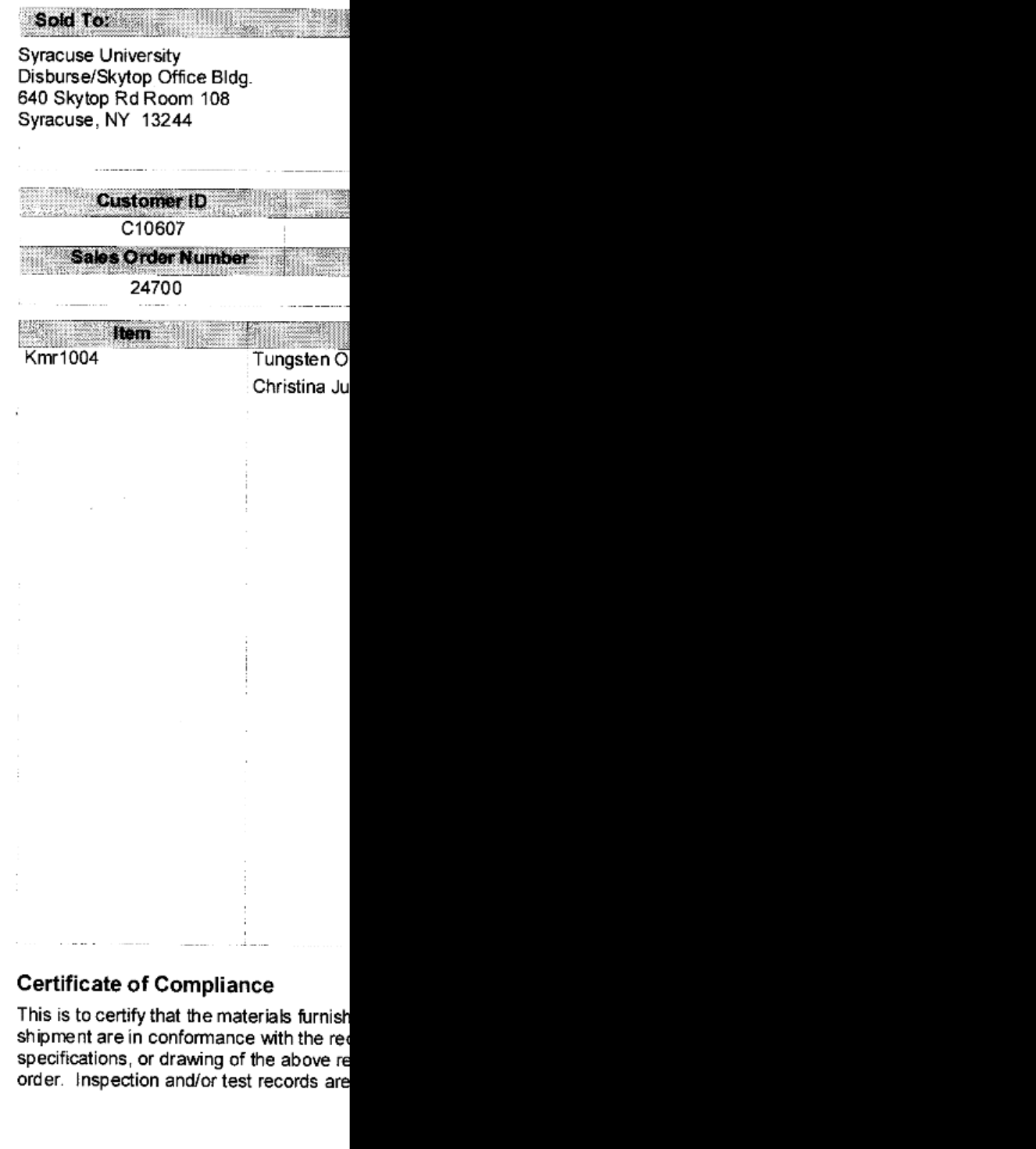




\section{A4.5 Material Certification of Tungsten Oxide (ESPI Metals) Continued}

\author{
ESPI Metals \\ 1050 Benson Way \\ Ashland, OR 97520 \\ USA \\ Voice: 8006382581 \\ Fax: $\quad 5414888313$
}

CERTIFICATION

Invoice Number: 24868

Invoice Date: Jun 15, 2010

Page:

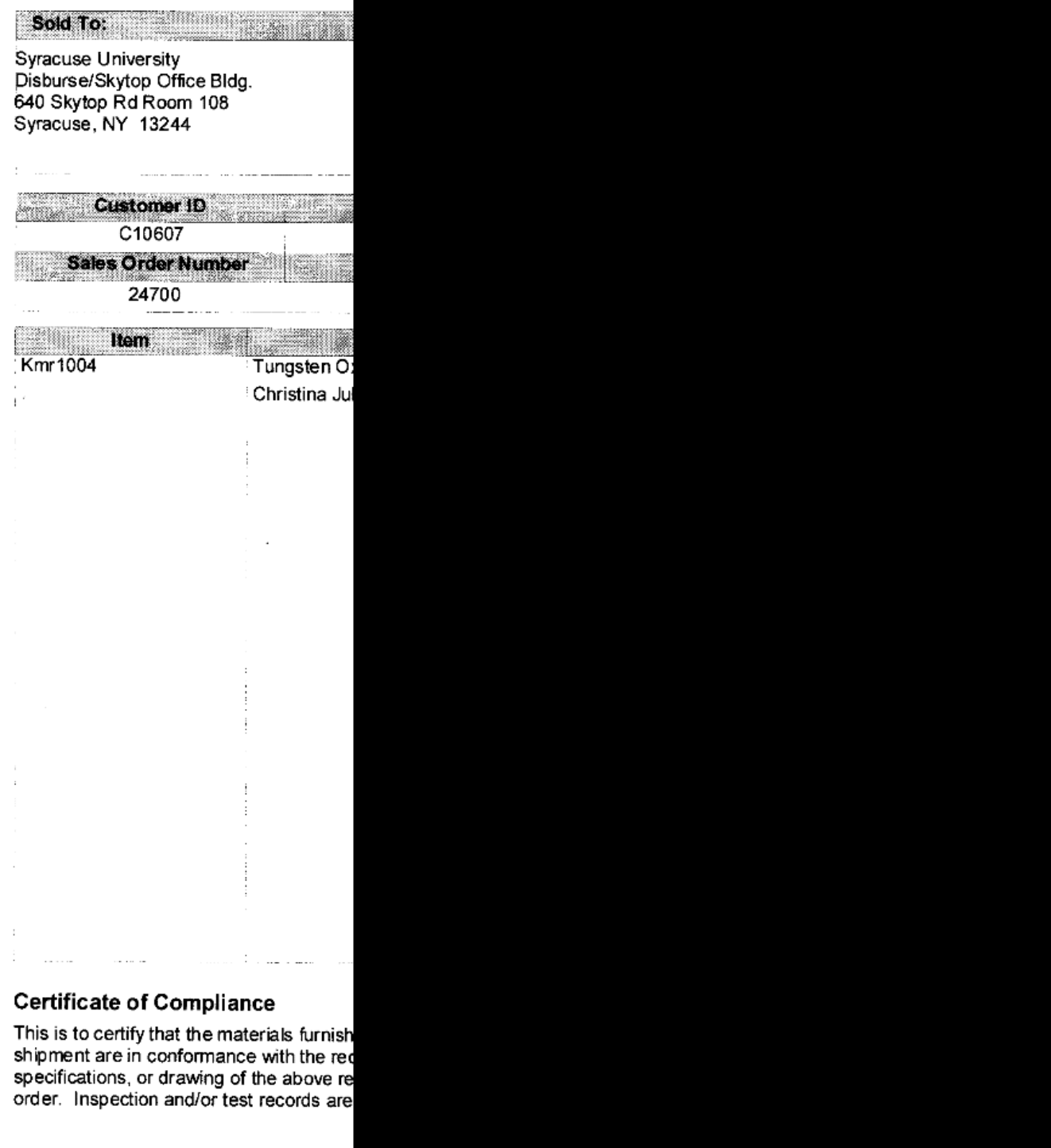

Authorized Signature 